\title{
تنمية فاعلية الذات لتحسين طيب الحياة الذاتية لاي طالبات الجامعة
}

$$
\begin{aligned}
& \text { فاطمة عمر عبد العزيز } \\
& \text { باحثة دكتوراه ـ قسم علم النفس } \\
& \text { كلية البنات للأداب و العلوم والتربية } \\
& \text { جامعة عين شمس - مصر }
\end{aligned}
$$

\section{Fatma.omar@rocketmail.com}

$$
\begin{aligned}
& \text { أ.م.د// ماجى وليم يوسف علف ألفيكا } \\
& \text { أستاذ علم النفس المساعد ولئ } \\
& \text { كلية البنات - جامعة عين شمس النفس الفي } \\
& \text { - مصر - معل }
\end{aligned}
$$

\section{Tadres@gmail.com}

$$
\text { كلية أبنات - عزة صلم النفس الألفى }
$$

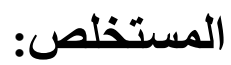

هدف البحث الحالي إلى اختبار فاعلية برنامج إرشادي في تنمية فاعلية الذات على تحسين طيب الإني

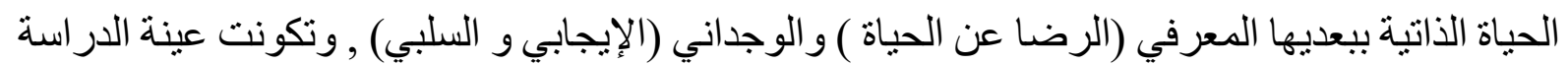

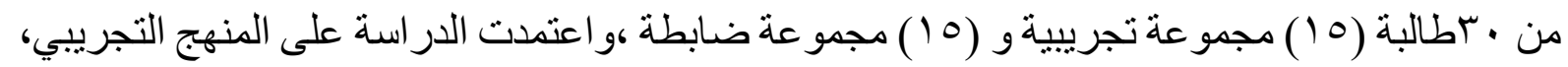

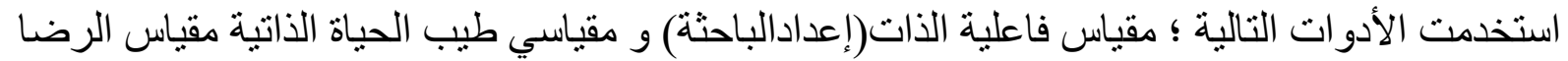

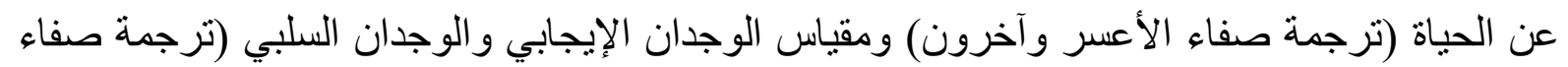

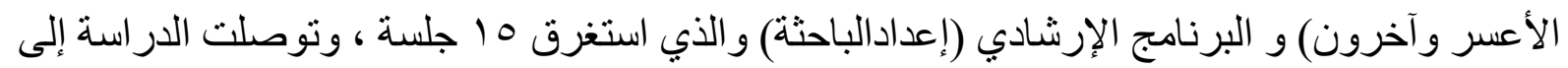

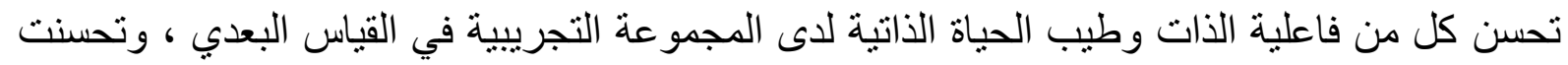

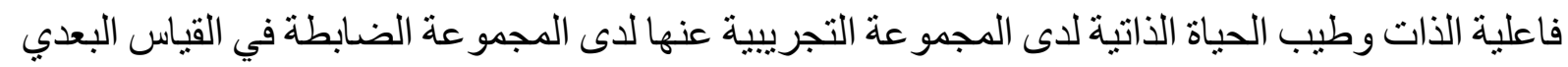

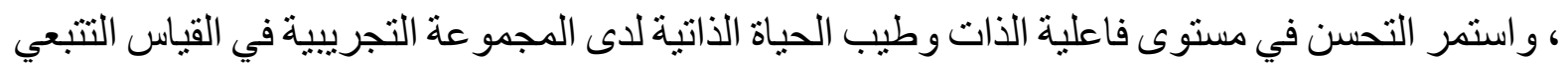

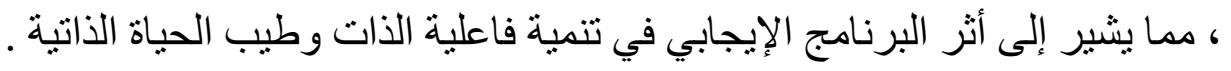

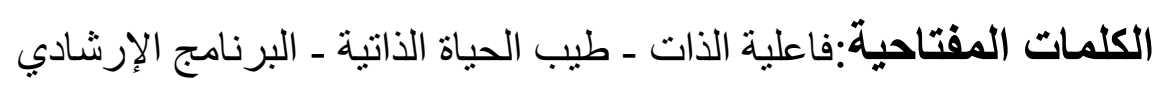

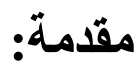

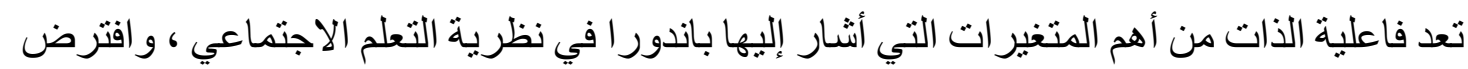

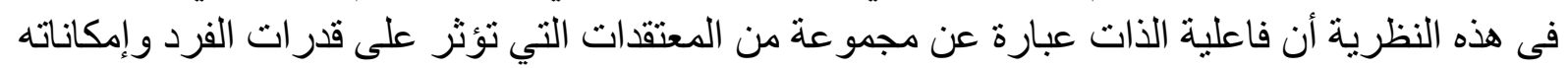

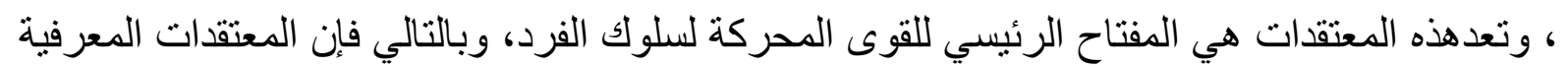

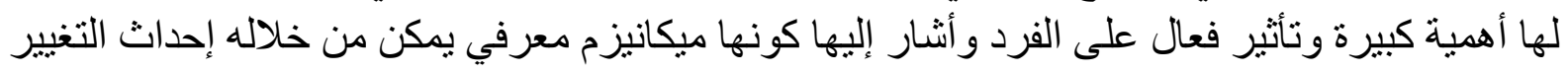


تنمية فاعلية الذات لتحسين طيب الحياة الذاتية لاي طالبات الجامعة

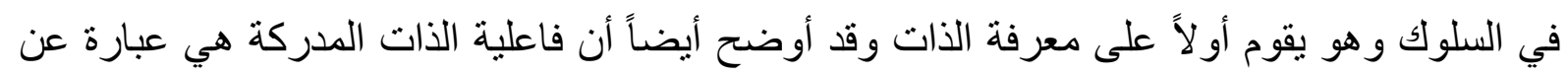
أحكام الناس عن قدر اتهم في فعل شيء لتحقيق النتيجة المرجوة،كما تعد فاعلية الذات من أهم المتغيرات

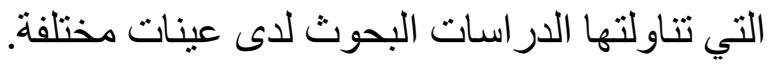

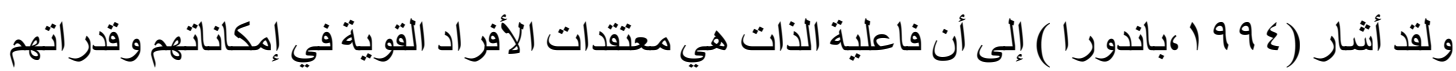

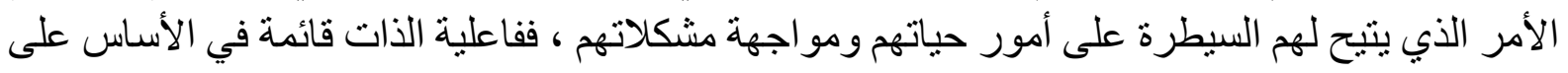

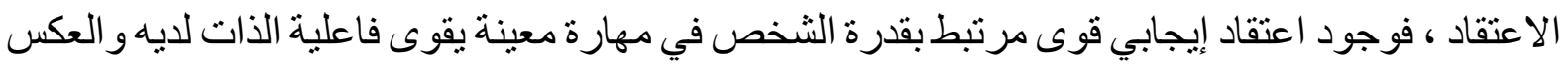

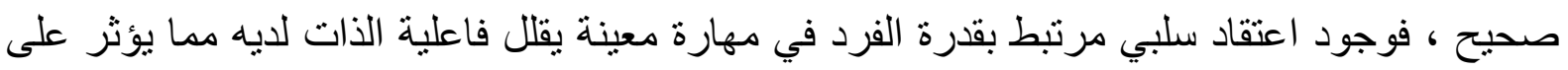

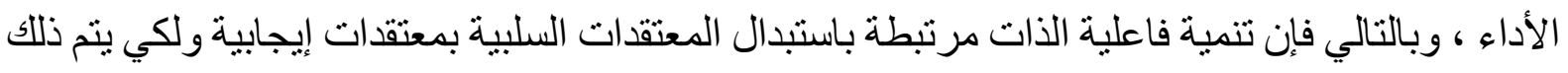

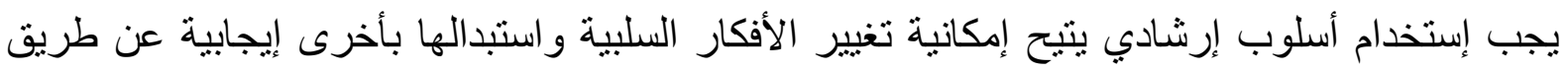
الإرشاد المعرفي السلوكي. و تعد فاعلية الذات من المحددات الأساسية لطيب الحياة الذاتية ببعديها المعرفي و الوجداني فالرضا

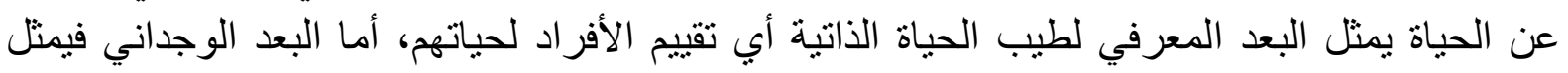
المشاعر الإيجابية (السعادة) والسلبية أي تقييم الأفراد لحالتهم الوجدانية: (هل يشعروا بالسعادة أم لا؟).

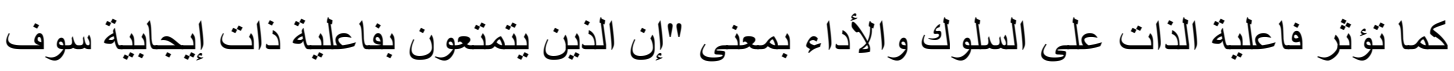

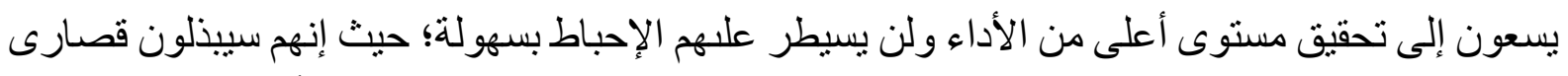
جهدهم وسيحثُون عن حلول جديدة، كذلك سوف يثابرون في حالة المهام الصعبة، أما من كانت فاعلية

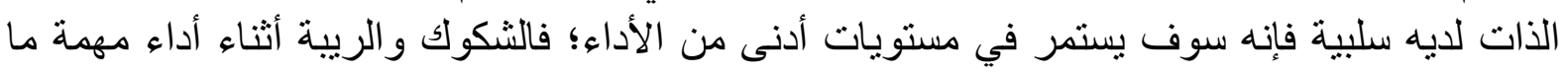
تضعف تركيز الفرد ومن ثم فإنه سر عان ما يستسلم بسهولة في في أي مهرة صنية صعبة.

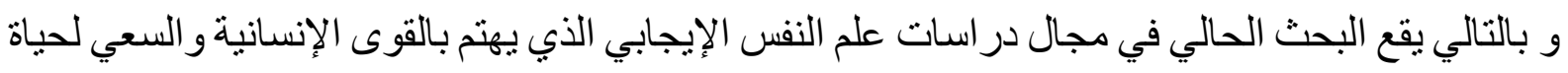

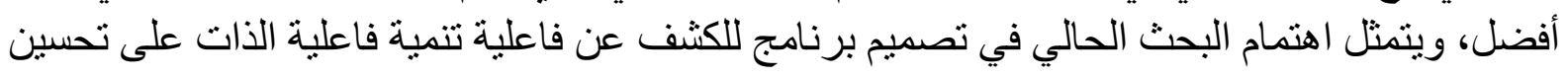

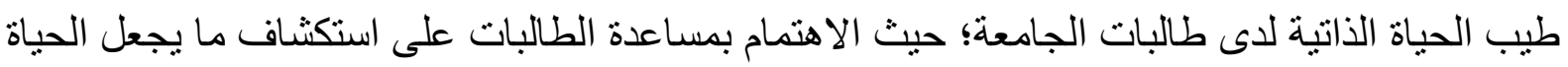

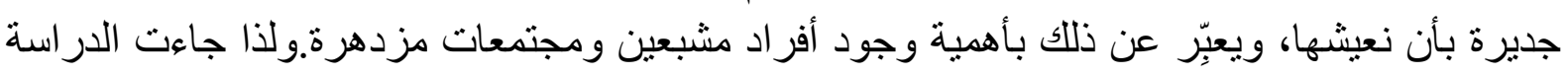

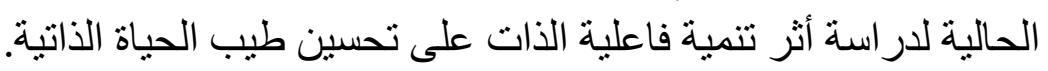
مشكثلة البحث وتساؤلاته:

كثفت دراسات عديدة عن الجانب الإيجابي لفاعلية الذات وأهميتها في بناءات الذات الإيجابية، ومن هذه الدر اسات در اسة (Hwiad Liu, 2004) التي كثفت عن وجود ارتباط موجب بين فاعلية الذات وثقة الفرد في نفسه وبقدر اته على إنجاز السلوك، وكذلك بمستويات المنافسة؛ لأن ألفاعلية الذاتية تؤثر في

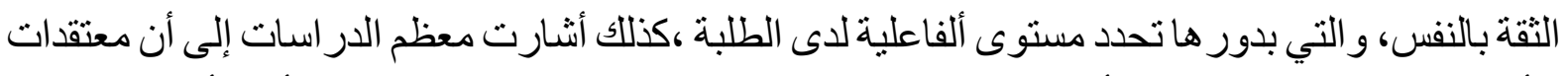

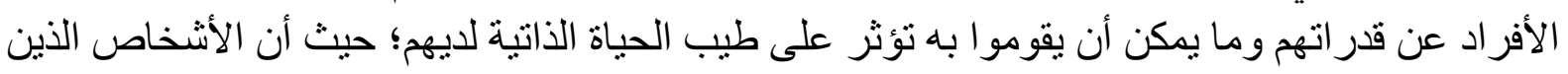

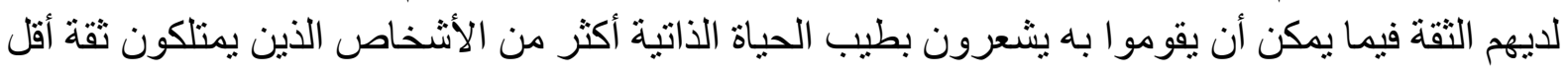
فيما يمكن أن يقومو ا به، ومن هذه الدر اسات ; Scholz \& Schwalzar, ; Caprara \& Steca, 2005 ; Lent et al., 2005 ; \& Deci, 2001 2005. ومن هنا جاءت مشكلة الدر اسة الحالية في سؤال رئيسي هو :

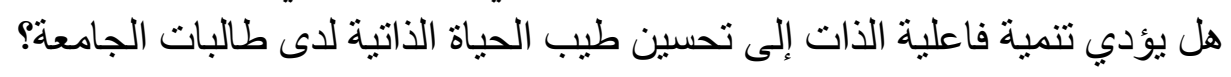
ويتفرع من السؤال السابق الأسئلة الفرعية التالية: 
تنمية فاعلية الذات لتحسين طيب الحياة الذاتية لاي طالبات الجامعة

ا - هل توجد فروق دالة إحصائياً بين متو سطي درجات القياسين القبلي و البعدي في فاعلية الذات

لاى المجمو عة التجريبية؟

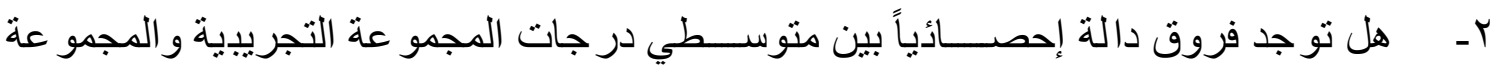
الضابطة في فاعلية الذات في القياس البعدي؟ r- هل توجد فروق دالة إحصائياً بين متوسطي درجات القياسين البعدي و التتبعي في فاعلية الذات

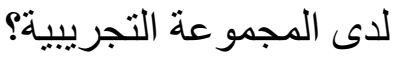
ع - هل توجد فروق دالة إحصـائياً بين متوسـي درجات القياسـين القبلي و البعدي في طيب الحياة

الذاية لاى المجمو عة التجريبية؟

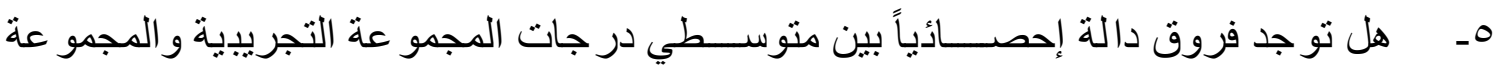

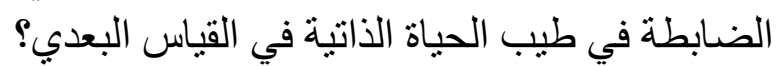
7- هل توجد فروق دالة إحصائياً بين متوسطي درجات القياسين البعدي و التتبعي في فاعلية الذات لدى المجمو عة التجريبية؟ أهداف البحث:

يمكن تحديد هدف البحث الحالي في ملاحظة وتفسير أثر تنمية فاعلية الذات على تحسين طيب الحياة

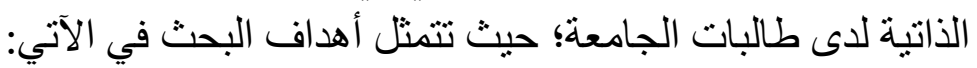
ا ـ الكثف عن الفروق في مستوى كل من فاعلية الذات وطيب الحياة الذاتية لدى طالبات الجامعة بالمجموعة التجريبية باختلاف القياسين القبلي و البعدي. r- الكثف عن الفروق في مستوى كل من فاعلية الذات وطيب الحياة الذاتية بين طالبات الجامعة بالمجمو عة التجريية والمجموعة الضابطة في القياس البعدي. r- الكثف عن الفروق في كل من مستوى فاعلية الذات وطيب الحياة الذاتية لدى طالبات الجامعة بالمجمو عة التجريبية باختلاف القياسين البعدي و التنبئي.

$$
\text { أهمية البحث: }
$$

الأهمية النظرية:

ا - يهتم البحث الحالي بالتنظير لمتغيرين رئيسيين من مفاهيم علم النفس الإيجابي؛ ألا و هما فاعلية

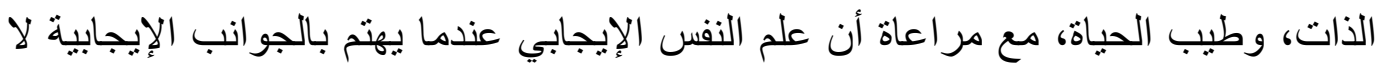

$$
\text { يغفل جو انب الضعف الإنساني. }
$$

r- - يهتم البحث الحالي بفئة عمرية مهمة ألا وهي مرحلة طلاب الجامعة؛ حيث تتلقى الطالبات الخدمات الأكاديمية باعتبار ها الأولوية الأهم في هذه المرهية الميلة وذللك على حساب الاهتمام

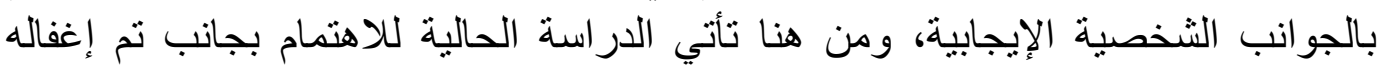

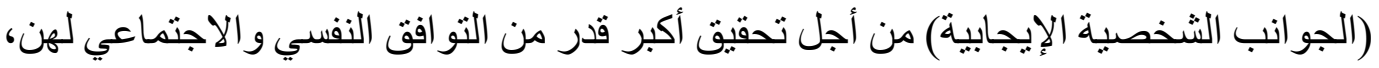

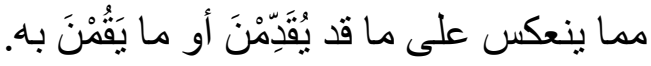


1 - تصميم أدوات سيكومترية مقياس فاعلية الذات.

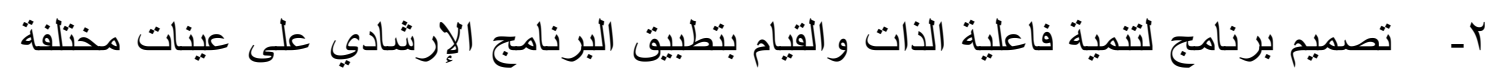
وملاحظة أثر ذلك على طيب الحياة الذاتية لديهر.

r- ما سيصل إلـه البحث الحالي من توصيات بمكن أن تفبد المتمين بهذه الفئة العمرية. مصطلحات البحث الإجرائية: فاعلية الذات (Self Efficacy): عرفت الباحثة فاعلية الذات بأنها:

معتقدات الفرد عن قدر اته الثخصية، و التي تظهر في اعتقاده بأن لديه القدرة على التهى ممارسة السيطرة

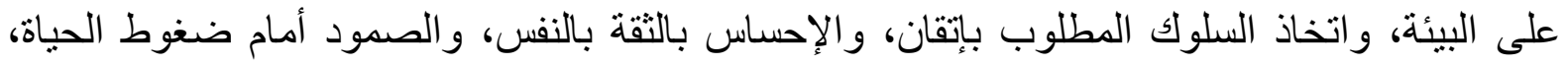

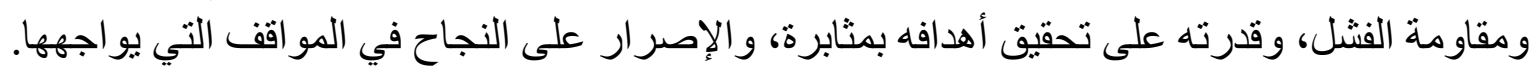

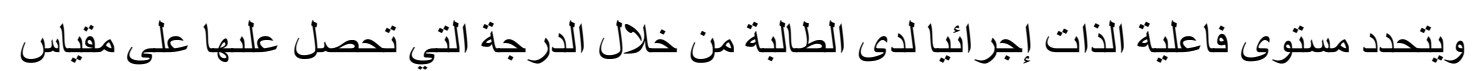

فاعلية الذات.

\section{طيب الحياة الذاتية (Subjective Well Being):}

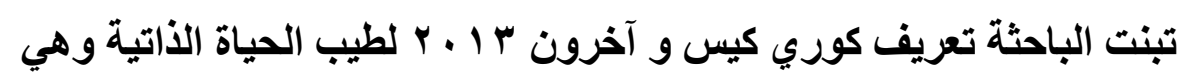

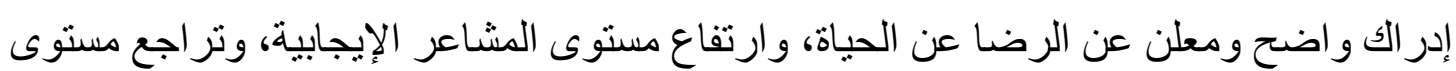

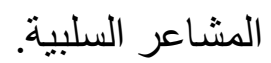

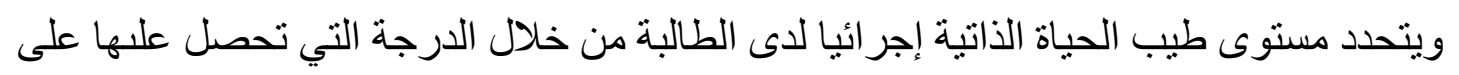

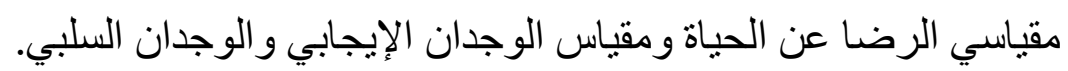

\section{الإطار النظري والدراسات السابقة:}

أولاً: فاعلية الذات: - (الات

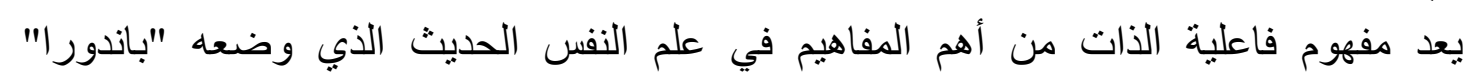

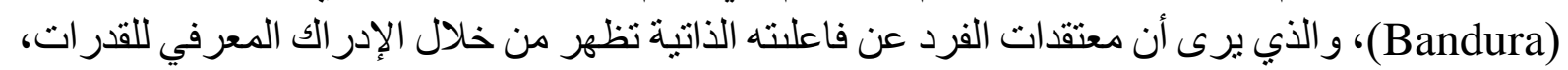

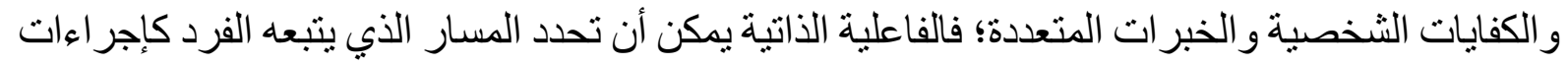

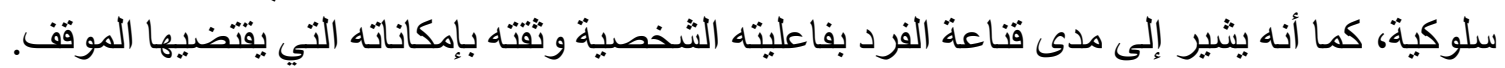

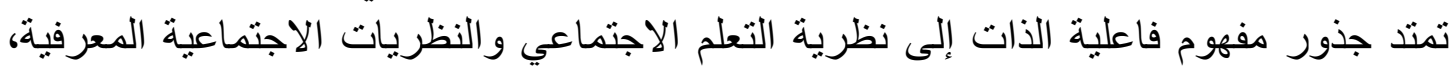

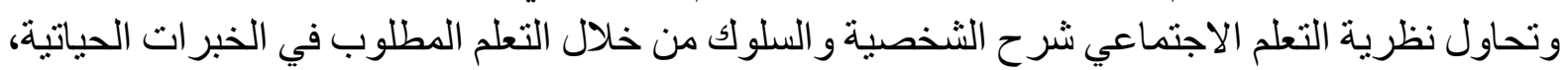

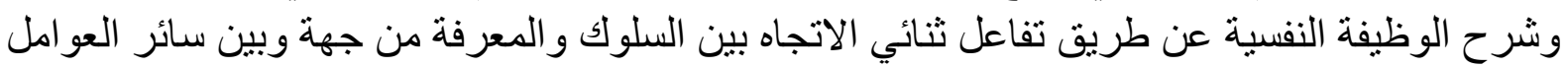

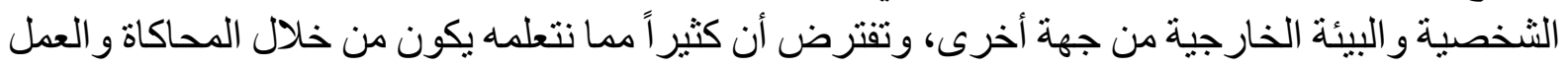

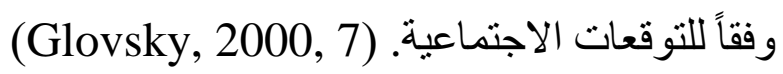




\section{تنمية فاعلية الذات لتحسين طيب الحياة الذاتية لاي طالبات الجامعة}

كما أعاد (باندور ا) تسمية نظرية التعلم الاجتماعي بالنظرية الاجتماعية المعرفية؛ للتأكيد على أن

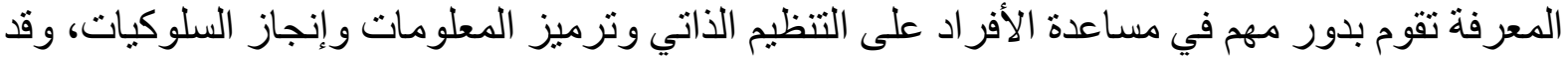

تؤثر البيئات و النظم الاجتماعية في السلوك من خلال الإلبات النفسية للذات. (Stratton, 2005, 5) وتقوم هذه النظرية على عدة افتر اضات نظرية ومحددات تثمثل في:

- معظم أنواع السلوك ذات هدف معين، كما أنها موجهة بالقدرة على التفكير المستقبلي. تعلم الفرد عن طريق ملاحظة سلوك الآخرين ونتائجها يقلل بشكل كبير من الاعتماد على التعلم عن طريق المحاولة و الخطأ، ويسمح بالاكتساب السريع للمهار ات المعقدة التي ليس من الممكن اكتسابها عن طريق الممارسة. امتلاك الفرد القدرة على إنتاج الرموز والتي تسمح بإنشاء نماذج داخلية للتحقق من فاعلية التجارب قبل القيام بها، وتطوير مجموعة مبتكرة من الأفعال. و الاختيار لهذه المجمو عة من الأفعال من خلال

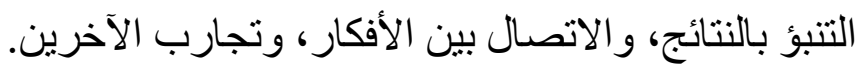

قدرة الفرد على التتظيم الذاتي عن طريق التحكم المباشر في السلوك، واختيار أو تغيير الظروف البيئية التي تؤثر عله. كما يضع الأفراد معايير شخصية لسلوكهم، ويقِّمون سلوكهم بناء على هذه ونه المعايير.

امتلاك الفرد القدرة على التأمل الذاتي و القدرة على تحليل وتقييم الأفكار والخبرات الذاتية، وهذه القدر ات ثتيح التحكم الذاتي في السلوك.

قدر ات الفرد هي نتيجة تطور الميكانيزمات و الأبنية النفسية العصبية المعقدة التي تتفاعل مع بعضها

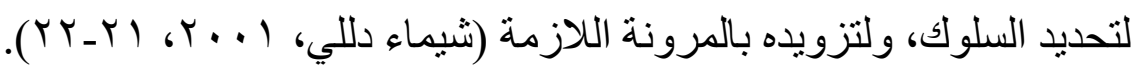

من خلال ما سبق يمكن القول أن النظرية المعرفية الاجتماعية لـ"باندور ا" أكدت أن فاعلية الذات قوة مهمة تفسر الدو افع الكامنة ور اء أداء الأفر اد في مختلف المجالات، و أنها تسهم في تحديد سلوك لك المثابرة و مستويات ردود الأفعال للضغوط الانفعالية، وضبط الذات، والاختيار المهني، و المثابرة من أجل الإنجاز.

\section{مفهوم فاعلية الذات:}

عرف باندور ا فاعلية الذات بأنها معتقدات الناس في قدر اتهم لإنتاج مستويات معينة من الأداء و التي تمارس تأثنير اً على الأحداث المهمة في حياتهم (Designated Levels of Performance) كذلك معتقدات الأفر اد في قدر اتهم على تنظيم وتنفيذ مسار ات الفحل المتطلبة لإنتاج إنجاز ات محددة أو أو لإدارة المو اقف المستقبلية.

(Bandura, 1990, 9, Bandura, 1994, 1, Bandura, 1995, 2, Bandura, 1997, 3, Bandura, 1998, 53)

ويعرفها (Schunk) بأنها: الأحكام الثخصية حول إمكانية تأدية الأفعال في مو اقف محددة قد تكون غامضة أو لا يمكن التتبؤ بها أو ضاغطة محددة، ومن المفترض أن تؤثر فاعلية الذات على اختيار الفرد للأنشطة والجهد المبذول و المثابرة عند مو اجهة المشكلات و الأداء الماهر. (Schunk, 1984, 29) 
تنمية فاعلية الذات لتحسين طيب الحياة الذاتية لاي طالبات الجامعة

و اتفق (Pajares) مع باندور أبأن فاعلية الذات هي القدر ات المدركة للفرد لبلوغ أنو اع محددة

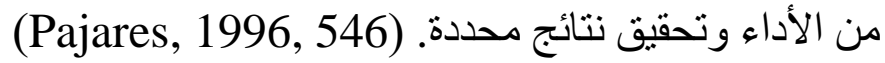

ويرى (Jackson) أنها: مجمو عة من المعتقدات بشأن الكفاءة الثخصية في صياغة وتتفيذ مسار

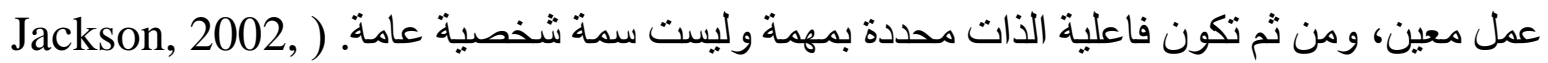

وتؤثر معتقدات فاعلية الذات على المعرفة و الوجدان والسلوك، كما يتضح من تعريفات. ( Wood

(\& Bandura, 1989; Reddy, 2011

وقد تساعد أيضاً في التعامل مع الظروف العصبية، كما يتضح من تعريف. )

.(Reddy, 2011

ومن خلال العرض السابق لتعريفات فاعلية الذات يمكن القول: - أن فاعلية الذات عُرَِّت مرة كأحكام ومعتقدات واقتناع أو ثنقة الفرد في قدر اته، و لا توجد فروق

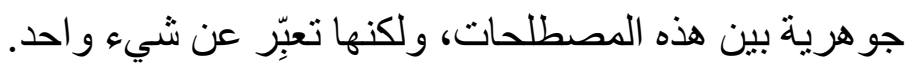

يغلب على فاعلية الذات الطابع المعرفي باعتبار ها تعبّرِ عن معتقدات الفرد.

كما فال (Jackson) أن فاعلية الذات ليست ثابتة أو مستقرة في الثخصية وتتفق معه الباحثة. أن فاعلية الذات قد تكون لمهمة محددة (نوعية)، وقد تكون عامة لأنها ليست سمة ثابتة؛ لأن اعتقاد

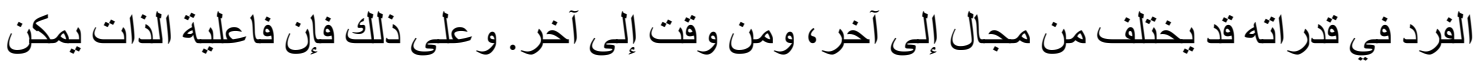
أن تتغير مع مرور الزمن؛ فكلما اكتسب الفرد مزيداً من الخبرة و المعلومات الجديدة كلما تم تغيير ها ولها من قِبَّل الفردد.

المعتقدات المرتبطة بفاعلية الذات لا تهتم بالقدرات الفعلة للفرد (أي المعرفة، والمهارات،

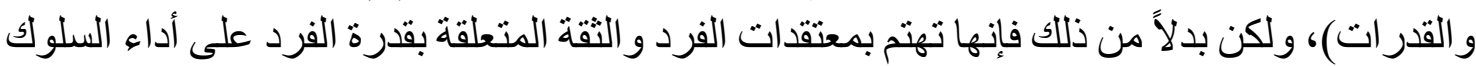

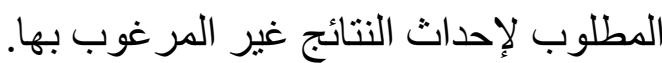

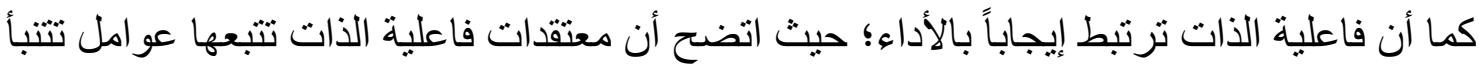

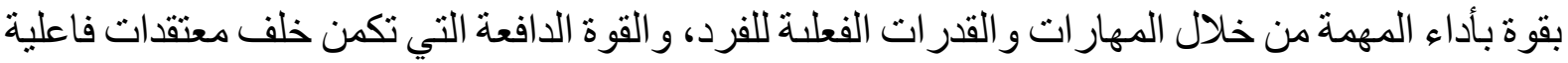

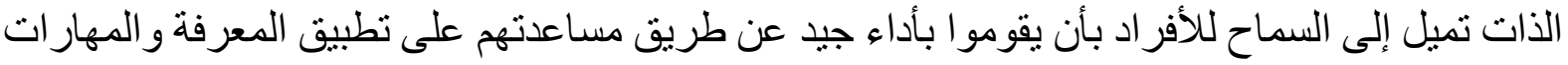

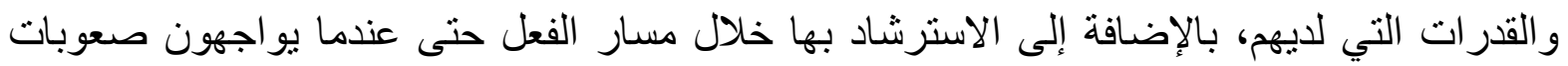

(Kepes, 2008, 11).

عرض لنتائج بعض الدراسات السابقة التي تناولت فاعلية الذات لاى طلبة الجامعة: أثنارت در اسة "دوير" و "كيومن" (Dwyer \& Cummn,2001) و التي هدفت لمعرفة العلاقة التهاتة

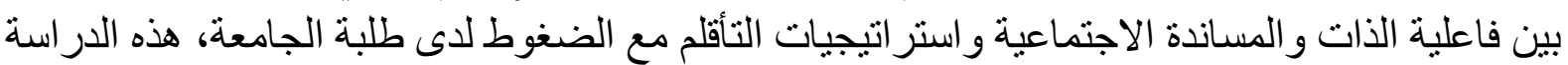

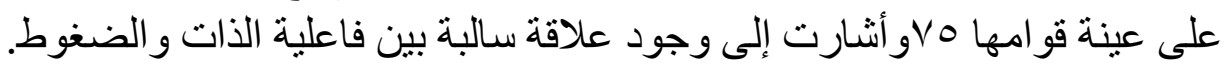
در اسة "سكر ابسكي" وآخرون (Skrabski et al., 2005) التي هدفت إلى معرفة العلاقة بين

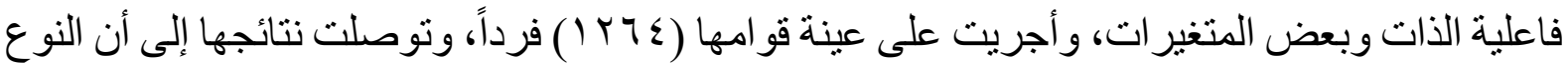


تنمية فاعلية الذات لتحسين طيب الحياة الذاتية لاي طالبات الجامعة

والعمر والتعليم لا يؤثروا في معنى الحياة، بينما ارتبط معنى الحياة إيجابياً بألفاعلية الذاتية والدعم الاجتماعي وحل المشكلات.

كذلك دراسة "دوستين" (Dustine, 2009) التي هدفت إلى فحص المتغيرات التي تسهم في

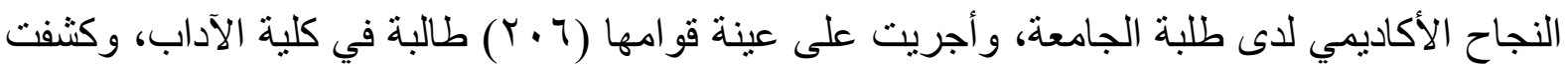

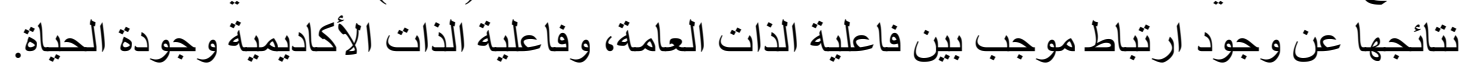
وهو ما أشارت إلبه دراسة "يو لاندفان" و "مانيلادروب" (201and Van \& Manima Dhurup, )

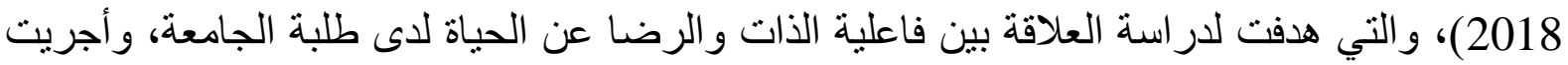

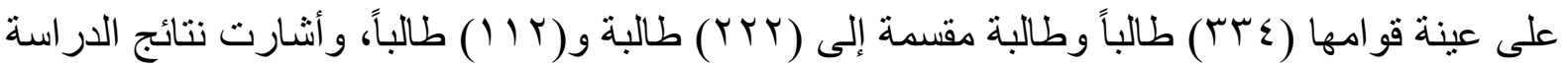

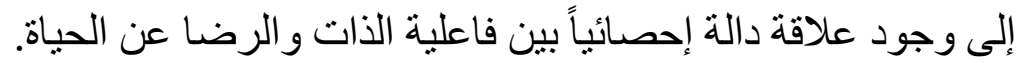
كذلك اتفقت مع در اسة (paula Alvaeez,et al,2019) و التي هدفت إلى قياس أثر فاعلية الذات على الطلاب في السنة الأولى من الدر اسة الجامعية و التي أجريت على الطلاب من قسم العلوم الاجتماعية و أشارت إلى أهمية فاعلية الذات لطلبة الجامعة كذلك وجدت فروف فين بين الذكور و الاناث في فاعلية الذات

من خلال الدر اسات السابقة، يمكن القول أن فاعلية الذات تحدد كيف يشعر الأفر اد، وكيف يفكرون، لصالح الذكور. وكيف يتحفزون، وكيف يتصرفون؟ فهي ليست مجرد إدر الك أو نوقع فقط، ولكنها يجب أن تترجم إلى بذل فئل جه وتحقيق نتائج مرغوب بها، و هذه الخصائص يمكن من خلالها إخضاع فاعلية الذات الإيجابية للتنمية و التطوير وذلك بزيادة الخبر ات المناسبة.

ثانياً: طيب الحياة الأتية:

مفهوم طيب الحياة الذاتية:

بدأت در اسة طيب الحياة الذاتية خلال السنوات الماضية من أو ائل عام ^؟ 9 ( ؛ حيث حددت منظمة الصحة العالمية أن الصحة النفسية ليست مجرد الخلو من المرض النفسي، بل هي أكثر من ذللك؛ لذا بدأ العلماء در اسة العو امل و الأبعاد المرتبطة بالصحة النفسية وطب الحياة الذاتية، ويشير كل من ( Jose et

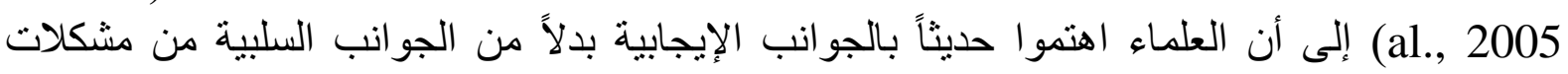

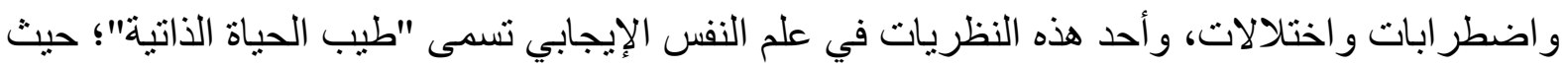

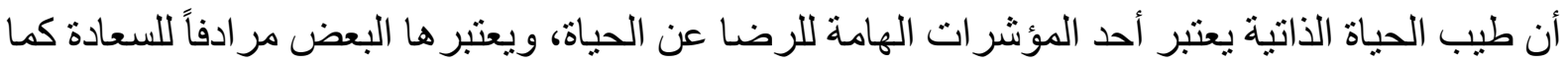
يثير (Kulaksizoglu and Topuz) إلى أن طيب الحياة الذاتية مفهوم شاع في علم النفس الإيجابي.

(Kulaksizoglu and Topuz, 2014, 25)

كما تعرف رابطة علم النفس الأمريكية (American Psychological Asso Ciation- APD)

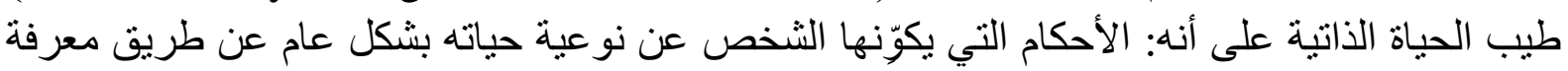
و تحديد انفعالاته؛ لتقرير مدى جودة ظروف حياته الفعلية، وإلى مدى تشابه هذه الظروف من فع توقعاته وأمنياته فيما ير غب أن يشعر به ويعيثه. ( American Psychological Asso Ciation- APD,

(2007, 904

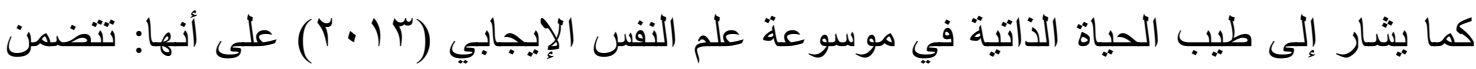

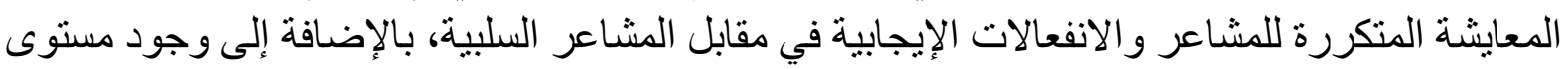

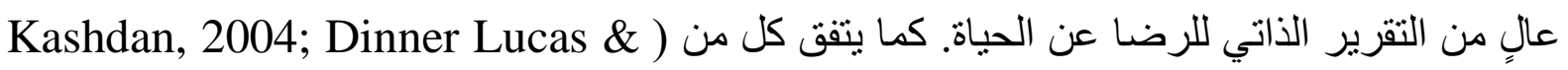


تنمية فاعلية الذات لتحسين طيب الحياة الذاتية لاي طالبات الجامعة

(Oishi, 2005; Jovanovie, 2011; Tanannaeifaral Mota Ghedifard, 2014

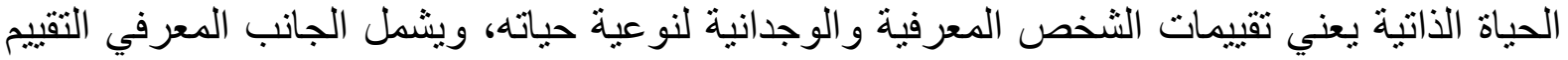

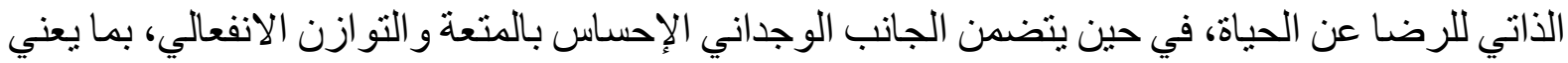
التكرار النسبي للمشاعر الإيجابية في مقابل المشاعر السلبية. (Thomas, et al., 2016, 82)

\section{تعريف طيب الحياة الذاتية:}

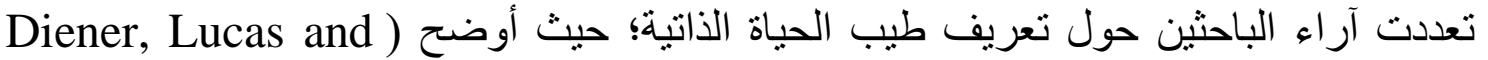
(Oishi

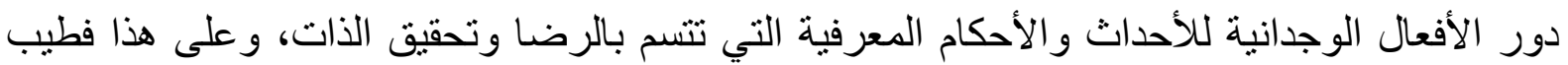

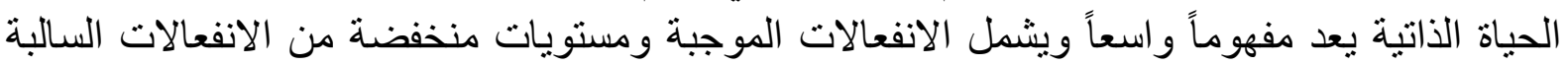

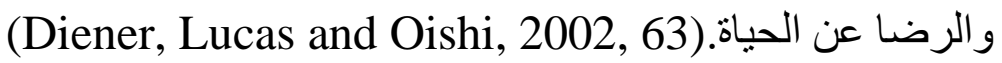

ويحدده (Carr) على أنه: حالة نفسية إيجابية تعكس مسنوى مرتفعاً من الرضا عن الحياة،

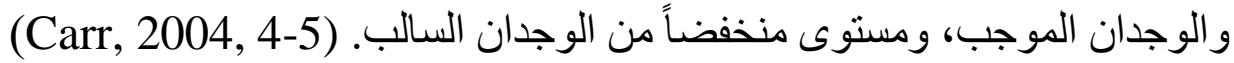

إذ تثبير (Jeromy Dsharon) إلى أن طيب الحياة الذاتية يتكون من ثلاثة جو انب تتمثل في الانفعال الإيجابي، و الانفعال السلبي، والرضا عن الحياة. ويعكس هذا المفهوم سيطرة الأفكار و المشاعر الإيجابية الإنية

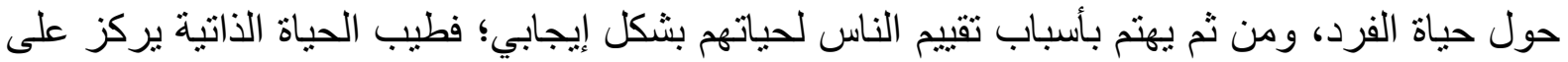

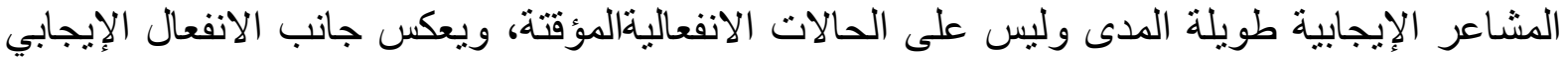

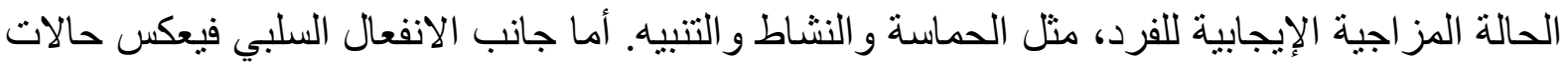

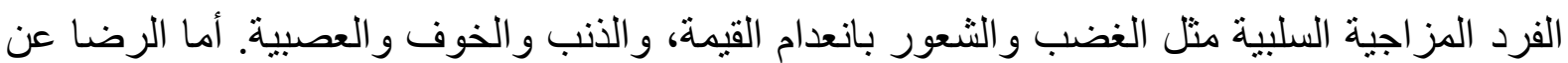

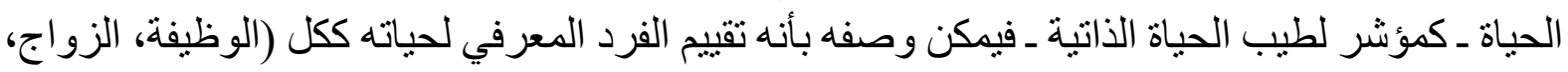

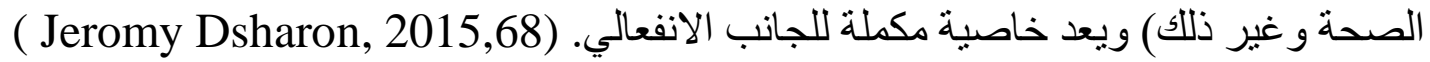

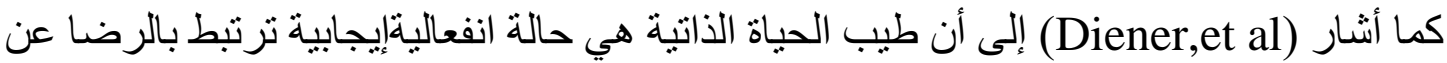

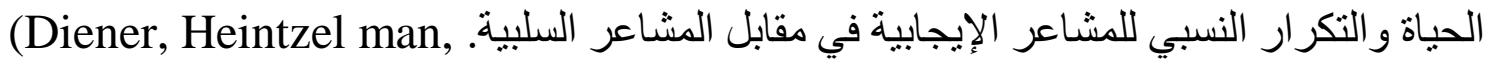

Kushler, Tay, Wirtz, Lutes and Oishi, 2016)

من خلال التعريفات السابقة لطيب الحياة الذاتية يمكن القول أن هذه التعريفات تتبع من منحنيين

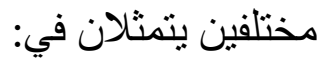

أ- منحنى المتعة (Hedonism): الذي ير ادف بين طيب الحياة الذاتية و السعادة فيما يتعلق بتحقيق

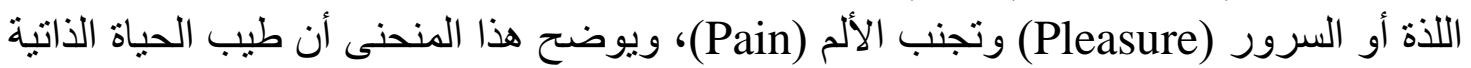

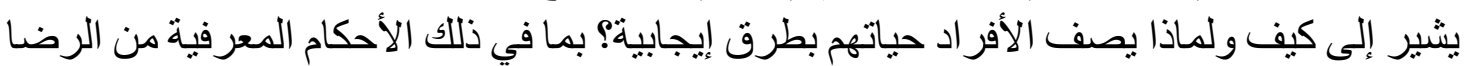
عن الحياة و التقييمات و الوجدانية الإيجابية من المز اجج و العو اطفئ. بـ منحنى الإشراق (Eudainomic): الذي يعكس النظرة لطيب الحياة الذاتية على أنه ينكون من الإمكانات البشرية المزدهرة. وتستخلص الباحثة من التعريفات السابقة ما يلي: 1 - تعدد تعريفات طيب الحياة الذاتية لاختلاف توجهات الباحثين النظرية. 
تنمية فاعلية الذات لتحسين طيب الحياة الذاتية لاي طالبات الجامعة

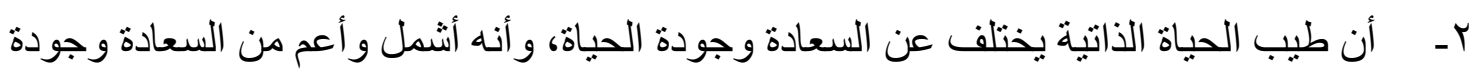
الحياة.

وسوف تتبني الباحثة تعريف (Diener) لطيب الحياة الذاتية و الذي يتمثل في أنه: حالة نفسية إيجابية تتميز بمستوى مرتفع من الرضا عن الحياة، والوجدان الإيجابي، ومستوى منخفض من الوجدان السلبي،

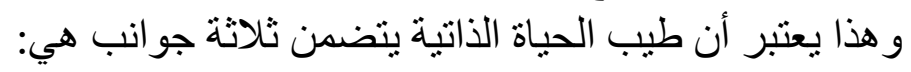

أـ الرضا عن الحياة (Life Satisfaction): وهو أحكام الفرد المعرفية العامة على حياته ككل باعتبار ها إيجابية ومُرضية وتقبله غير المشروط لحياته سواء الماضية أو الحالية أو المستقبلية، وذلك في ضوء معاييره الذاتية التي يتقبلها لنفسه.

ب- الوجدان الموجب (Positive Affect): و هو الجانب الذي يتضمن مستويات متباينة من الانفعالات السارة.

ج- الوجدان السالب (Negative Affect): وهو الجانب الذي يتضمن مستويات متباينة من الانفعالات غير السارة.

الملامح المميزة لطيب الحياة الذاتية:

قد يكون سمة مستقرة لدى الفرد تستثار في مو اقف معينة دون غير ها، وقد يكون هدفاً في ذاته يكافح Larsen, Eid, الأفر اد من أجل تحقيقه، أو وسيلة تساعد الأفراد على تحقيق النواتج الإيجابية الأخرى $(2008,8)$.

ويعتبر طيب الحياة الذاتية خبرة ذاتية للفرد ويعد المصدر الأول للمعلومات عنه هو التقارير الذاتية

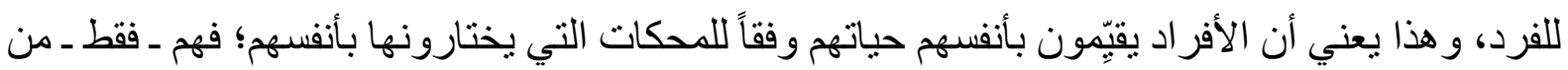

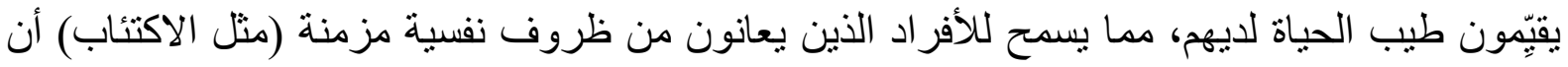
تكون لديهم درجات ـ ولو منخفضة ـ من طيب الحياة الذاتية رغم معاناتهم. ( Denvan \& Macaskiu, (2017, 521

و عن العلاقة بين فاعلية الذات وطيب الحياة الذاتية اهتمت در اسة (Cuprar CV, 2006) - بعنو ان "طيب الحياة لدى المر اهقين (دور فاعلية الذات كمحدد للسعادة و التفكير الإيجابي)" ـ بتحديد تأثثير فاعلية

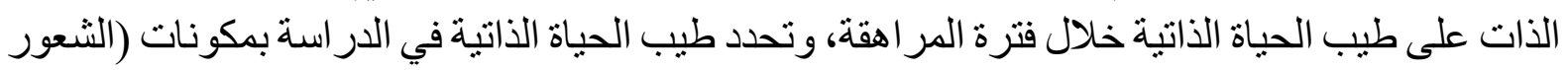

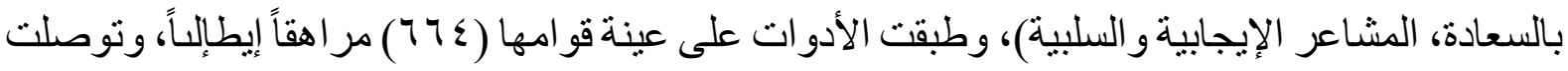

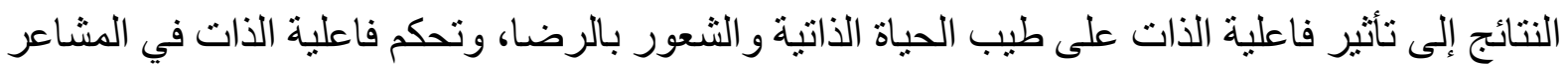
الإيجابية و السلبية.

و هدفت در اسة (Maria Strobel, 2011) - بعنوان: "كن نفسك، صدق نفسك، وكن سعيداً: فاعلية

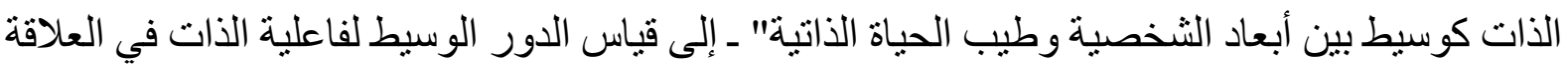
بين الأبعاد الخمسة الكبرى للشخصية وطيب الحياة الذاتية على عينة من طلاب الجامعة، واستخدمت

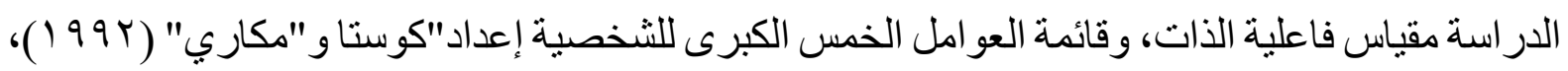
ولقياس طيب الحياة الذاتية استخدمت الدراسة مقياس الرضا فاس عن الحياة ومقياس المشاعر الإيجابية والسلبية إعداد(Diener, Emmons, 1985)، وقد توصلت هذه الدر اسة إلى وجود علاقة موجبة دالة إحصائياً بين 
تنمية فاعلية الذات لتحسين طيب الحياة الذاتية لاي طالبات الجامعة

أبعاد الثخصية (الضمير، الانبساطية، التقبُّ، الانفتاح على الخبرات، العصابية) وطيب الحيبه الحياة الذاتية

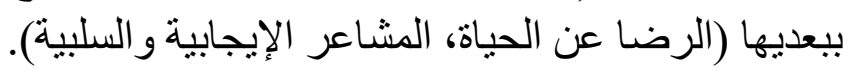

و اهتمت در اسة (Müller, Dareen, et al, 2014) - بعنو ان: "طيب الحياة الذاتية/ الشخصية في الرشد المتأخر ، فاعلية الذات هي المفتاح" ـ بالبحث في تأثثير التقدم في العمر على العلاقة بين فاعلية الذات

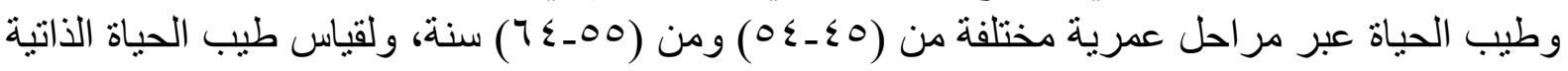

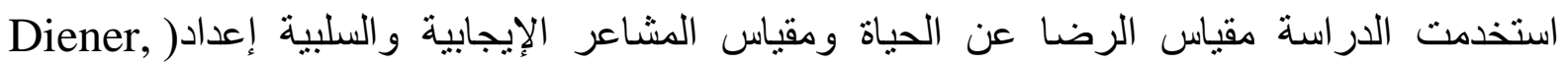

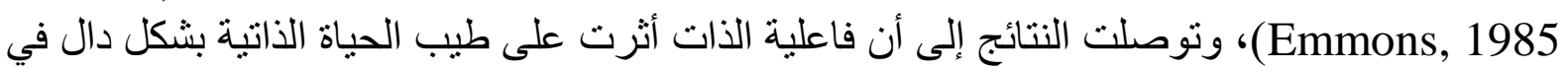
المرحلة العمرية من (0 ـ ـ ع م) سنة.

وهو ما أشارت إلبه در اسة (Kueong- Hocha, 2019) بعنوان "طيب الحياة الذاتية لدى طلبة

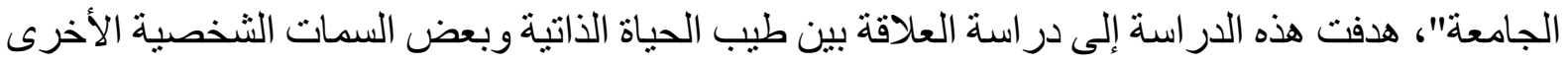

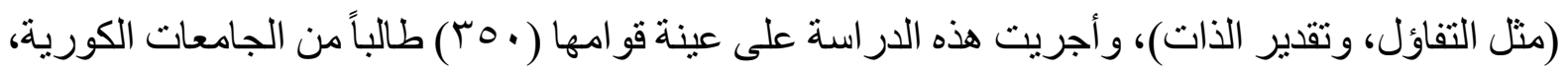

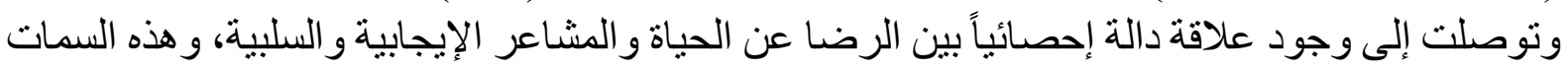
الثخصية التي تم در استها.

وبناء على ما سبق، ترى الباحثة أن فاعلية الذات تؤثر بثكل دال ومباشر على طيب الحياة الذاتية، وبالتالي هدف البحث الحاليإلى تنمية فاعلية الذات لما لها من أثر في تنمية طيب الثية الحياة الذاتية.

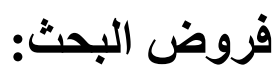

ـ ـ توجد فروق دالة إحصـائياً بين منوســي درجات القياسـين القبلي و البعدي في فاعلية الذات لدى الدي المجمو عة التجريبية. ץ- توجد فروق دالة إحصـائياً بين منوسطي درجات المجمو عة التجريبية و المجموعة الضـابطة في فاعلية الذات في القياس البعدي.

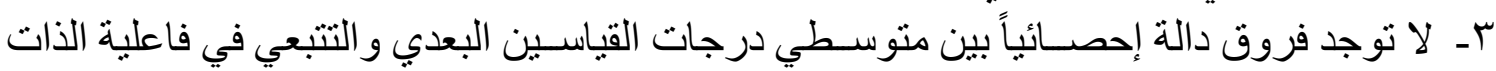
لدى المجمو عة التجريبية. ع ـ توجد فروق دالة إحصـائياً بين متوسـطي درجات القياسـين القبلي و البعدي في طيب الحياة الذاية

لاى المجمو عة التجريبية.

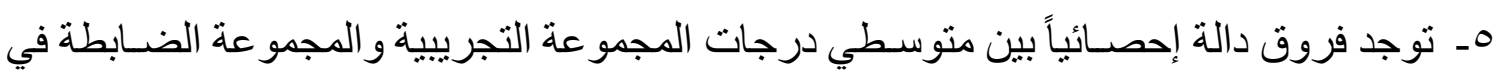
طيب الحياة الذاتية في القياس البعدي.

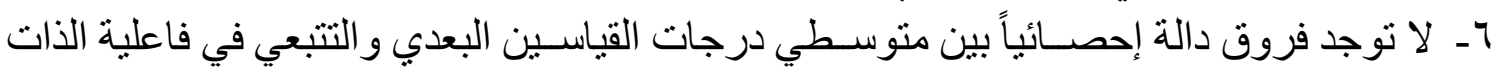
لدى المجمو عة التجريبية.

\section{منهج البحث:}

يعتمد البحث الحالي على استخدام المنهج التجريبي وذللك ليناسب أهداف الدر اسة حيث تعتمد الدر اسة على التصميم التجريبي (القياس القبلي _ القياس البعدي) و القائم على استخدام مجموعتين متكافئتين من الطالبات ويهدف إلى اختبار فاعلية برنامج لتنمية فاعلية الذات. 
المجتمع الأصلي للبحث يتمثل في طالبات الجامعة، وقد نم تطبيق أدوات البحث على عينة استطلاعية وأخرى للار اسة التجريية على النحو التالي:

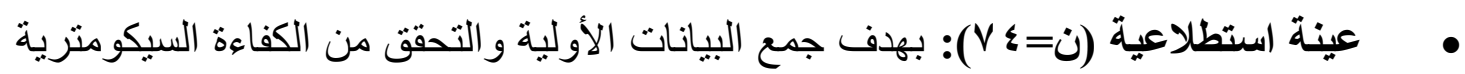

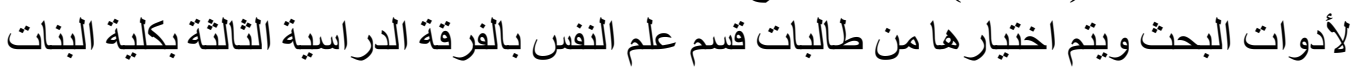

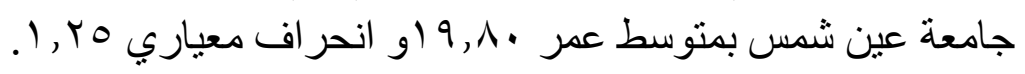

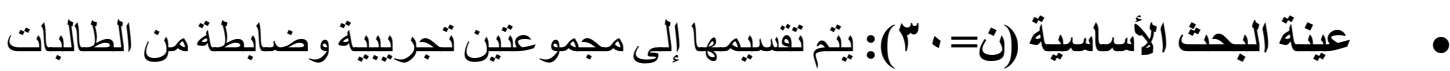

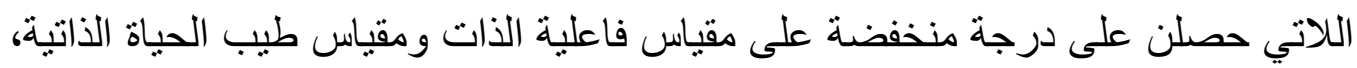

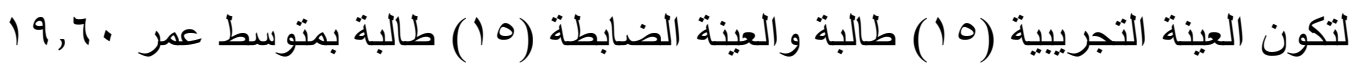

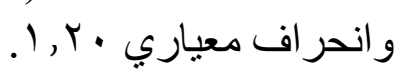

وصف العينة والتحقق من التكافؤ بين المجموعة التجريبية والمجموعة الضابطة: التكافؤ في التطبيق القبلي لمقياس فاعلية الذات لتونئ

\begin{tabular}{|c|c|c|c|c|c|c|c|c|}
\hline الإحصائية & "تيمة & $\%$ & العظمى الدرجة & الانحراف المعياري & المستوسط & العدد & المجموعة & البعد \\
\hline \multirow{2}{*}{$\cdot, 1 r$} & \multirow{2}{*}{1,09} & $\% \vee r, \vee \leq$ & \multirow{2}{*}{ זr } & $1, \lambda$. & $r \leqslant, r r$ & 10 & التجريبية & \multirow{2}{*}{ للقدرات الإدراك المعرفية } \\
\hline & & $\% \vee \neg, \vee \vee$ & & זד, & r & 10 & الضابطة & \\
\hline \multirow{2}{*}{ •, Yr } & \multirow{2}{*}{$1, Y_{7}$} & \% & \multirow{2}{*}{$r}$. & 1,94 & $r, r$. & 10 & التجريبية & \multirow{2}{*}{ الثقة بالنفس } \\
\hline & & $\% \vee r, \vee \wedge$ & & $T, T \leq$ & $r Y, I T$ & 10 & الضابطة & \\
\hline \multirow{2}{*}{ תT, } & \multirow{2}{*}{$\cdot, 99$} & $\%\urcorner 9, \wedge \wedge$ & \multirow{2}{*}{$r V$} & r Tr, & $1 \wedge, \wedge V$ & 10 & التجريبية & \multirow{2}{*}{ المثابرة } \\
\hline & & \% & & r,Ar & $19, \wedge$ & 10 & الضابطة & \\
\hline \multirow{2}{*}{$\cdot, V}$. & \multirow{2}{*}{$\cdot, r q$} & \% & \multirow{2}{*}{ Tr } & $r, 1 \leq$ & $r \leq, r$. & 10 & التجريبية & \multirow{2}{*}{ التحكم في ضغوط } \\
\hline & & $\% \vee \leq, 1 \leq$ & & 1,01 & $r \leq, \leq V$ & 10 & الضابطة & \\
\hline \multirow{2}{*}{ r } & \multirow{2}{*}{$\cdot, 0$} & $\% \vee r, \neg т$ & \multirow{2}{*}{ Tr } & $T, Y$. & $9 \cdot, 7$. & 10 & التجريبية & \multirow{2}{*}{ إجمالي فاعلية الذات } \\
\hline & & $\% \vee \leq, 0 \wedge$ & & 7,19 & $91, v \pi$ & 10 & الضابطة & \\
\hline
\end{tabular}

جدول (1) التكافؤ في التطبيق القبلي لمقياس فاعلية الذات

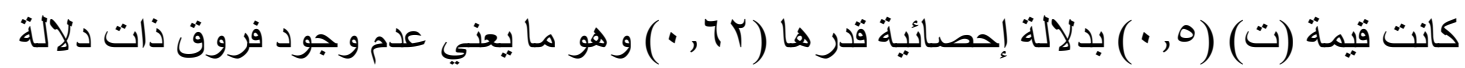

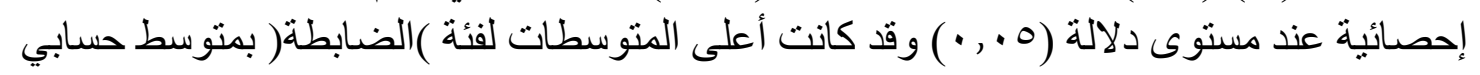

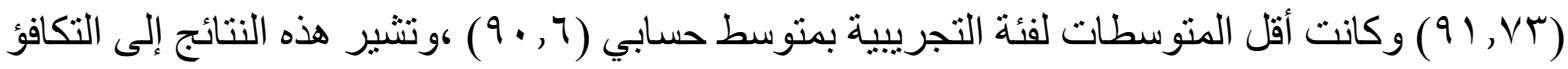
بين المجمو عة التجريبية و المجموعة الضابطة في التطبيق القبلي لمقياس فاعلية الذات.

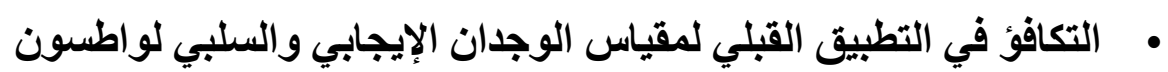
جدول (Y) التكافؤ في التطبيق القبلي لمقياس الوجدان الإيجابي والسلبي والبي لوني 
تنمية فاعلية الذات لتحسين طيب الحياة الذاتية لدي طالبات الجامعة

\begin{tabular}{|c|c|c|c|c|c|c|c|c|}
\hline الإحصائية الالة & "قيمة" & $\%$ & الألطمى & المعياري & الحستوسط & العدد & المجموعة & البعد \\
\hline \multirow{2}{*}{$\cdot, 19$} & \multirow{2}{*}{$-1, r \leqslant$} & $\%{ }^{7 \cdot, 7}$ & \multirow{2}{*}{$1 \ldots$} & $7, \cdot V$ & $7 \cdot, 7 V$ & 10 & التجريبية & مقياس الوجدان \\
\hline & & $\%\urcorner \varepsilon$, & & $V, V Y$ & $T \varepsilon, \cdot V$ & 10 & الضابطة & الإيجابي و السلبي \\
\hline
\end{tabular}

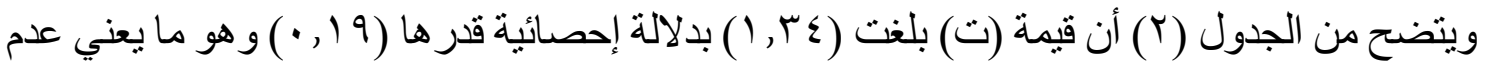

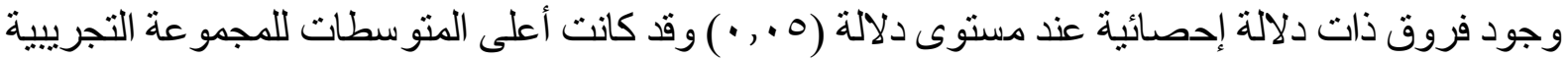

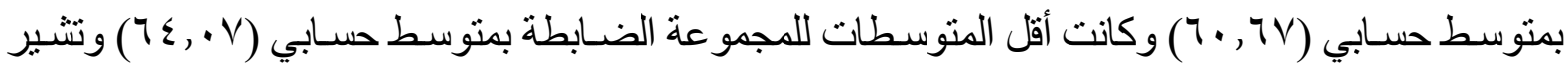
هذه النتائج إلى التكافؤ بين المجمو عة التجريبية و المجمو عة الضـــابطة في التطبيق القبلي لمقياس الوجدان الإيجابي و السلبي.

• • التكافؤ في التطبيق القبلي لمقياس الرضا عن الحياة

جدول (r) التكاقؤ في التطبيث القبلي لمقياس الرضا عن الحياة

\begin{tabular}{|c|c|c|c|c|c|c|c|c|}
\hline الإحصائية & "تيمة" & $\%$ & العظمى الارجة & الالمعياري & الحستوسطي & العدد & المجموعة & البعد \\
\hline \multirow{2}{*}{ • } & \multirow{2}{*}{$\cdot, \wedge \vee$} & $\% \vee \cdot, \leqslant \Lambda$ & \multirow{2}{*}{ ro } & $\varepsilon,+7$ & $r \leq, T V$ & 10 & التجريبية & \multirow{2}{*}{ الرضا عن } \\
\hline & & $\% 70,9$. & & $0, \wedge \vee$ & $r r, \cdot V$ & 10 & الضابطة & \\
\hline
\end{tabular}

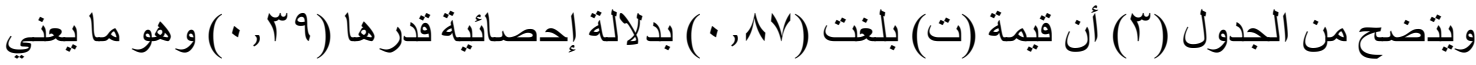

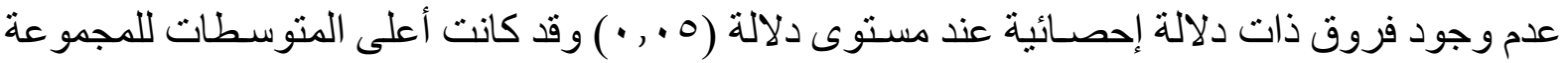

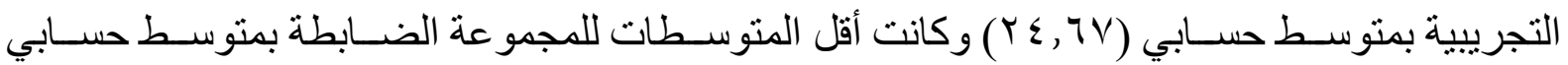

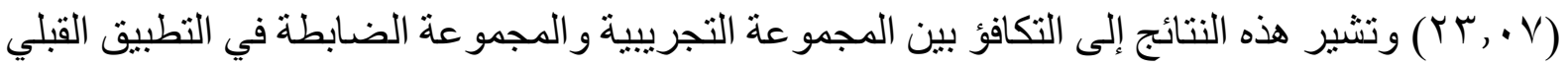

لمقياس الرضا عن الحياة. أدوات البحث:

الأداة الأولى: مقياس فاعلية الذات (إعدادالباحثة)

بناء مقياس فاعلية الذات:

قامت الباحثة بالاطلاع على عدد من المقاييس السابقة للاستفادة منها في تحديد أبعاد فاعلية الذات

وكيفية صياغة العبار ات المقاييس التي تناولت فاعلية فاعلية الذات: مقياس فاعلية الذات إعداد(schwarzer,1993). تكون المقياس من · 1 عبار ات و هو مقياس أحادى البعد يهدف إلى التعرف على مستوى فاعلية الذات العامة

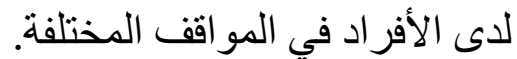

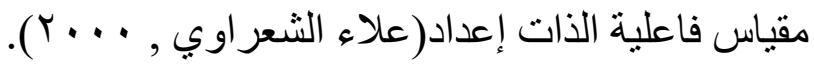

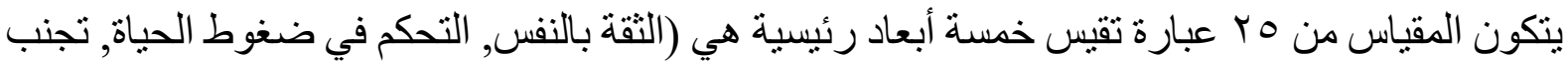

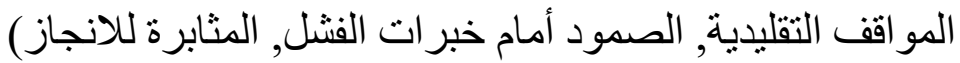
مقياس فاعلية الذات إعداد(عادل العدل, ( . ب). 
تنمية فاعلية الذات لتحسين طيب الحياة الذاتية لاي طالبات الجامعة

يتكون المقياس من • م مفردة تدور حول فاعلية الفرد في التنبؤ بمسار سلوكه بصفة عامة

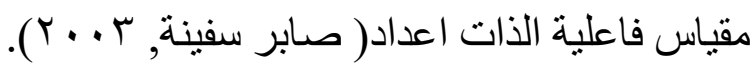
يتكون المقياس من وب عبارة تقيس (الرغبة في بدء السلوك، المثابرة في مواجهة المحنة، السعي المستمر

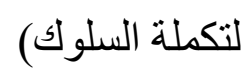

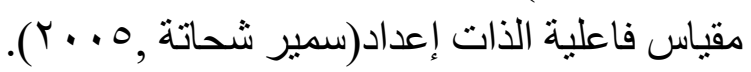

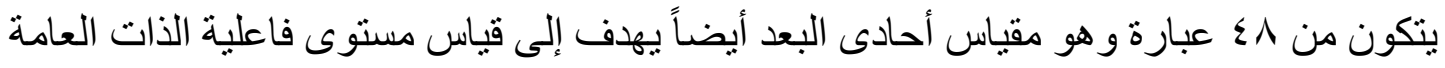

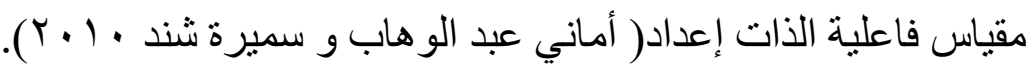

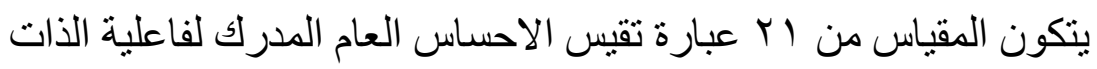
مقياس فاعلية الذات إعداد( هو يدة محمود وفوزية الجمالي , • ( • (Y).

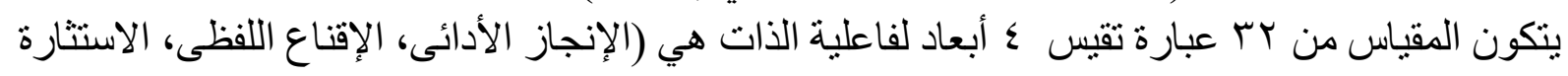

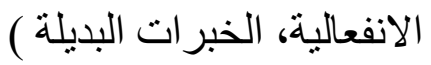

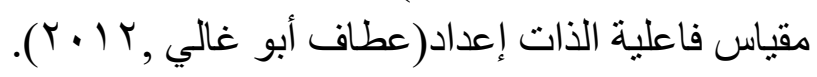

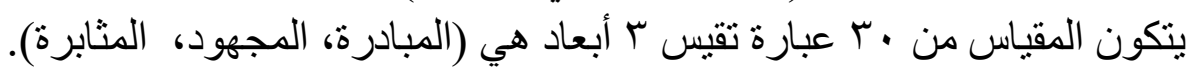

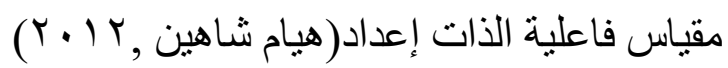
يتكون المقياس من و؟ عبارة تقيس (المثابرة، الثقة بالنفس، التخطيط وتنظيم العمل، تحقيق الأهداف، التو اصل الفعال مع الأخر ). مقياس فاعلية الذات اعداد(إيمان مر عى، 10 . ب) تكون المقياس من عدة أبعاد منها( المثابرة و الثقة بالنفس و التحكم في ضغوط فئرة الحياة). واعتماداً على المصادر السابقة قامت الباحثة بصياغة بـ بع عبارة تقيس فاعلية الذات من خلال ع أبعاد

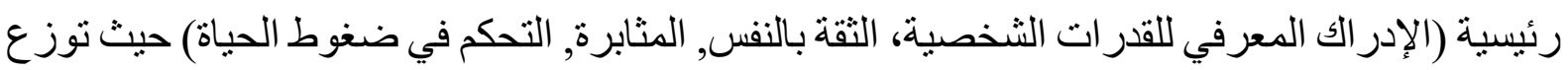

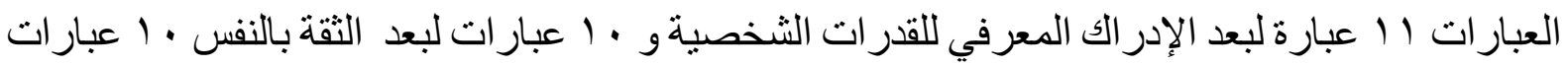

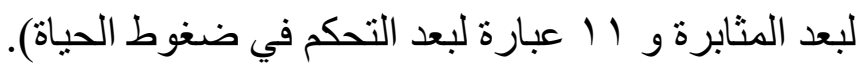

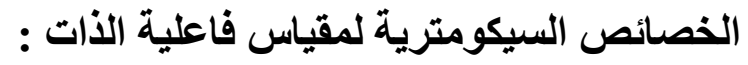

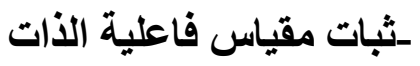

تم استخدام معامل ألفا كرونباخ لحساب ثبات مقياس فاعلية الذات وقد كاتت النتائج كما هو موضح جدول ( ع) معامل ألفا كرونباخ لثبات مقياس فاعلية الذات

\begin{tabular}{|c|c|c|}
\hline معامل ألفا كرونباخ & عدد الفقر ات & الأداة \\
\hline$\cdot, 71$ & $\varepsilon r$ & مقياس فاعلية الذات \\
\hline
\end{tabular}

يتضح من الجدول ( ) أن معامل ألفا كرونباخ لثبات مقياس فاعلية الذات قد بلغ ( الج , • ) و هو ما يثير إلى درجة ثبات مرتفعة.

كذلك تم حساب الثبات لمقياس فاعلية الذات بطريقة التجزئة النصفية وقد كاتت النتائج كما هو موضح (•) بالجدول جدول (0) التجزئة النصفية لمقياس فاعلية الذات (0) 
تنمية فاعلية الذات لتحسين طيب الحياة الذاتية لاي طالبات الجامعة

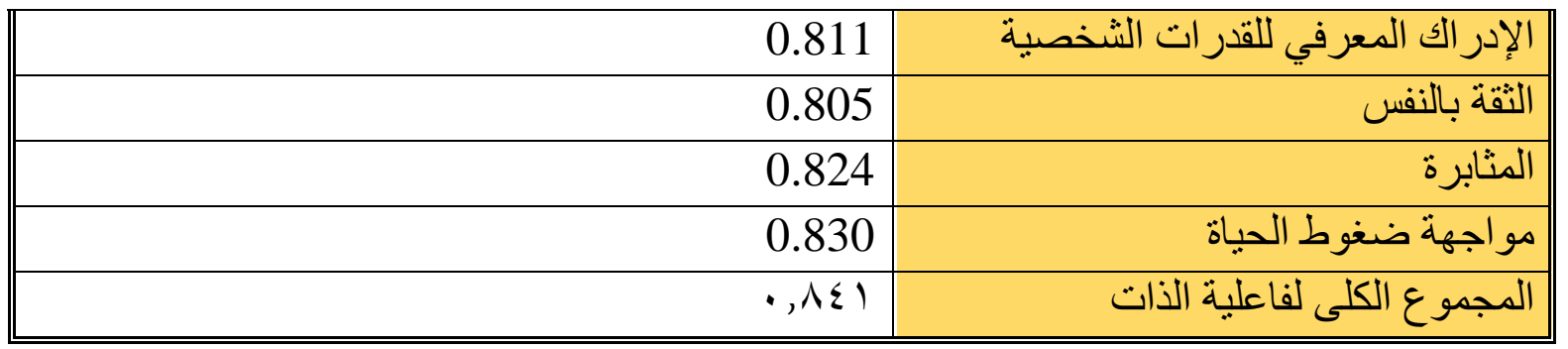

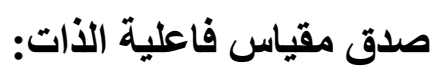
ـصدق المقارنة الطرفية لمقياس فاعلية الذابـ الذات

تم حساب صدق المقارنة الطرفية لمقياس فاعلية الذات باستخدام اختبار

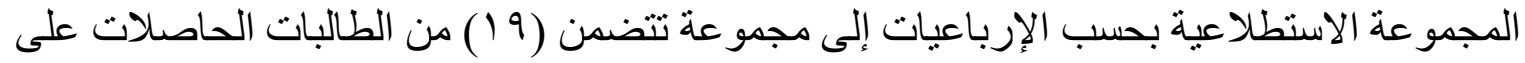

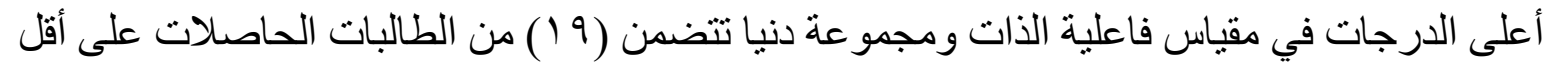

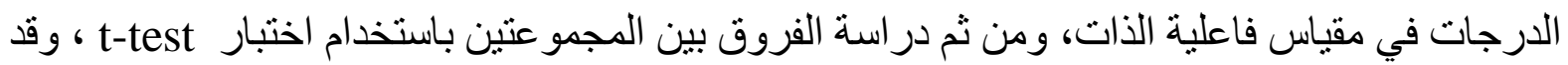

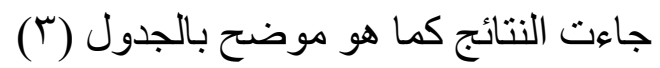
جدول (7) صدق المقارنة الطرفية لمقياس فاعلية الذات

\begin{tabular}{|c|c|c|c|c|c|c|}
\hline الإلالة الائية & قيمة "ت" & الانحرياري & الحسابي & العدد & المجموعة & البعد \\
\hline \multirow{3}{*}{$\cdot, \cdots$} & \multirow{3}{*}{$7, \Gamma \wedge$} & $T, 70$ & $r r, \ldots$ & 19 & الدنيا & \multirow{3}{*}{ للإدر الك } \\
\hline & & $1, \lambda$. & $r V, T \wedge$ & 19 & العليا & \\
\hline & & & & & & \\
\hline \multirow{2}{*}{$\cdot, \cdot$} & \multirow{2}{*}{$V, r V$} & $r, v q$ & 19,74 & 19 & الدنيا & \multirow{2}{*}{ النقة } \\
\hline & & $r, \cdot T$ & $Y_{0}, \varepsilon Y$ & 19 & العليا & \\
\hline \multirow{2}{*}{$\cdot, \cdot$} & \multirow{2}{*}{$T, r Y$} & $1,0 Y$ & 19,11 & 19 & الدنيا & \multirow{2}{*}{ المثابرة } \\
\hline & & 1,49 & $Y Y, \ldots$ & 19 & العليا & \\
\hline \multirow[b]{2}{*}{$\cdot, \cdot$} & \multirow[b]{2}{*}{$\varepsilon, \pi$} & $Y, Y \varepsilon$ & $r Y, 1 T$ & 19 & الدنيا & \multirow{2}{*}{ لتئي } \\
\hline & & $r, I r$ & $r 0, r)$ & 19 & العليا & \\
\hline \multirow{2}{*}{$\cdot, \cdots$} & \multirow{2}{*}{$\mid r, q T$} & $\varepsilon, V V$ & $\wedge r, \wedge q$ & 19 & الدنيا & \multirow{2}{*}{ ككل المقياس } \\
\hline & & $r, \lambda)$ & $1 \cdots, r r$ & 19 & العليا & \\
\hline
\end{tabular}

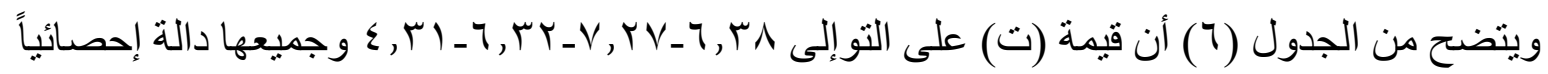

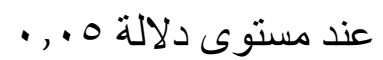
وتتثير هذه النتيجة إلى صدق الدقارنة الطرفية لمقياس فاعلية الذات وقدرته على التمييز بين الطالبات ذوي المستويات المختلفة لفاعلية الذات. 


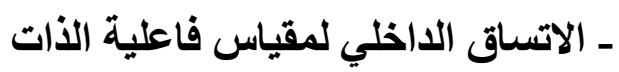

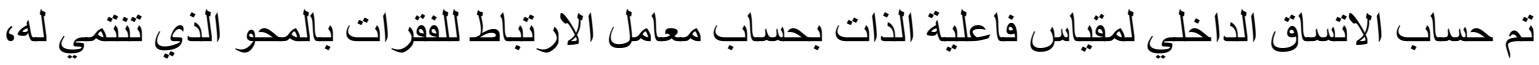

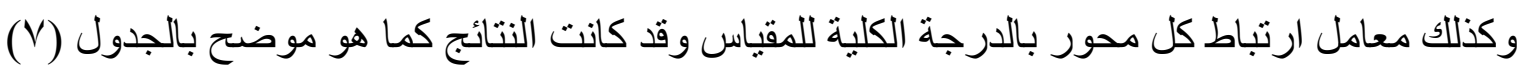
جدول (V) معامل الاتساق الداخلي لمقياس فاعلية الذات

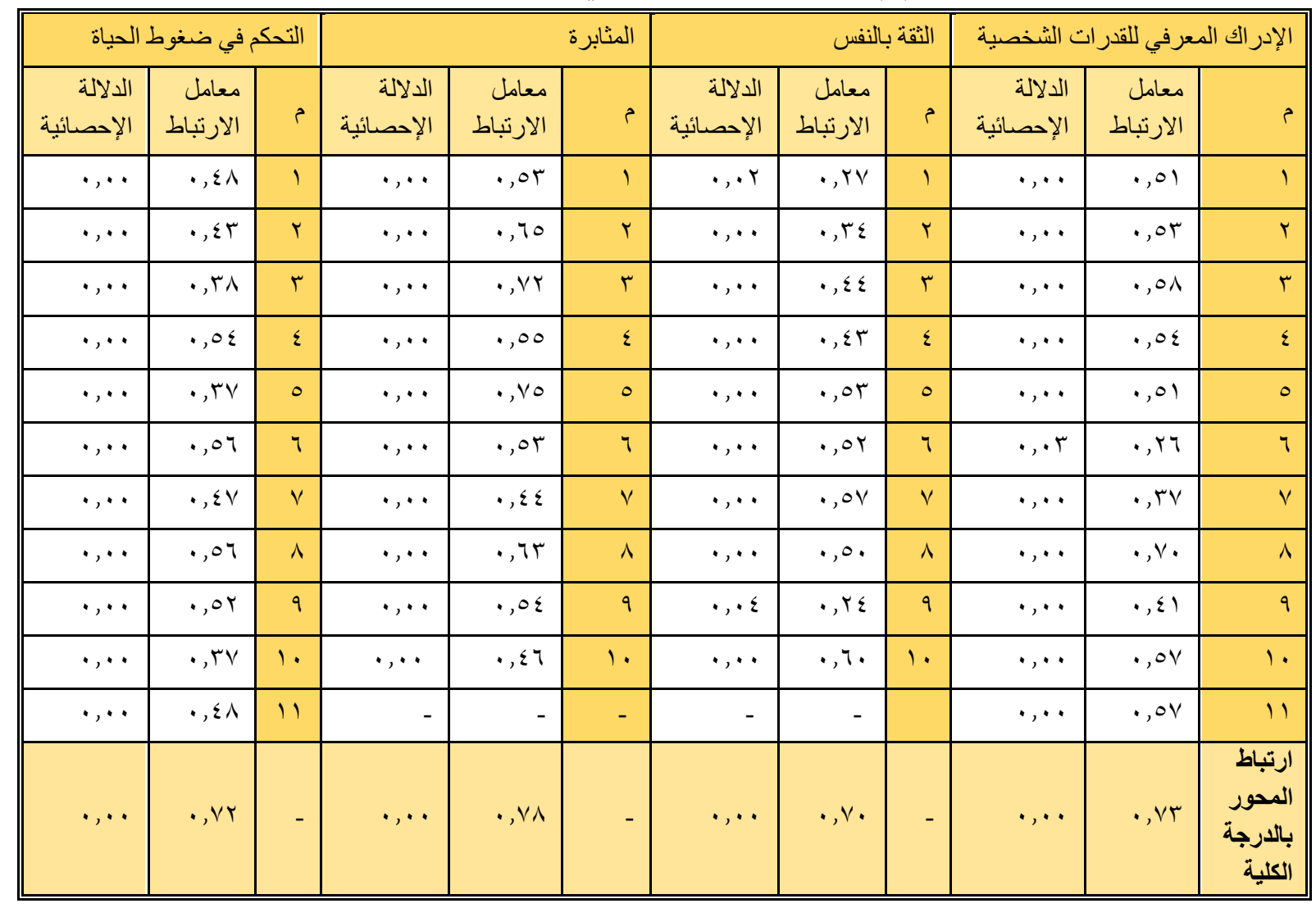

يتضح من الجدول (V) أن جميع فقرات مقياس فاعلية الذات ترتبط بالبعد الذي تنتمي له به بمعامل ارتباط

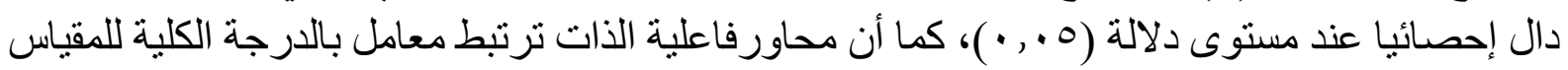

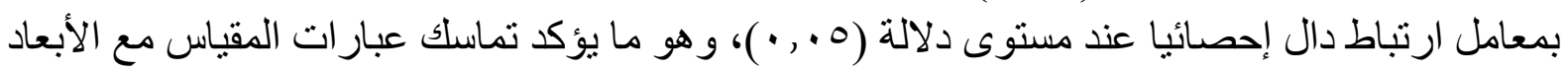
الني تنتمى إليها.

الأداة الثانية: مقياس الوجدان الإيجابي والوجدان السلبي:من إعداد (Watson et al., 1988) ترجمة

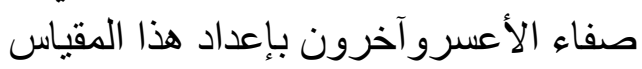
قام واطسون و آخرون بإعدادهذا المقياس (Watson et al., 1988) على عينة من طلاب المرحلة

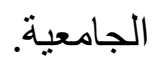

وتتكون قائمة الوجدان الإيجابي و السلبي من · r كلمة تصف مشاعر و انفعالات مختلفة، ويقوم

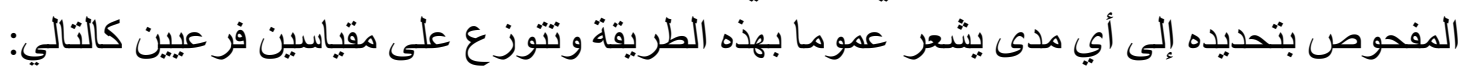


مقياس الوجدان الإيجابي (PA):

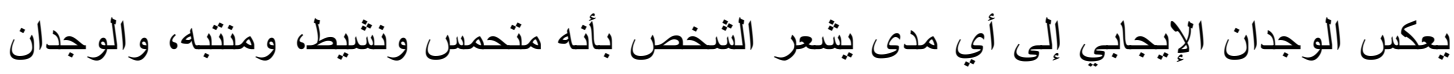

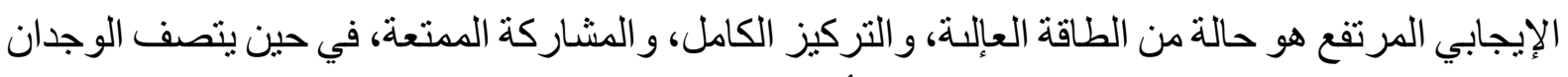

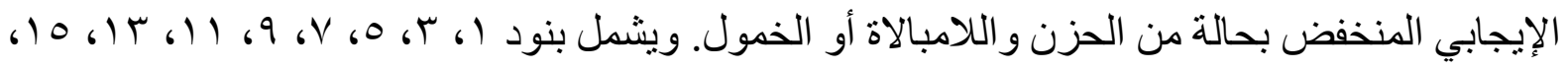

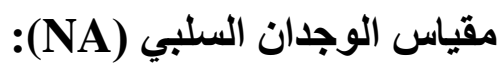

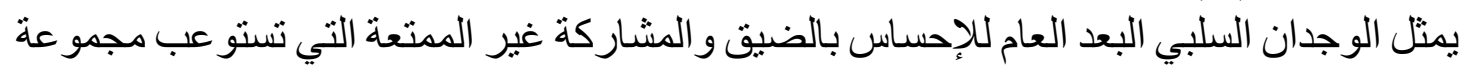

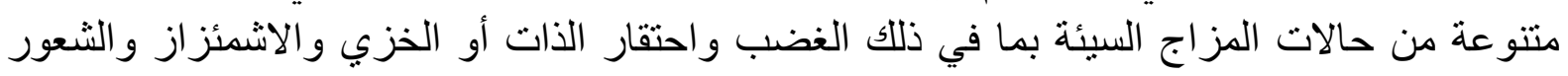

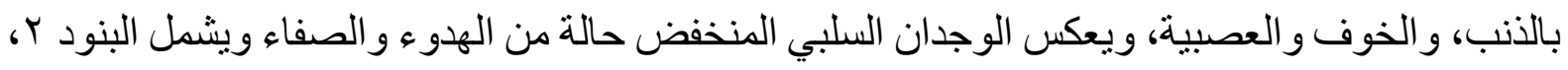

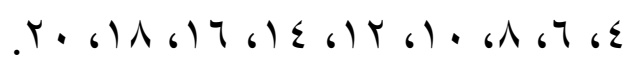

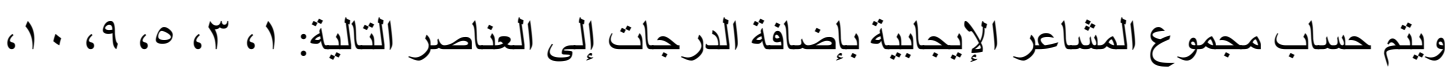

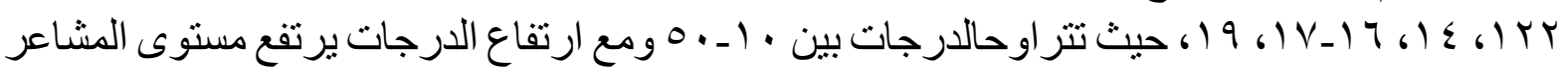

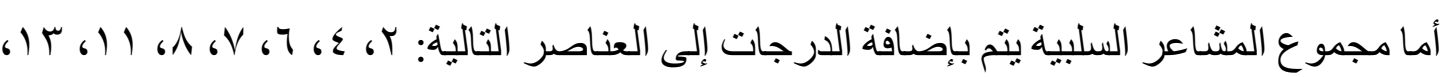

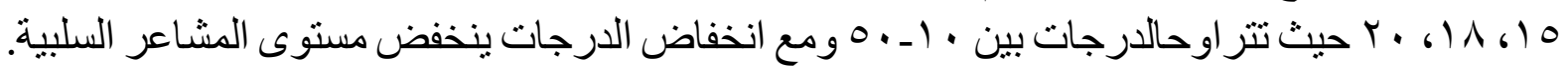

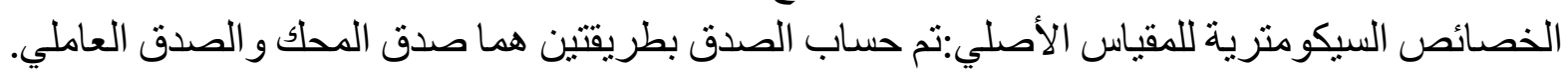

(Watson D.,Lee Anna clarkL.A.,pp1066-1068) الخصائص السيكومترية للمقياس في البحث الحالي:

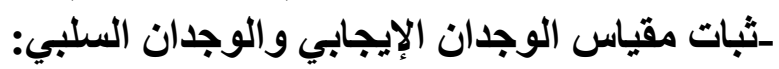

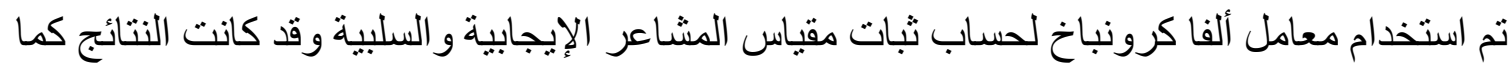

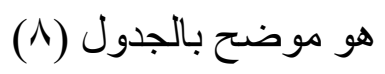

جدول (^) معامل ألفا كرونباخ لثبات مقياس المشاعر الإيجابية والسلبية

\begin{tabular}{|c|c|c|}
\hline معامل ألفا كرونباخ & عدد الفقر ات & 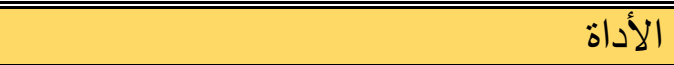 \\
\hline$\cdot, \mathrm{V} \varepsilon$ & $r$. & مقياس الوجدان الإيجابي والوجدان السلبي \\
\hline
\end{tabular}

يتضح من الجدول (^) أن معامل ألفا كرونباخ لثبات مقياس المشاعر الإيجابية و السلبية قد بلغ (ع V , • )

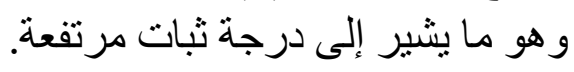

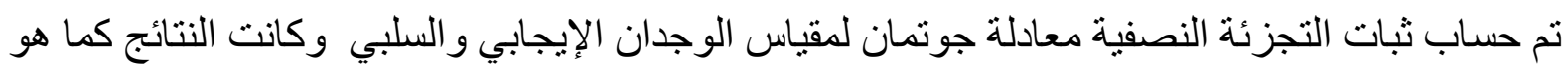

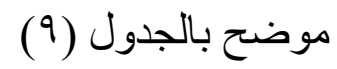
جدول (9) حساب ثبات التجزئة النصفية لمقياس الوجدان الإيجابي و السلبي

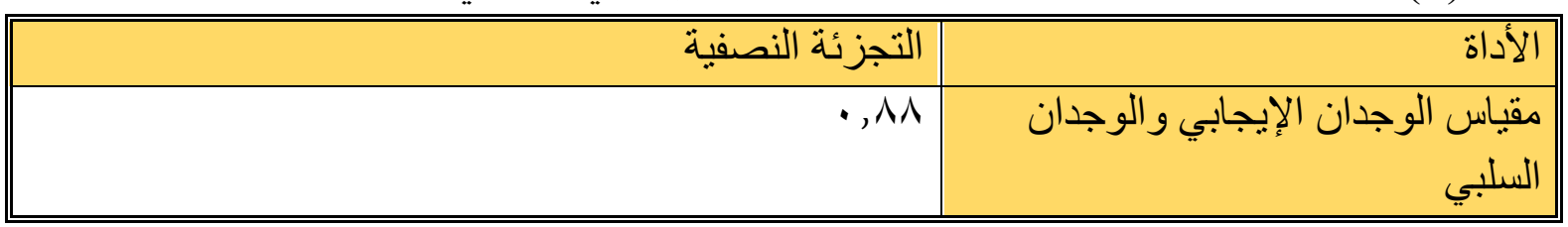

صدق مقياس الوجدان الإيجابي و الوجدان السلبي: 
-صدق المقارنة الطرفية لمقياس الوجدان الإيجابي والوجدان السلبي: تم حساب صدق المقارنة الطرفية لمقياس المشاعر الإيجابية والسلبية باستخدام اختبار

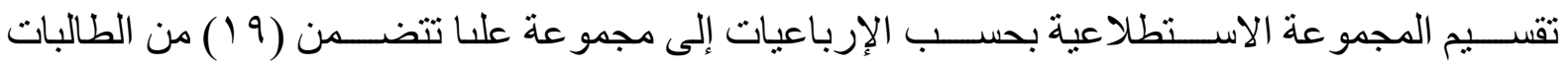

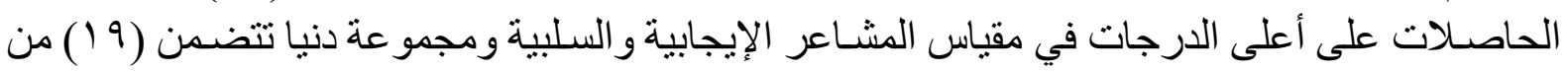

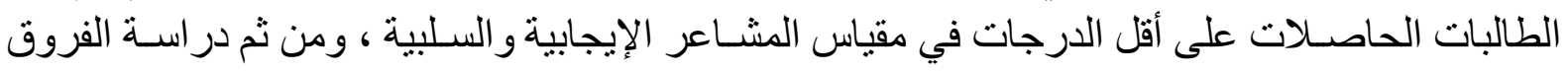

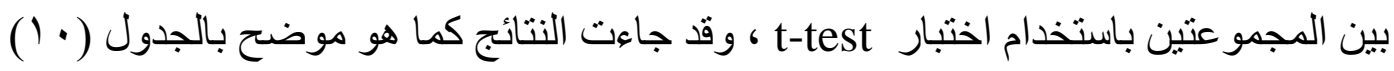

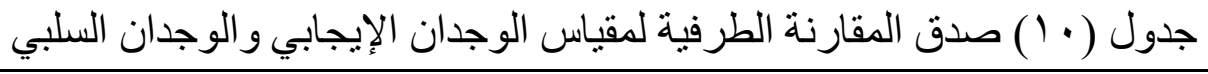

\begin{tabular}{|c|c|c|c|c|c|c|}
\hline الإلالالة & قيمة "ت" & الالمعياري اف المي & المتوسط الحسي & العدد & المجمو عة & البعد \\
\hline \multirow[b]{2}{*}{$\cdot, \cdot \cdot$} & \multirow[b]{2}{*}{ 11, } & $0,0 \leqslant$ & 01,11 & 19 & الدنيا & \multirow{2}{*}{ والإيجابي الوجدان } \\
\hline & & $7, \wedge$. & $\vee \leqslant, \wedge q$ & 19 & العليا & \\
\hline
\end{tabular}

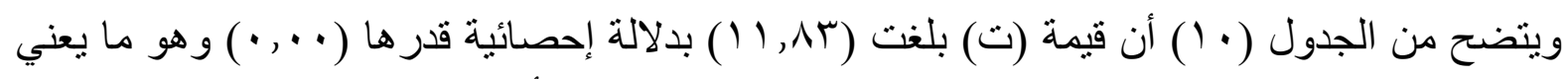

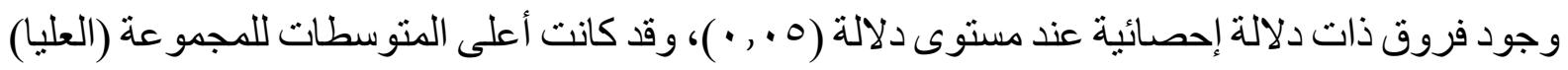

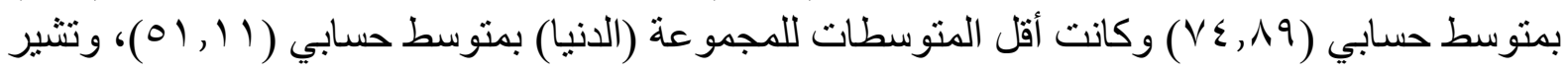
هذه النتائج إلى صدق المقارنة الطرفية لمقياس الوجدان الإيجابي و الوجدان السلبي وقدرته على التمييز بين الطالبات ذوات المستويات المختلفة في الوجدان الإيجابي و الوجدان السلبي.

\section{- - صدق المحك لمقياس الوجدان الإيجابي والوجدان السلبي:}

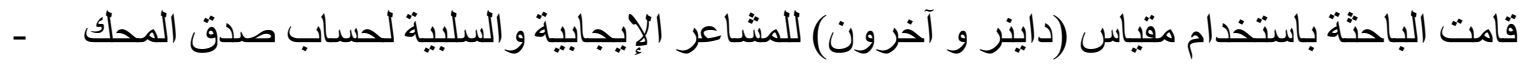

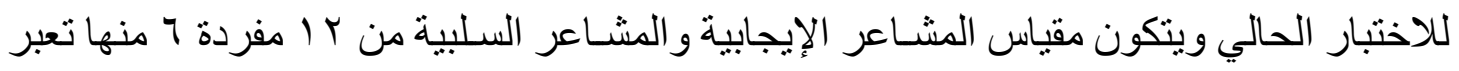

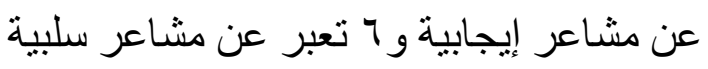

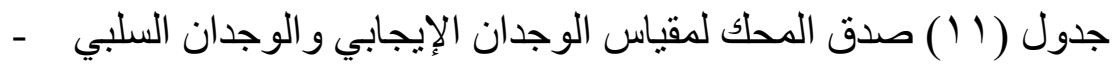

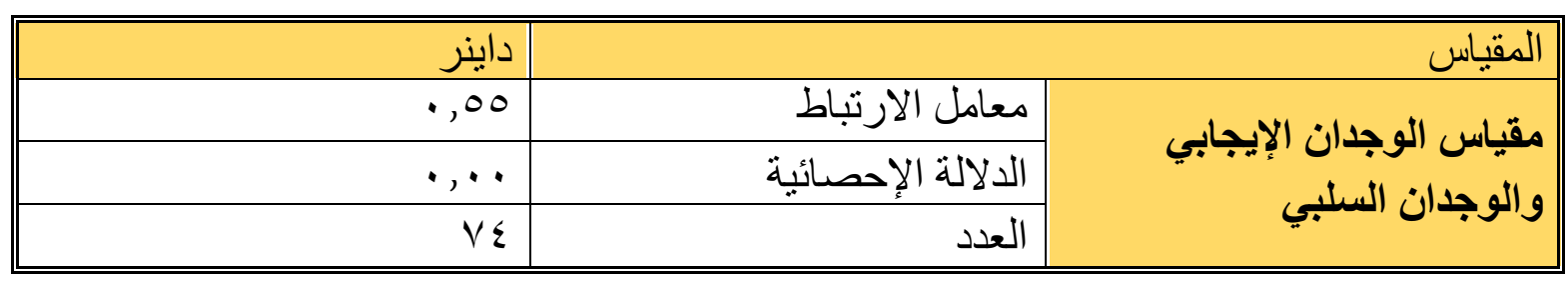

يتضح من الجدول (11) أن قيمة معامل الارتباط بين درجات الطلاب على مقياس المشاعر الإيجابية

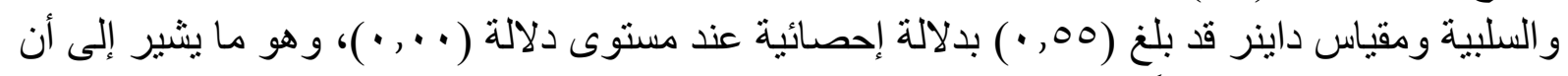
صدق المقياس دال إحصائياً. ـ الاتساق الاخلي لمقياس الوجدان الإيجائي الإني والوجدان السلبي:

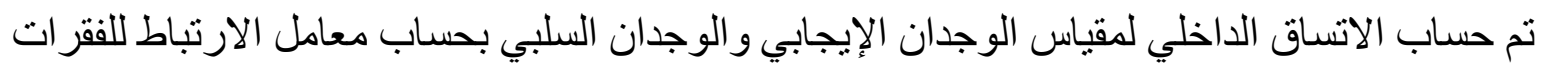

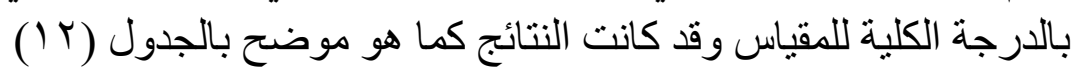


تنمية فاعلية الذات لتحسين طيب الحياة الذاتية لاي طالبات الجامعة

جدول (Y T T) معامل ارتباط المفردة بالدرجة الكلية للمقياس

\begin{tabular}{|c|c|c|c|c|c|}
\hline الإلالالة & الارتباط & r & الإلالة الإئة & الارثباط & r \\
\hline$\bullet, \cdots$ & • & 11 & $\cdot, \cdot$ & $\cdot, \leqslant 0$ & 1 \\
\hline$\cdots$ & $\cdot, 0$ & $1 T$ & $\cdot, \cdots$ &., 01 & $r$ \\
\hline$\cdot, \cdots$ & $\cdot, \leqslant \wedge$ & $1 T$ & $\cdot, \cdots$ &., 01 & $r$ \\
\hline 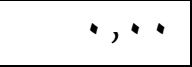 & $\cdot, \mu^{\prime}$ & $1 \leq$ & $\cdot, \cdot$ & $\cdot, \mu \nu$ & $\varepsilon$ \\
\hline$\cdots$ & $\cdot, 0 T$ & 10 & $\cdots$ & $\cdot, \leqslant 1$ & 0 \\
\hline$\cdots$ & דוז, & 17 & $\cdot, \cdots$ & $\cdot, \pi q$ & 7 \\
\hline$\cdots$ & $\cdot, \xi$. & IV & $\cdots$ & $\cdot, 0$. & V \\
\hline$\cdots$ & $\cdot, \leqslant V$ & 11 & ,, & $\cdot, \leqslant Y$ & $\lambda$ \\
\hline$\cdots$ & $\cdot, r V$ & 19 & $\cdots$ & $\cdot, 04$ & 9 \\
\hline 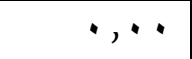 & $\cdot, 0\}$ & $r$. & $\cdot, \cdots$ & $\cdot, \leqslant 7$ & 1. \\
\hline
\end{tabular}

يتضح من الجدول (r ( ) أن جميع فقرات مقياس الوجدان الإيجابي و الوجدان السلبي ترتبط بالدرجة

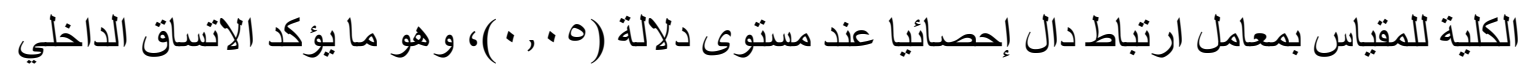
لمقياس الوجدان الإيجابي و الوجدان السلبي. الأداة الثالثة: مقياس الرضا عن الحياة: إعداد داينر وآخرين .Diener et al ترجمة صفاء الأعسرو آخرون الهُف من المقياس:

هو مقياس وضعه داينر و آخرين . Diener et al (910 (190) المقياس يهدف إلى قياس درجة رضا الفرد العام عن الحياة، ويمثل الرضا عن الحياة الجانب المعرفي لطيب الحياة الذاتية ويشير إلى التيل التقييم المعرفي العام من قبل الثخص لمدى رضاه عن حياته ويمكن تقييم الرضا عن الحياة الخاص بمجال معين من الحياة أو على الصعيد العام كما هو الحال في المقياس الحالي. ويتكون مقياس الرضا عن الحياة (0) مفردات، وضعت لمقياس مستوى الرضا العام عن الحياة، أي لا يتعلق بتقييم الرضا عن الحياة الخاصة بمجال معين. تقوم الطالبة بقر اعة عبار ات المقياس ووضع علامة تحت الوصف الذي يعبر عن مدى انطباقها علنه باستخدام تدريج سباعي كالتالي:

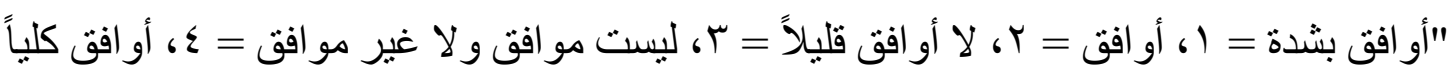
V = = ويتم تصحيح المقياس وفقاً لمفتاح التصحيح التالي: 
تنمية فاعلية الذات لتحسين طيب الحياة الذاتية لاي طالبات الجامعة

\begin{tabular}{|c|c|c|c|}
\hline تفسير ها & الارجة & تفسير ها & الارجة \\
\hline راضي إلى حد ما & $r 0-Y I$ & غير ر اضي بتاتاً & 9.0 \\
\hline ر راضي & $r \cdot-r \tau$ & غير راضي & $1 \leq-1$ \\
\hline راضي بشكل كبير جدا & ro_m & حيادى & $r$. \\
\hline - & - & غير ر اضي إلى حد ما & $19-10$ \\
\hline
\end{tabular}

الخصائص السيكومترية للمقياس الأصلي للرضا عن الحياة:

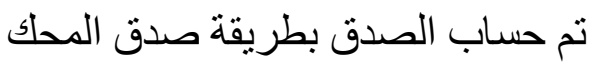

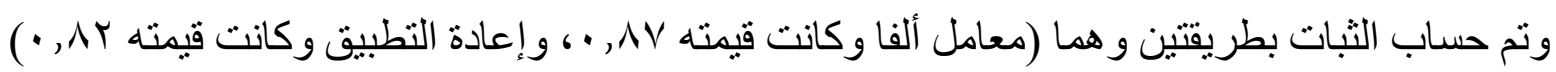

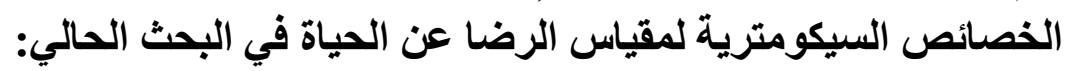
- تبات مقياس الرضا عن الحياة تم حساب معامل ألفا كرونباخ لثبات مقياس الرضاء الرضا عن الحياة وقد كانت النتائج كما هو موضح بالجدول

جدول ( ب ا ) معامل ألفا كرونباخ لثبات مقياس الرضا عن الحياة

\begin{tabular}{|c|c|c|}
\hline معامل ألفا كرونباخ & عدد الفقرات & الاداة \\
\hline$\cdot$, vo & 0 & ياس الرضا عن الحياة \\
\hline
\end{tabular}

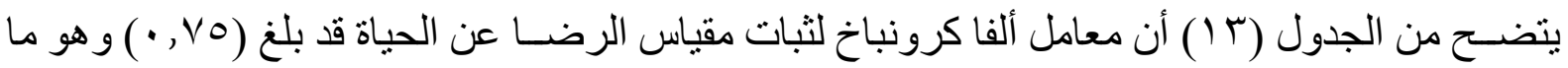

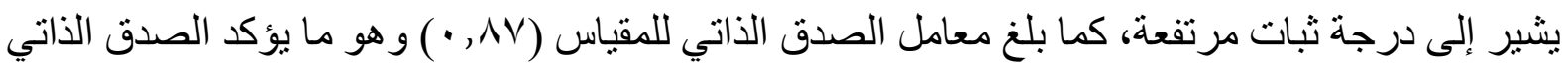
للمقياس. صدق مقياس الرضا عن الحياة:

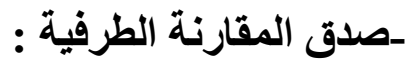

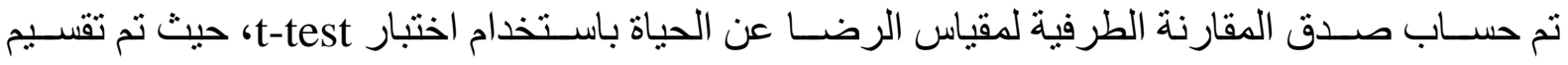

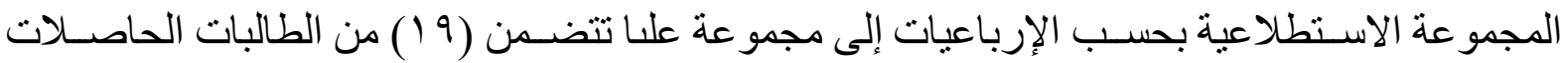

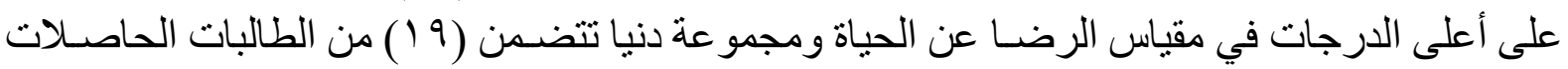

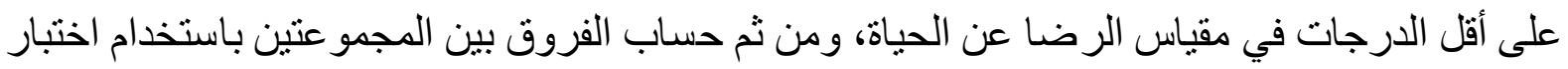
t-test

جدول (ع ( ) صدق المقارنة الطرفية لدقياس الرضا عن الحياة

\begin{tabular}{|c|c|c|c|c|c|c|}
\hline الإحصائية & قيمة "ت" & الانحياري & الحسابي & العدد & المجمو عة & البعد \\
\hline \multirow{2}{*}{$\cdot, \ldots$} & \multirow{2}{*}{$14.79-$} & $\Gamma, Y T$ & 17,90 & 19 & الدنيا & الرضسا عن \\
\hline & & $r, 11$ & $r \cdot, 11$ & 19 & العليا & الحياة \\
\hline
\end{tabular}


تنمية فاعلية الذات لتحسين طيب الحياة الذاتية لاي طالبات الجامعة

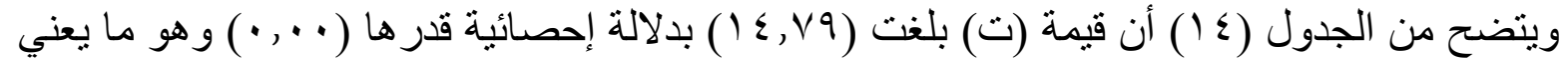

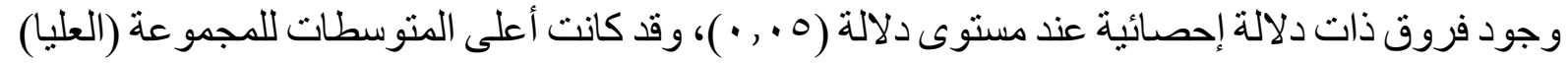

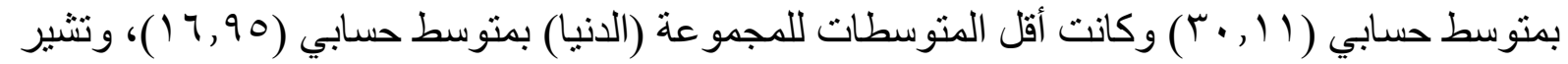
هذه النتائج إلى صدق المقارنة الطرفية لمقياس الرضا عن الحياة وقدرته على التمييز بين الطالبات ذوي

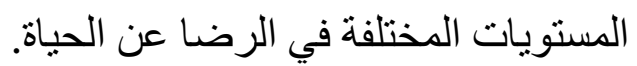

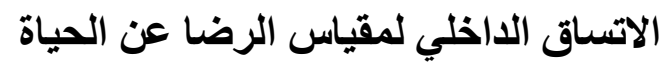

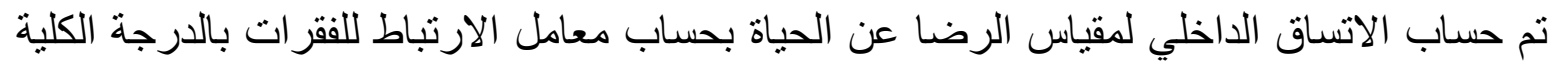

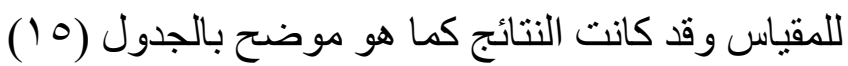

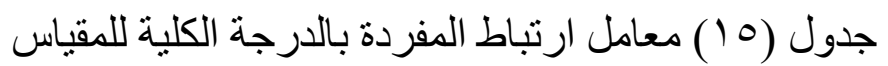

\begin{tabular}{|c|c|c|}
\hline الدلالة الإحصائية & معامل الارتباط بالدرجة الكلية & المفردة \\
\hline$\cdot, \cdots$ & $\cdot, \mathrm{VV}$ & 1 \\
\hline$\cdot, \cdots$ & $\cdot, V 7$ & $r$ \\
\hline$\cdot, \cdots$ & $\cdot, T$ & $r$ \\
\hline$\cdot, \cdots$ & $\cdot, V T$ & $\varepsilon$ \\
\hline$\cdot, \cdots$ & $\cdot, V \cdot$ & 0 \\
\hline
\end{tabular}

يتضح من الجدول (0 1) أن جميع فقر ات مقياس الرضا عن الحياة ترتبط بالدرجة الكلية للمقياس بمعامل

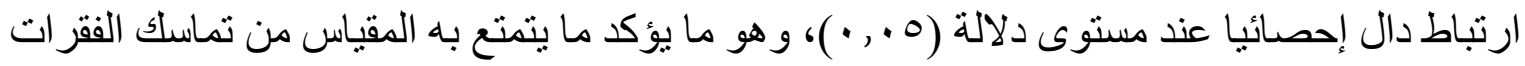

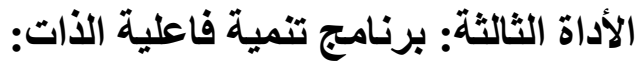
اللهدف العام للبرنامج:

هدف البرنامج الحالي إلى تنمية فاعلية الذات لدى عينة من طالبات المرحلة الجامعية عينة الدر اسة وذللك من خلال تدريبهن على التنظيم الذاتي الذي يصمم لزيادة إحساس عينة الدر اسة بكفاءة في سلوكياتهن في مواقف تمثل لهن مشكلات أو تحديات. حيث أثنارت نظرية فاعلية الذات إلى أن التدخلات الرسمية يجب ألا تتوقف عند حل مشكلات محددة فقط، و إنما يجب أن تزود الأشخاص بالمهار ات و الإحساس بالكفاءة من أجل حل المشكلات بأنفهه و تبني بعض الاستر اتيجيات الأساسية لتنمية فاعلية الذات بناء على أبعاد فاعلية الذات الأربعة. ويمكن تحديد الأهداف الإجرائية لبرنامج فيما لإلي

ا - أن تتعلم المتدربة التحكم في سلوكياتها عن طريق العمليات المعرفية، و التي بدور ها تؤثر ليس

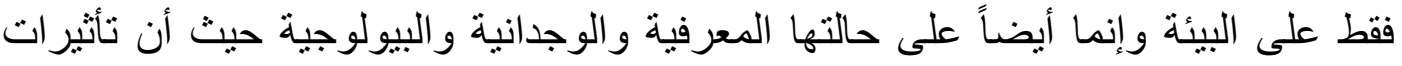

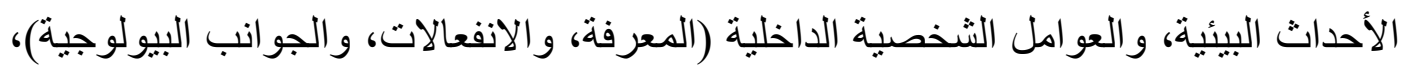
و السلوكيات تتفاعل معا فنحن نستجيب عقلياً، و انفعالياً، وسلوكياً للأحداث البيئية. ץ- أن تمارس المتدربة تنظيم الذات، فنحن نختار أهدافنا ونتظم سلوكنا في سعينا لهذه الأهداف.

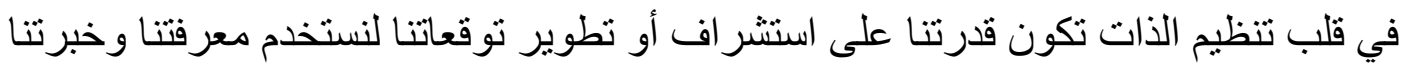
السابقة لنشكل معتقداتنا عن أحداث و أحو ال المستقبل ومعتقداتنا عن قدرتنا وسلوكنا.

خطوات تصميم البرنامـج: 
بناء البرنامج و الأساس النظري:

إن الهدف الأساسي للبرنامج هو إعادة البنية المعرفية الخاصة بأبعاد فاعلية الذات ومن ثم استدماج هذه

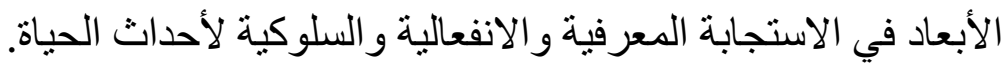

حيث يعتمد البرنامج التدريبي الحالي على نظرية العلاج المعرفي السلوكي و التي تهدف إلى تعليم المتدربين

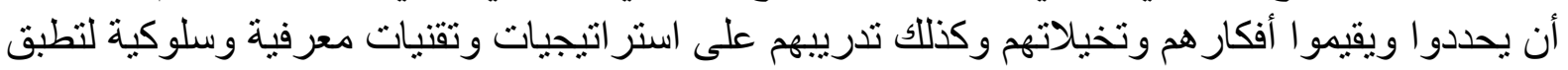
في الواقع خلال مواقف حياتية جديدة أو عند مواجهة مشكلات مستقبلية وتحسين المهار ات الاجتماعية للمتدربين من خلال تعليمهم حل المشكلات وتدريبهم على توجيه التعليمات للذات، ومن ثمّ تعديل سلوكهم وطريقتهم المعتادة في التفكير باستخدام خلال الحوار التهار الداخلي.

كما تعتمد فلسفة بناء البرنامج الحالي على فلسفة علم النفس الإيجابي الذي يركز على الجو انب الإيجابية في

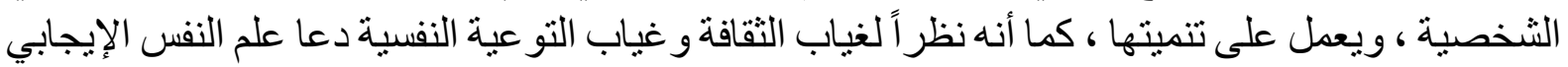

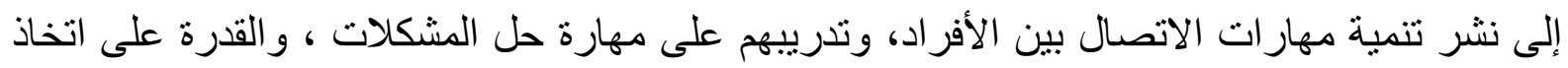

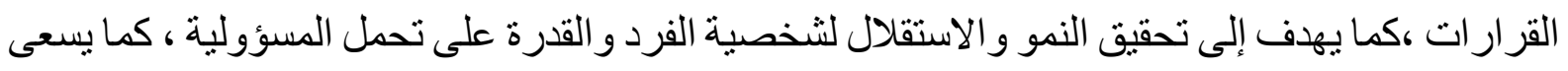
إلى تنمية وعى الفرد بينائه النفسي ، وتنمية الاستر اتيجيات المختلفة التي تمكن الفرد من ردود الأفعال الإيجابية في المو اقف المختلفة وعية الاستر اتيجيات المستخدمة في البرنامج:

( ) المحاضرة: وهي من أكثر الوسائل انتشار اً في نقل المعرفة، وتتطلب المحاضرة التفاعل الإيجابي

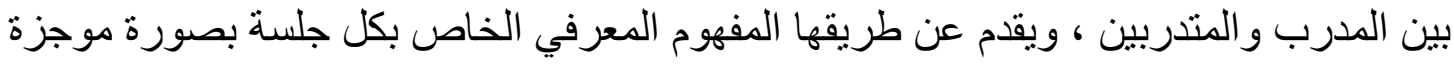

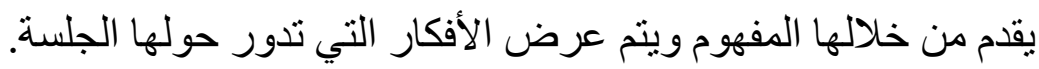
r) المناقثة: تتضمن التفاعل الإيجابي بين الباحثة و الطالبات وهو ما يتطلب حسن الاستماع لتور للآخرين

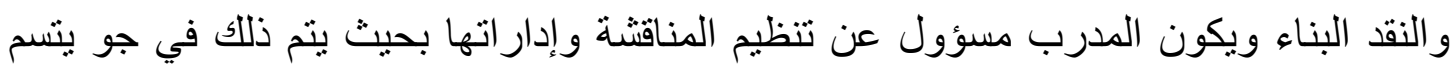

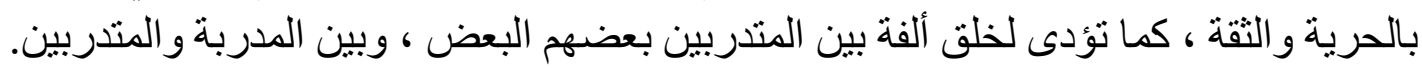

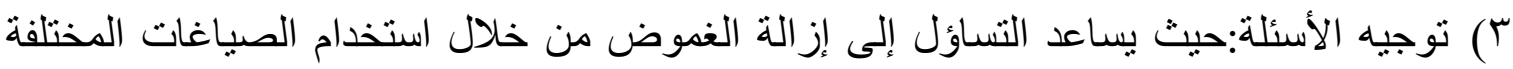

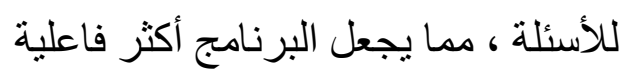

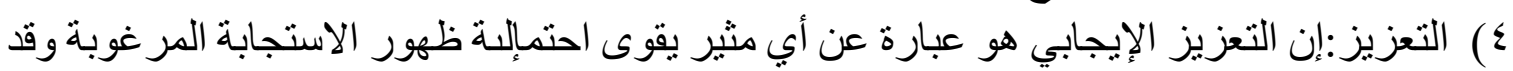

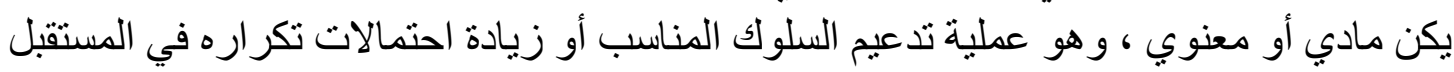
بإضافة مثير ات إيجابية أو إز الة مثير ات سلبية بعد مدئ حدوثنه ـ كذلك يعد له أثر إيجابي من الناحية الانفعالية|أيضاً (حيث يؤدى التعزيز إلى تحسين مفهوم الذاته).

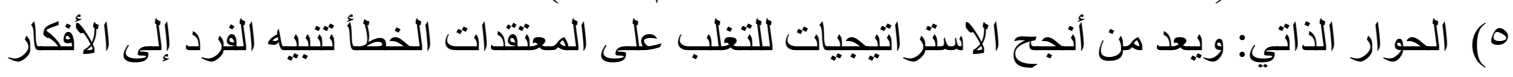

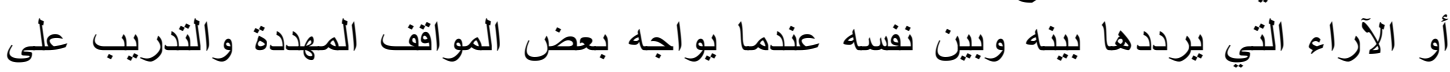

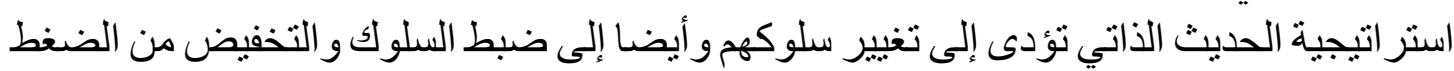

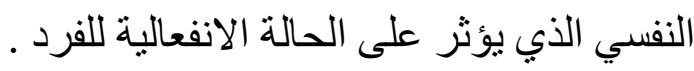

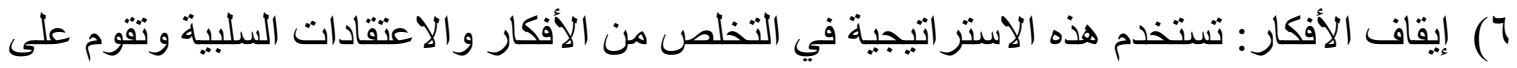

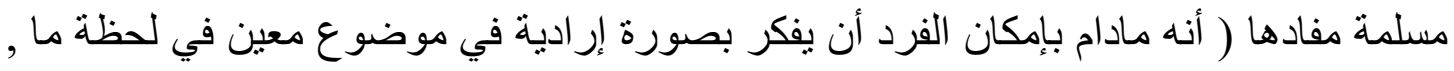
وتجنب التفكير في موضوع ما في لحظة بعينها , أي أن الفرد باستطاعته التحكم في أفكاره , ورن من فئن 
تنمية فاعلية الذات لتحسين طيب الحياة الذاتية لاي طالبات الجامعة

ثم فلابد من وقف تللك الأفكار و الاعتقادات اللاعقلانية واستبعادها على أن يحل محلها أفكار أخرى عقلانية حتى يستطيع أن يسلك بطريقة ملائمة. V الواجب المنزلي : يعنى تقديم مجمو عة من الوظائف و الواجبات المنزلية تكون بمثابة ممارسة

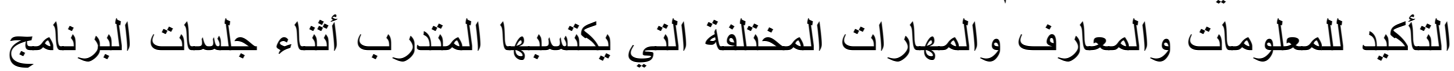
بهدف تعميم المتدرب للتغييرات الإيجابية التي يكون قد أنجزها وتستخدم بهدف تقوية التهارية أفكاره ومعتقداته الإيجابية عن ذاته ويكون الو اجب المنزلي مرتبط بالأهداف الاسترشادية.

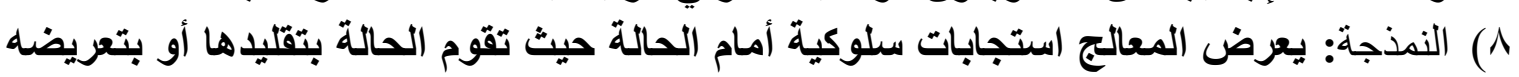

\section{لنماذج مصورة تشتمل على استجابات مؤكدة.}

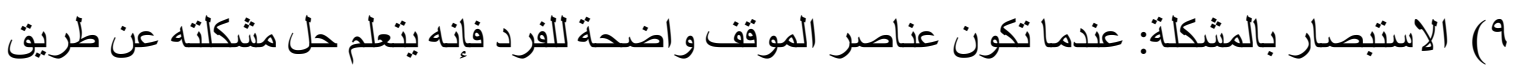
إعادة ترنيب عناصر الموقف بحيث يسمح هذا بإيجاد ـعلاقات جديدة بينها تؤدي إلى الحل الصحيح

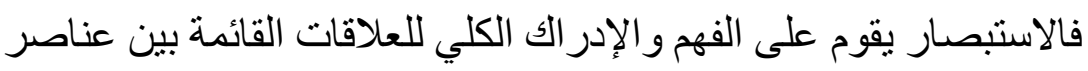
• ( )لعب الدور: أسلوب واسع الاستخدام في التعليم لاكتساب المهار ات المعرفية، كما أنه السبيل الوحيد لمحاكاة الخبرة لتظهر حقيقية. تكون البرنامج من 1 جلسة تم تطبيقهم خلال شهرين و الجدول التالي يوضح أهداف و استر اتيجيات

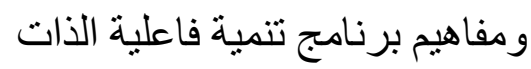

جدول جلسات البرنامج (7 1 ( )

\begin{tabular}{|c|c|c|c|c|}
\hline المستخدمة المفية فيم & الاستتراتيجيات & الأهداف الاجرائية للجلسات بعد الانتهاء من & الزمنية & رقم الجلسة \\
\hline علم الإيجسابي & المناقتشة الجماعية & 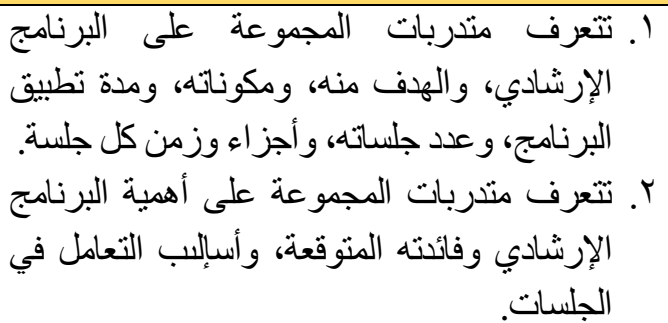 & ساعة & الجلسة \\
\hline فاعلية الذات & المناقتشة الجماعية & 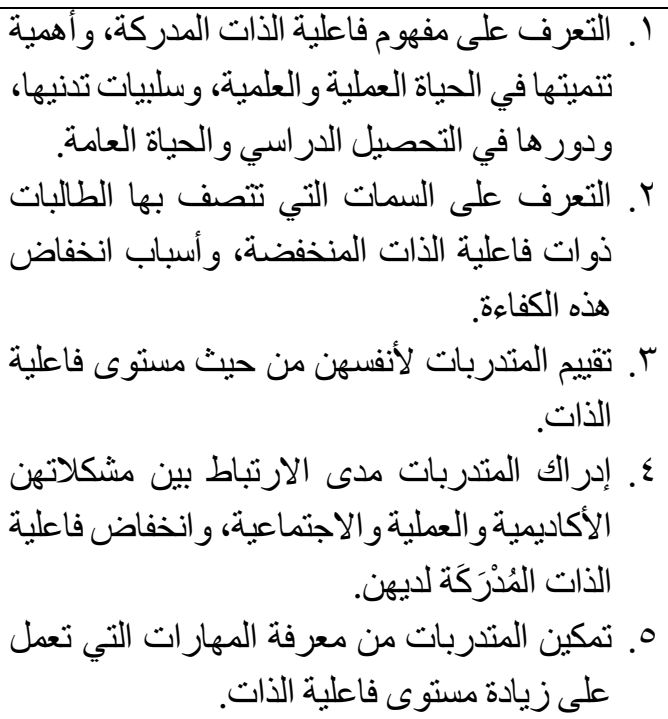 & ساعتان & الجألثة \\
\hline
\end{tabular}


تنمية فاعلية الذات لتحسين طيب الحياة الذاتية لاي طالبات الجامعة

\begin{tabular}{|c|c|c|c|c|}
\hline & & 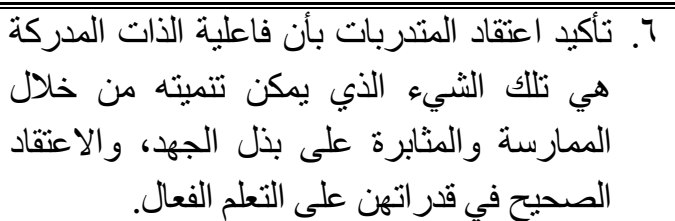 & & \\
\hline مهارة حلات & 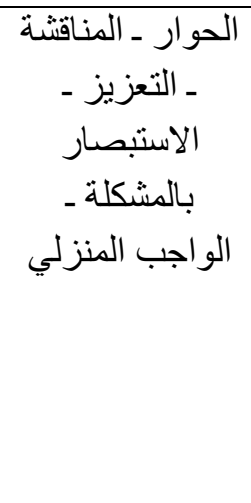 & 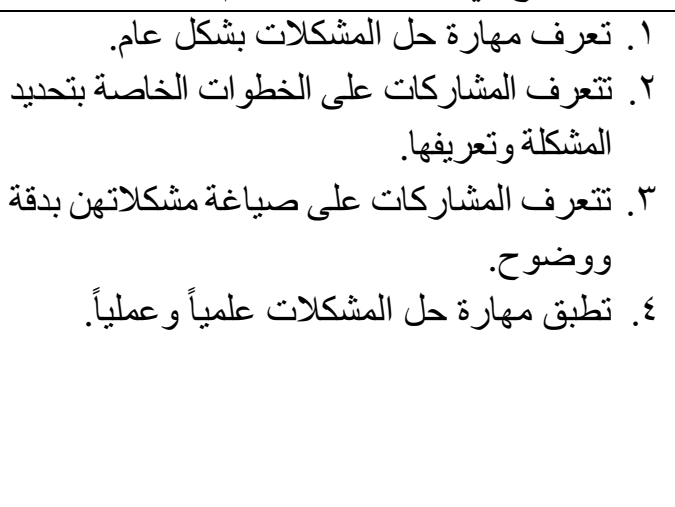 & ساعتان & 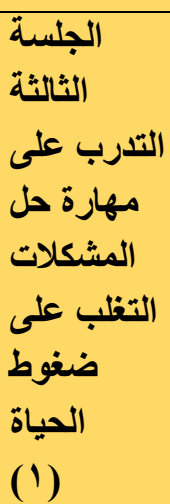 \\
\hline مفهار ات حل المشوم توليد & 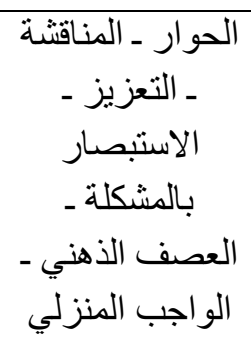 & 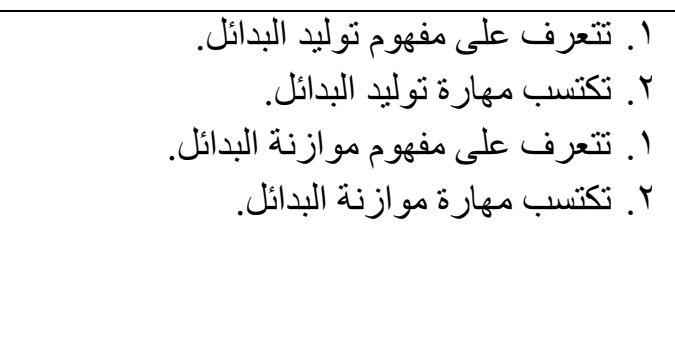 & ساعتان & 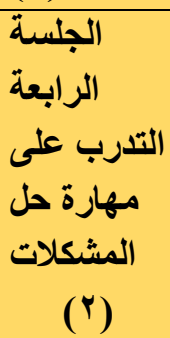 \\
\hline مهارة اتخاذ & 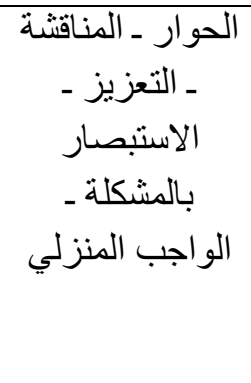 & 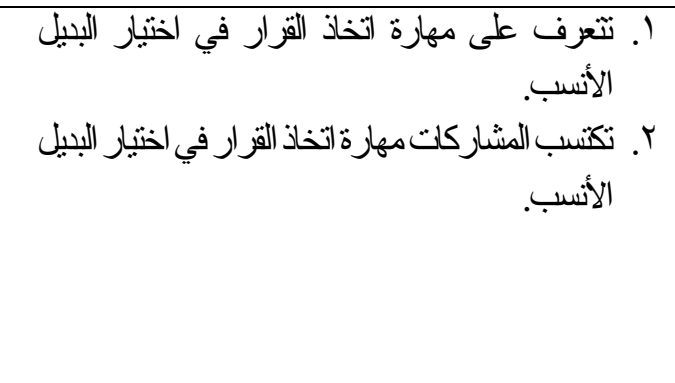 & ساعتان & 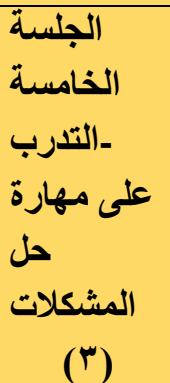 \\
\hline تعديل الإدر الك اللخاطئ & التمزجة ـ الجماعية ـ المناقنة & 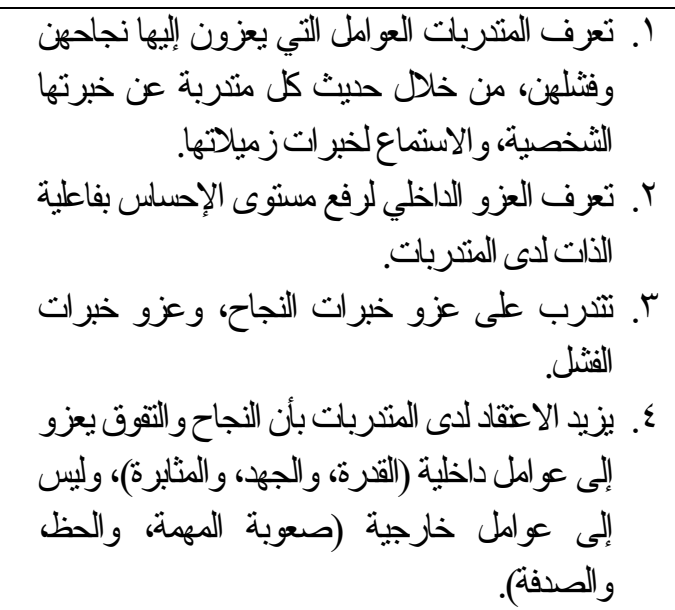 & ساعتان & 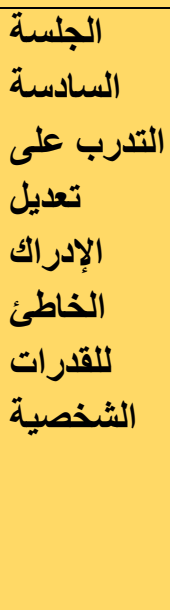 \\
\hline العقلاني & النمذجة ـ المناقنة & 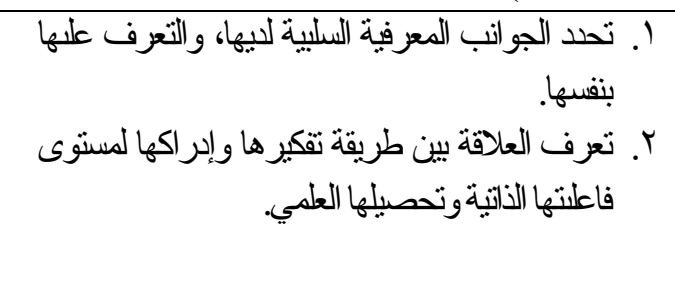 & ساعتان & $\begin{array}{l}\text { العقلاني(التفكير التسابعة } \\
\text { التسبة }\end{array}$ \\
\hline
\end{tabular}


تنمية فاعلية الذات لتحسين طيب الحياة الذاتية لاي طالبات الجامعة

\begin{tabular}{|c|c|c|c|c|}
\hline & & 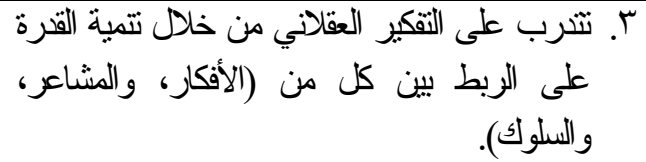 & & \\
\hline فالعوأدى لخفية الذات التي & 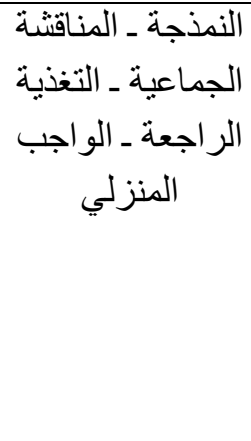 & 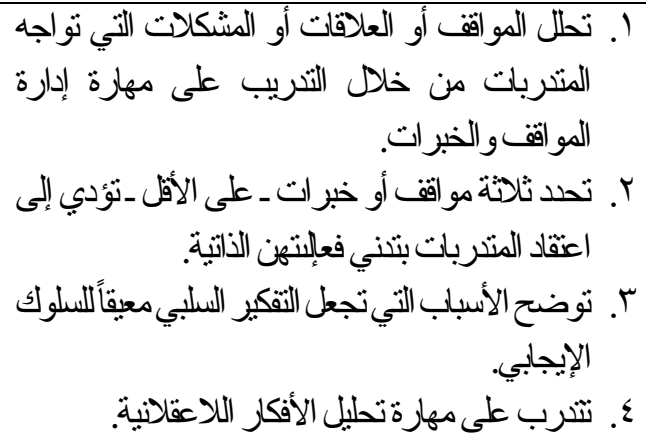 & ساعتان & 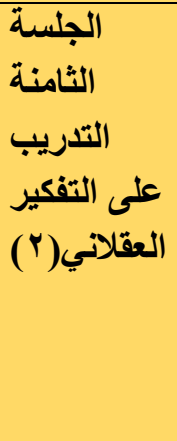 \\
\hline 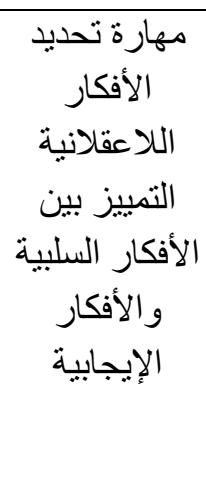 & 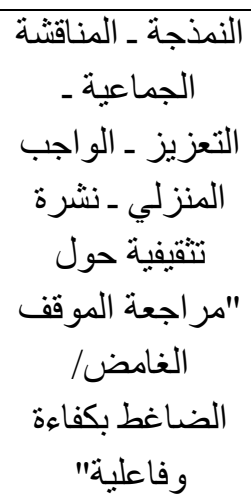 & 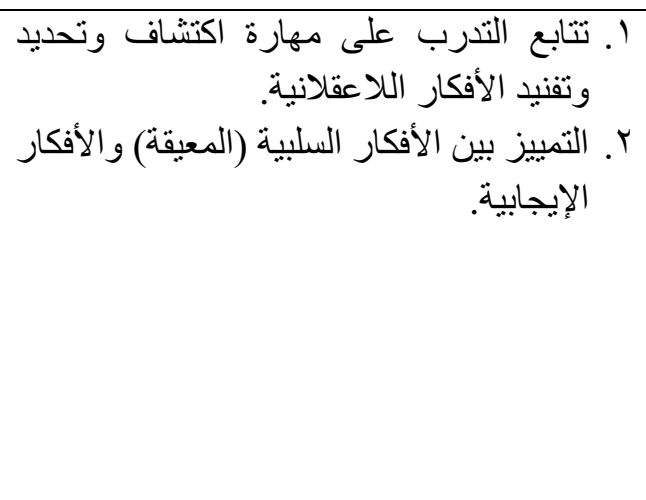 & ساعتان & 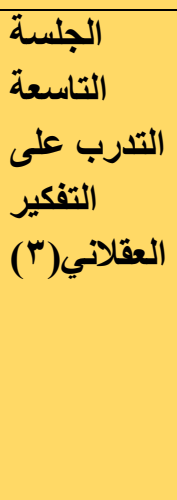 \\
\hline 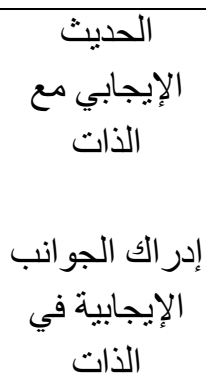 & 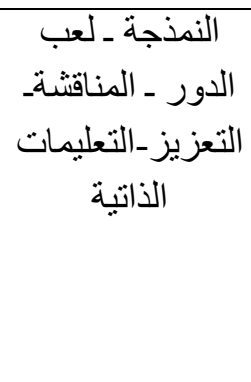 & 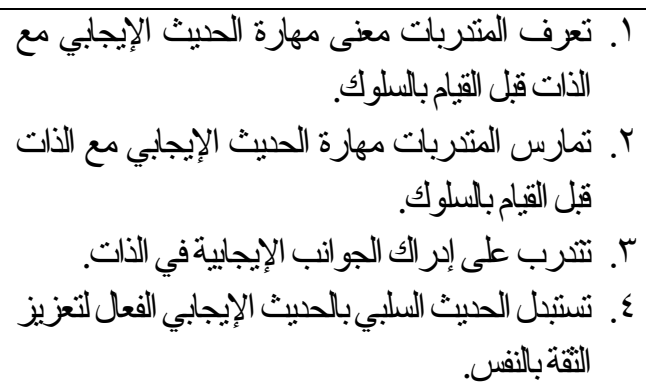 & ساعتان & 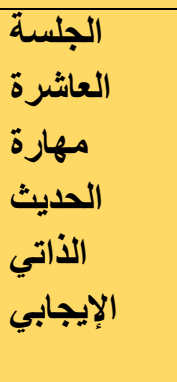 \\
\hline الأنة بالنفس & 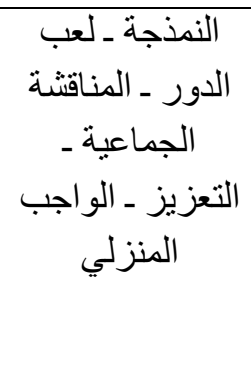 & 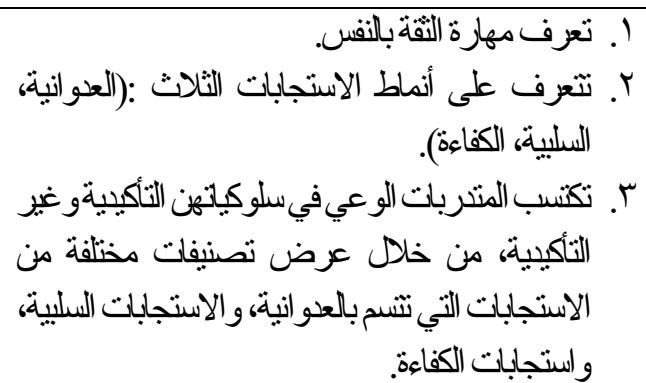 & ساعتان & 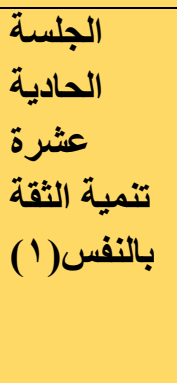 \\
\hline التقة بالنفس المقتلانية & 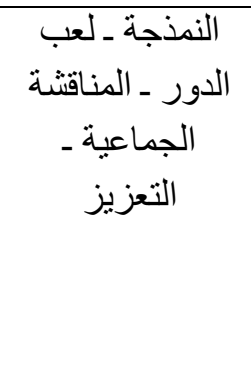 & 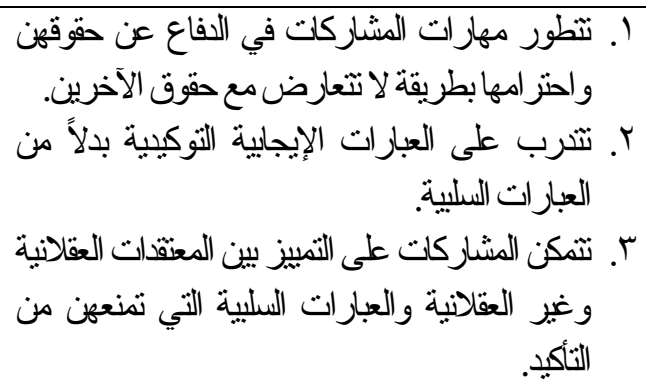 & ساعتان & بالنمية الثقة عشرة الثلية \\
\hline
\end{tabular}


تنمية فاعلية الذات لتحسين طيب الحياة الذاتية لاي طالبات الجامعة

\begin{tabular}{|c|c|c|c|c|}
\hline الاستقة بالنفس & 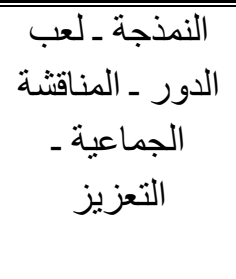 & 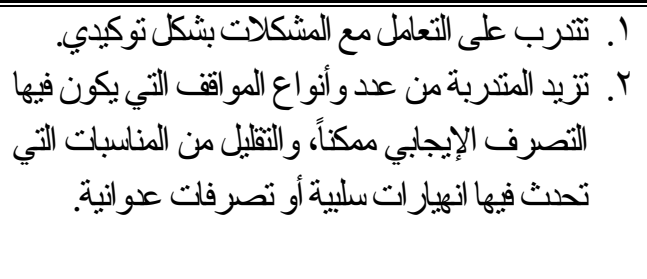 & ساعتان & بالنفسية الثقة عثرة \\
\hline & 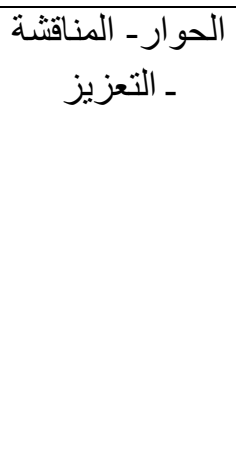 & 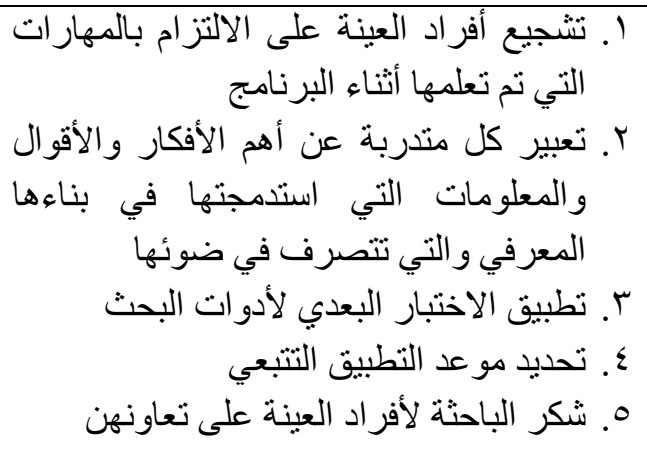 & • V دقيقة & الجابعة \\
\hline & المناقشة ـالحوار & 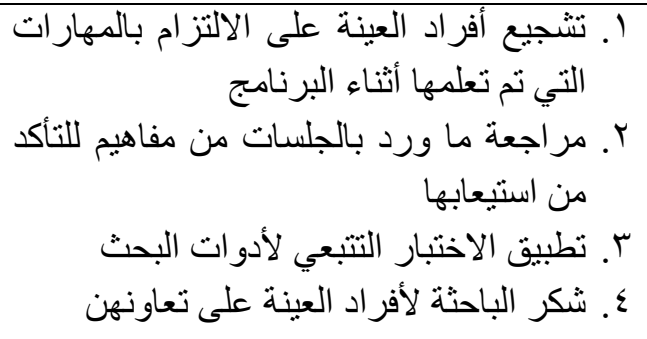 & ساعة & الخامسة \\
\hline
\end{tabular}

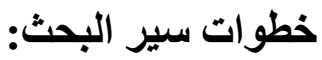

ا - تطبيق أدوات البحث على العينة الاستطلاعية (مقياس فاعلية الذاتـ مقياس الوجدان الإيجابي و السلبي -مقياس داينر للمشناعر الإيجابية و السلبية_مقياس الرضانية عن الحياة) للتحقق من الكفاءة

السيكومثرية لمقاييس البحث.

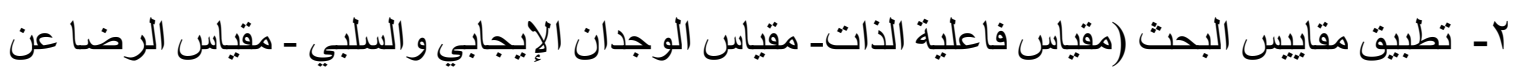
الحياة) في التطبيق القبلى (قبل تطبيق البرنامج )على عينة البحث.

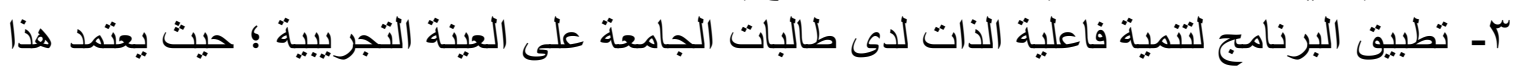

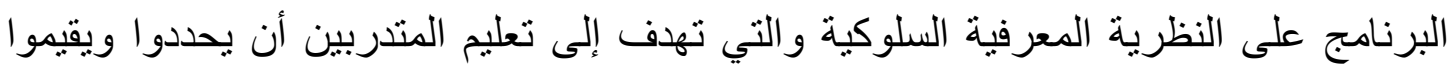

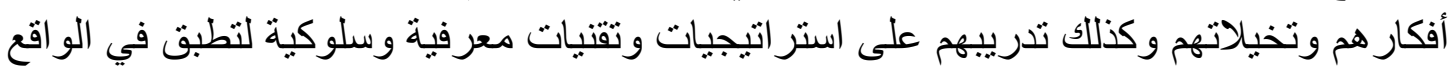

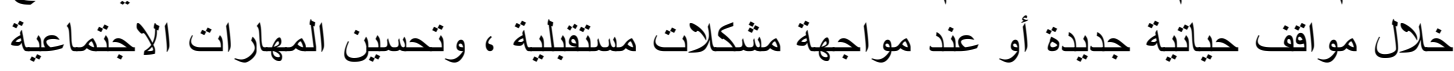

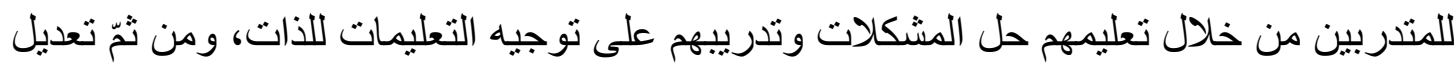
سلوكهم وطريقتهم المعتادة في التفكير باستخدام خلال الحوار الداخلي.

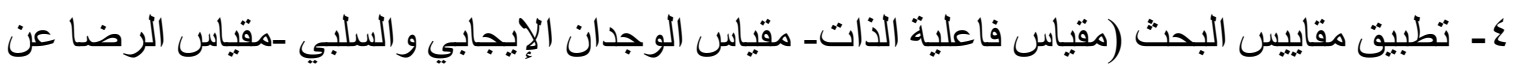
الحياة) في التطبيق البعدى(بعد تطبيق البرنامج) على عينة البحث.

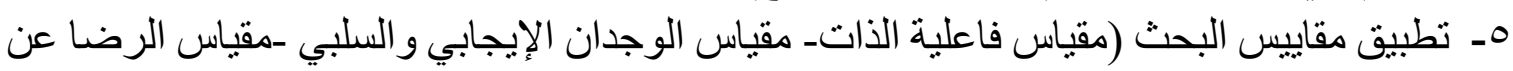
الحياة) في التطبيق التتبعى بعد مرور 7 أسابيع(بعد تطبيق البرنامج) على عينة البحث. 


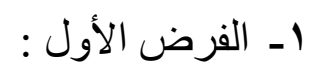

ينص الفرض الأول على أنه "توجد فروق دالة إحصائياً بين القياسين القبلي والبعدي في مستوى فاعلية الذات لاى المجمو النه التوجة فروف التجريبية"

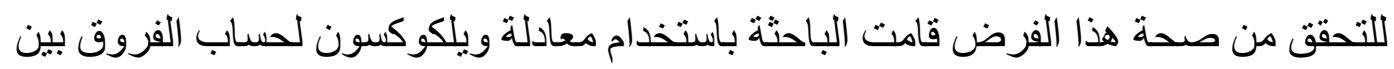

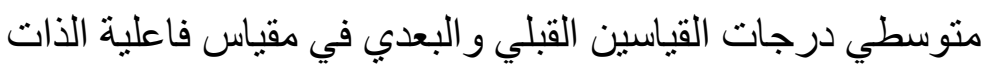
جدول (IV) الفروق بين منوسطي درجات المجموعة التجريبية في القياسين القبلي و البعدي لأبعاد فاعلية الذات

\begin{tabular}{|c|c|c|c|c|c|c|c|}
\hline الإلالة الائية & "z" قيمة & $\%$ & العظمي & الانحرياري & الحسابي & القياس & البعد \\
\hline \multirow[b]{2}{*}{$\cdot, \cdot 1$} & \multirow[b]{2}{*}{$r, 1 \wedge$} & $\% \vee Y, \vee \varepsilon$ & \multirow[b]{2}{*}{ Tr } & $1, \lambda$. & $T \varepsilon, \Gamma$ & القبلي & \multirow{2}{*}{ اللقدر الإدر الكي } \\
\hline & & $\% \wedge r, \cdot r$ & & r,or & $T V, \cdot V$ & البعدي & \\
\hline \multirow{2}{*}{$\cdot, \ldots$} & \multirow{2}{*}{$\varepsilon, V)$} & $\% \vee V, r r$ & \multirow{2}{*}{ r. } & 1,94 & $T r, r$. & القبلي & \multirow{2}{*}{ بالنفس } \\
\hline & & $\% \wedge \wedge, \wedge q$ & & $r, .9$ & $T Y, T V$ & البعدي & \\
\hline \multirow{2}{*}{$\cdot, \cdot$} & \multirow{2}{*}{$V, r)$} & $\% \%^{\top 9, \wedge \wedge}$ & \multirow{2}{*}{ r. } & $\overline{r, T r}$ & $\mid \Lambda, \Lambda V$ & القبلي & \multirow{2}{*}{ المثابرة } \\
\hline & & $\% \wedge r, 90$ & & $Y, T \varepsilon$ & $Y Y, T V$ & البعدي & \\
\hline \multirow[b]{2}{*}{$\cdot, .0$} & \multirow[b]{2}{*}{$r, 1 \wedge$} & $\%$ \% & \multirow[b]{2}{*}{ זי } & $r, I \varepsilon$ & $r \leqslant, Y$. & القبلي & \multirow{2}{*}{ التحكم في } \\
\hline & & $\% \wedge \cdot, \wedge)$ & & $r, 10$ & $Y 4, T V$ & البعدي & \\
\hline \multirow[b]{2}{*}{$\cdot, \cdot$} & \multirow[b]{2}{*}{$v, .0$} & $\% \vee r, \neg 7$ & \multirow[b]{2}{*}{$1 \times 4$} & $7, Y$. & $9 \cdot, 7$. & القبلي & \multirow{2}{*}{ إلاعلية } \\
\hline & & $\% \wedge r, \vee q$ & & $r, 90$ & $1 \cdot r, \cdot V$ & البعدي & \\
\hline
\end{tabular}

\section{ويتضح من الجدول (IV ) ما يلي:}

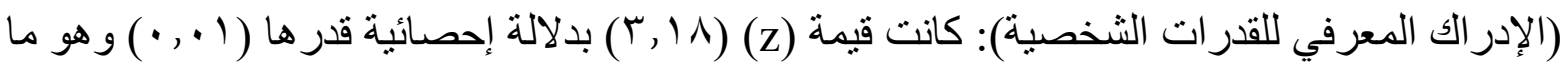

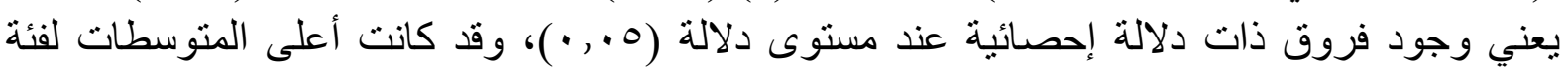

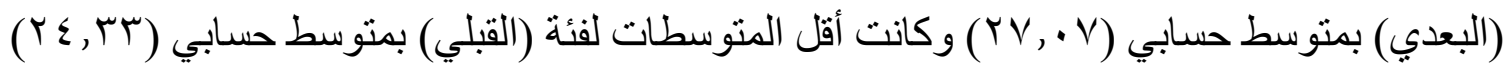

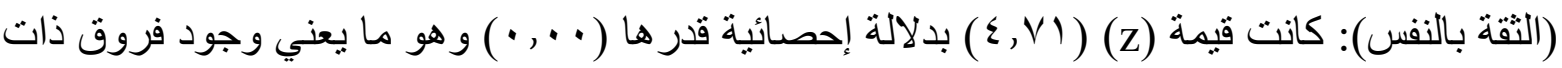

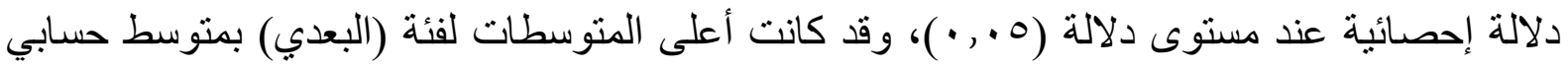

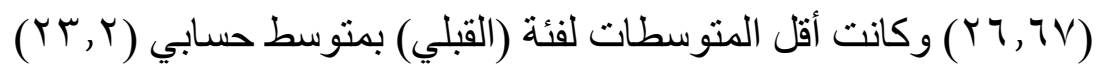

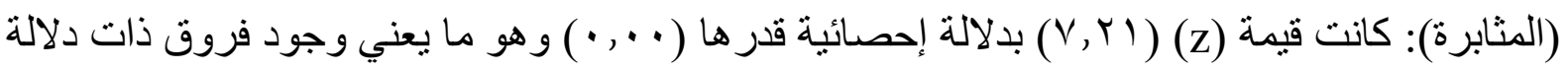

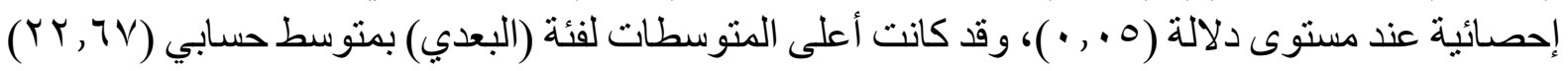

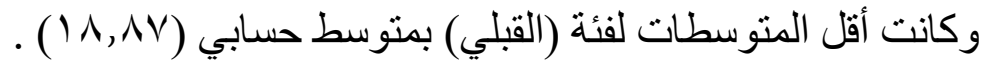




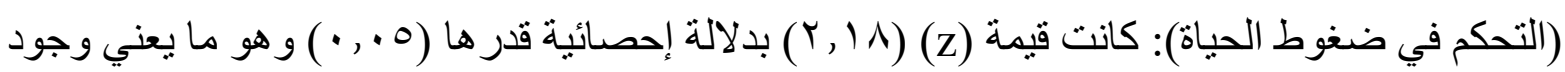
فروق ذات دلالة إحصائية عند مستوى دلالة (0 . . • )، وقد كانت أعلى المتوسطات لفئة (البعدي) بمتوسط

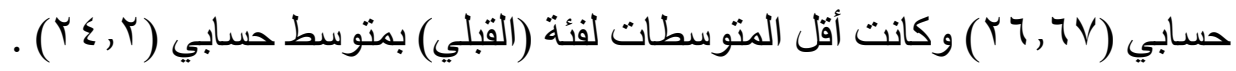

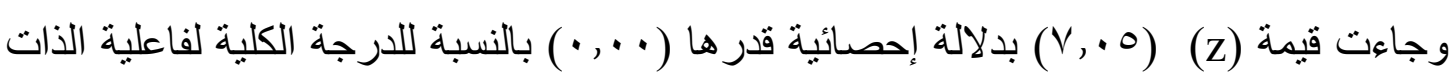
و هو ما يعني وجود فروق ذات دلالة إحصائية عند مستوى دلالة ( 1 • , • ) بين القياس القبلي و البعدي لفاعلية

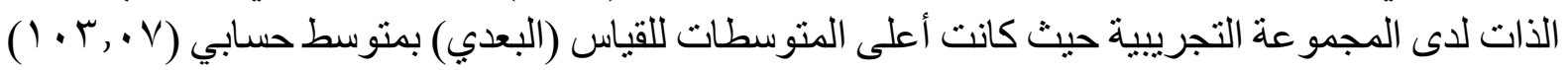
وكانت أقل المتوسطات للقياس (القبلي) بمنوسط حسابي ( • > • 9 9. ).

\section{تفسير ومناقشة نتائج الفرض الأول:}

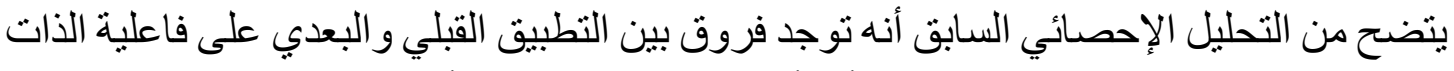
لاى المجموعة التجريبية لصالح القياس البعدي أي أن البرنامج الإرشادي أدئي أدى لتحسن في مستوى فاعلية

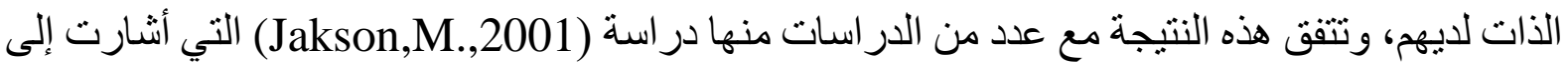
قابلية فاعلية الذات للنمو ودر اسة (Patric R.Muiien,et. Al.,2015) التي أشنارت إلى أيضاً إلى قابلية فاعلية الذات للنمو لدى طلبة الجامعة ودراسة (Rolind Y,et al.,2017) وتنفق أيضاً مع دراسة وتعزى هذه النتيجة أيضاً إلى أن مستوى فاعلية الذات كما يرى باندور ايؤثر

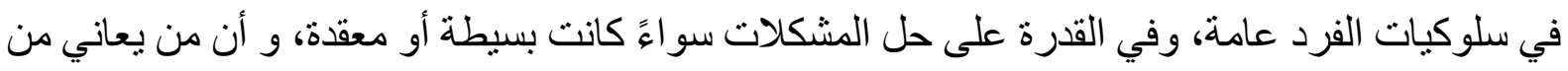

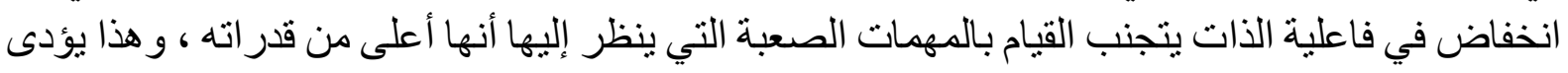

إلى الفثل في حل المشكلات ويقلل من الكفاءة الذاتية (Besharat;Parto,2011,p:642 )

كما أن تعديل الأفكار اللاعقلانبة وإعادة البناء المعرفي لاى الطالبات أثرت بشكل ملحوظ علبهم حيث استخدمت الباحثة أمثلة و اقعية في توضيح نموذج الافكان الذي ساعد على فهم و إدارة الانفعالات وتقبله

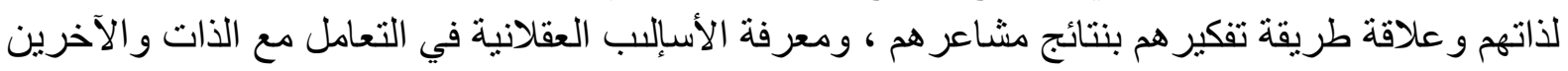

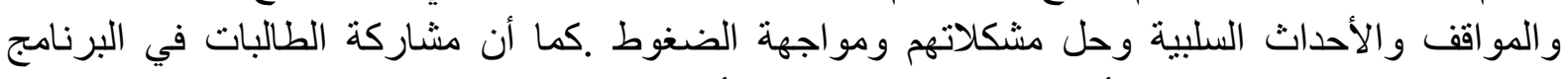

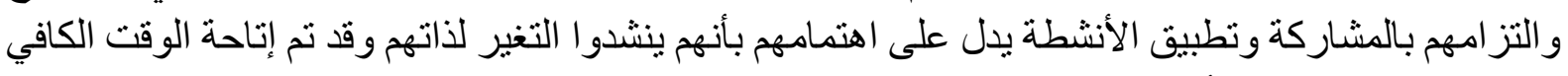

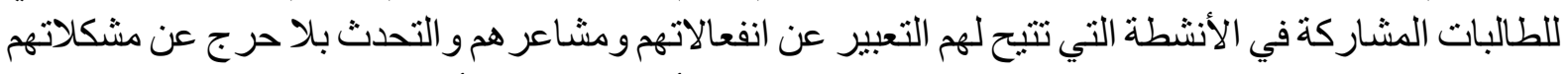

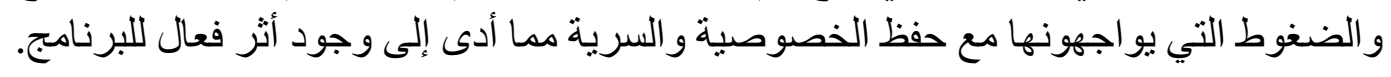

ينص الفرض الثاني على أنه " توجد فروق دالـة إحصـــائياً بين المجموعة التجريبيـة و

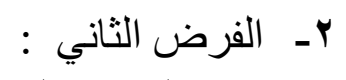

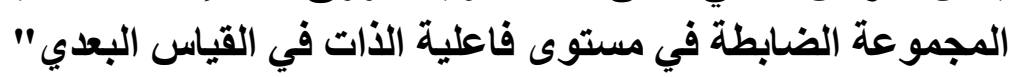

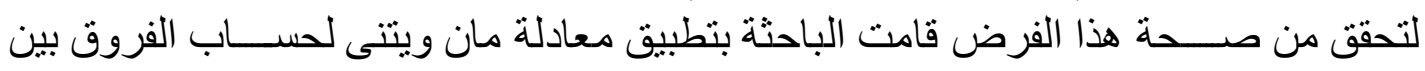

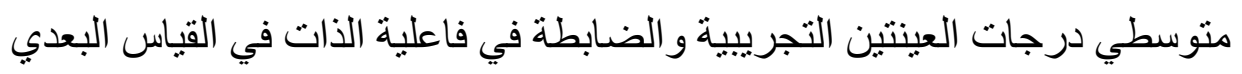

جدول (1 ا ) الفروق بين متوسطي درجات المجمو عتين الضابطة والتجريبية في أبعاد فاعلية الذات

\begin{tabular}{|c|c|c|c|c|c|c|c|c|}
\hline الإحلالة & "z" قيمة & $\%$ & العظمى الدرجة & الانحر افياري & الحسابي & العدد & المجمو عة & البعد \\
\hline \multirow{2}{*}{$\cdot, .1$} & \multirow{2}{*}{$r, 99$} & $\% \wedge r, \cdot r$ & \multirow{2}{*}{ זי } & $r, O Y$ & $r V, \cdot V$ & 10 & التجريبية & الإدر اك \\
\hline & & $\% \vee r, r Y$ & & $r, r q$ & $r r, \wedge V$ & 10 & الضابطة & المعرفي \\
\hline
\end{tabular}

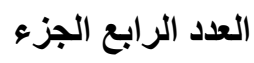


تنمية فاعلية الذات لتحسين طيب الحياة الذاتية لاي طالبات الجامعة

\begin{tabular}{|c|c|c|c|c|c|c|c|c|}
\hline & & & & & & & & الثخدية \\
\hline \multirow{2}{*}{$\cdot, \cdots$} & \multirow{2}{*}{$\varepsilon, 99$} & $\% \wedge \wedge, \wedge q$ & \multirow{2}{*}{ r. } & $r, \cdot q$ & $Y T, T V$ & 10 & التجريبية & \multirow{2}{*}{ بالنفس } \\
\hline & & $\% \vee \_, \wedge q$ & & $r, 0$. & $Y Y, \Sigma V$ & 10 & الضابطة & \\
\hline \multirow{2}{*}{$\cdot, \cdot r$} & \multirow{2}{*}{$r, \Sigma 1$} & $\% \wedge \wedge, 90$ & \multirow{2}{*}{$r}$. & $r, T \varepsilon$ & $Y Y, T V$ & 10 & التجريبية & \multirow{2}{*}{ المثابرة } \\
\hline & & $\% \vee \neg, r$. & & $r, \cdot r$ & $r_{\cdot}, T_{.}$ & 10 & الضابطة & \\
\hline \multirow{2}{*}{$\cdot, \cdot r$} & \multirow{2}{*}{$r, r r$} & $\% \wedge \cdot, \wedge)$ & \multirow{2}{*}{ זr } & $r, \wedge 0$ & $Y 7, T V$ & 10 & التجريبية & \multirow{2}{*}{ التخوطم في } \\
\hline & & $\% \vee r, q \varepsilon$ & & $r, 0$. & $r \varepsilon, \varepsilon$. & 10 & الضابطة & \\
\hline \multirow{2}{*}{$\cdot, \cdots$} & \multirow{2}{*}{0,99} & $\% \wedge \uparrow, \vee q$ & \multirow{2}{*}{ IYT } & $r, 90$ & $I \cdot r, V$ & 10 & التجريبية & \multirow{2}{*}{ فالجمالية } \\
\hline & & $\% \vee \leq, Y \circ$ & & $7, \leqslant \wedge$ & חוז, & 10 & الضابطة & \\
\hline
\end{tabular}

ويتضح من الجدول (1/ ) ما يلي:

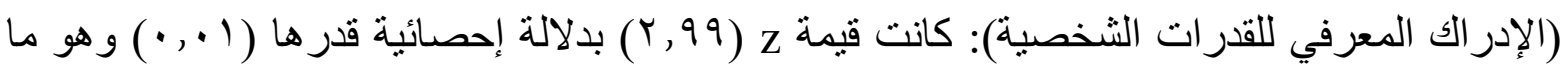
يعني وجود فروق ذات دلالة إحصائية عند مستوى دلالة (0. . • )، وقد كانت أعلى المتوسطات لفئة

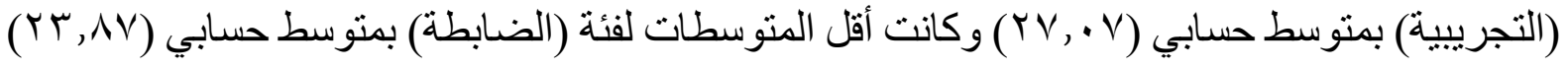

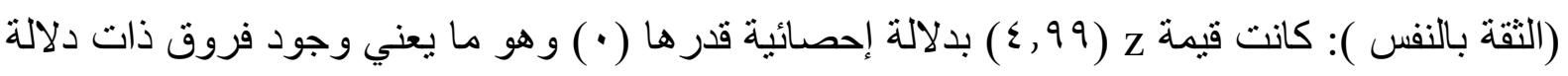

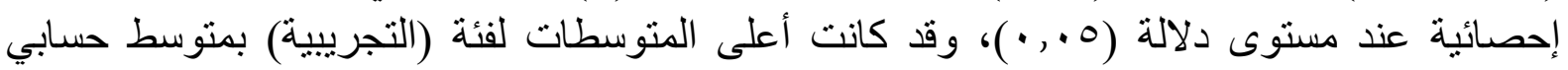

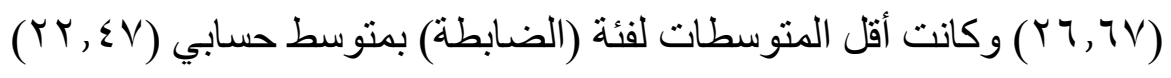

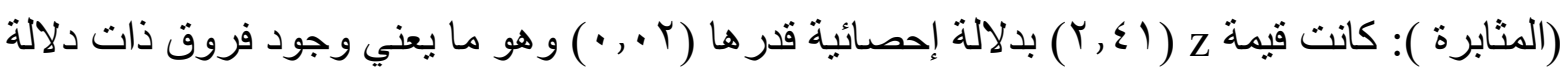

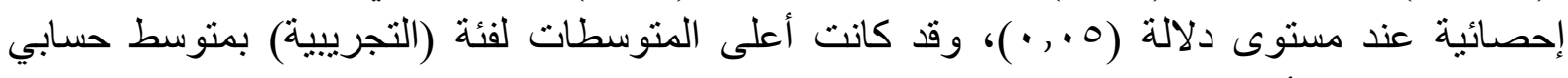

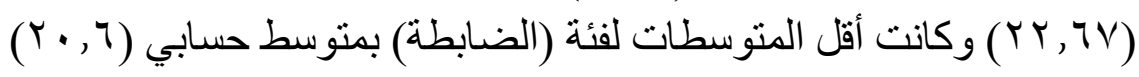

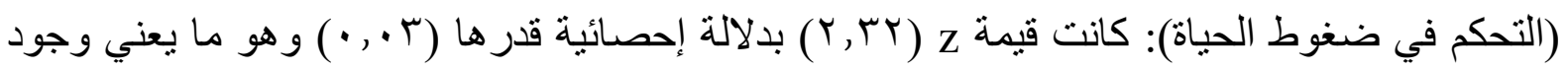

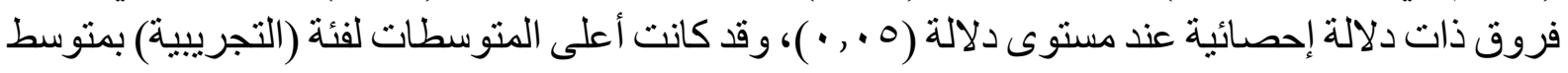

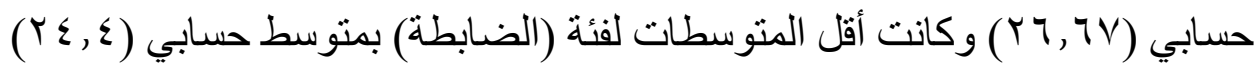

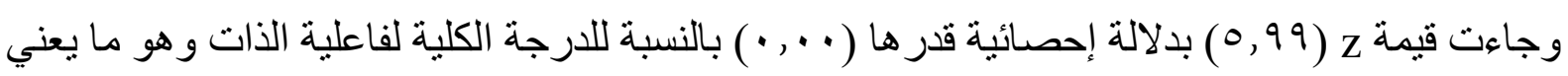

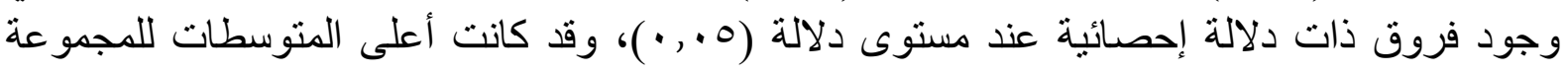
(التجريبية) بمنوسط حسابي (v • , • l ) وكانت أقل المتوسطات للمجمو عة (الضابطة) بمتوسط حسابي

وقد تم حساب حجم الأثر باستخدام مربع إيتا وقد كاتت النتائج كما هو موضح بالجدول (9 19 )

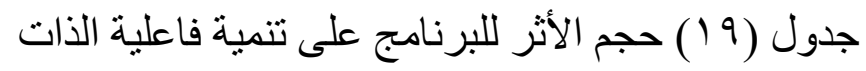


تنمية فاعلية الذات لتحسين طيب الحياة الذاتية لاي طالبات الجامعة

\begin{tabular}{|c|c|c|c|c|c|}
\hline الأثر مستوى حجم & حجم الأثر (d) & 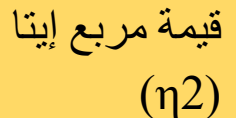 & الحرية & قيمة التاء & المتغير \\
\hline كبير & $r, Y T$ &., 07 & rᄉ & 0,99 & إجمالي فاعلية \\
\hline
\end{tabular}

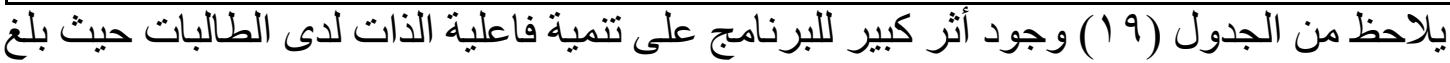

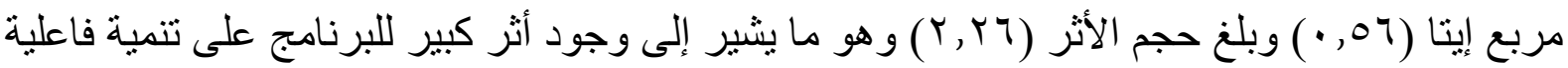

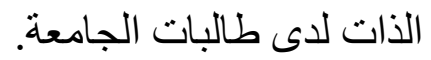

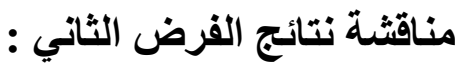

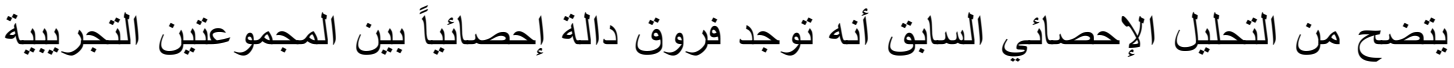

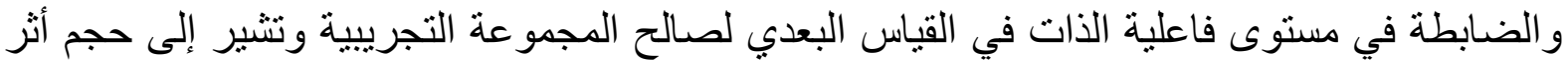

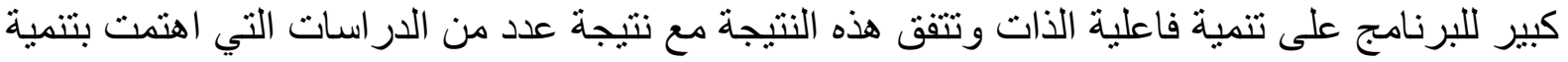

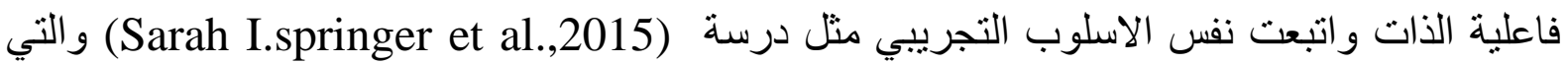

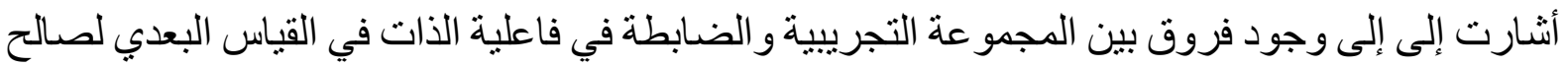

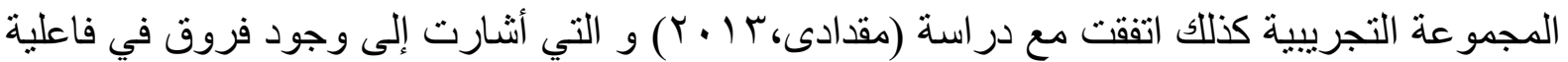

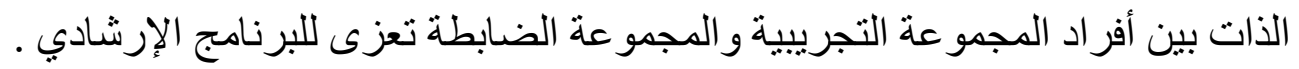
وتؤكد هذه النتيجة صدق نظرية باندورا التي تؤكد أن الطالب الذي يعتقد في كفاءته الذاتية يكون الأني

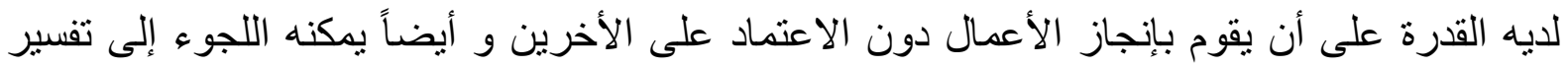

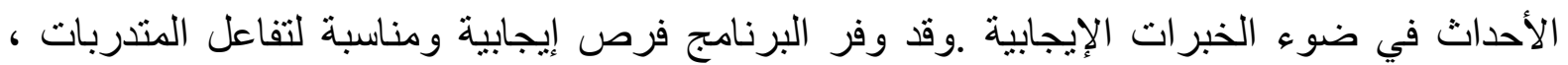

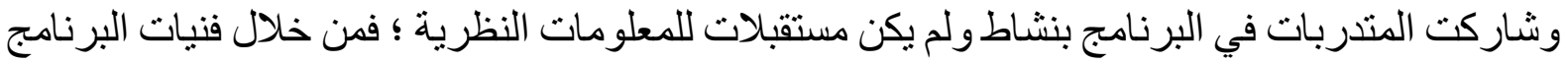

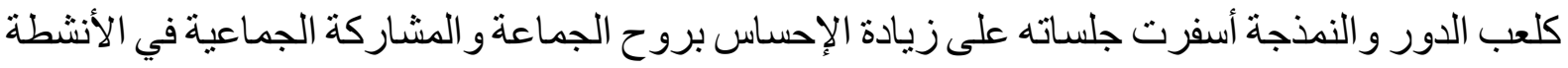

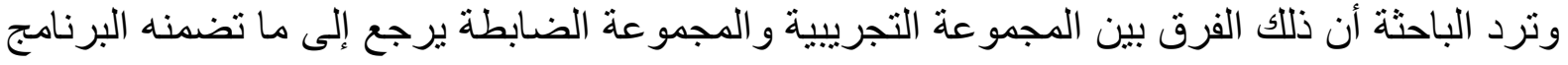

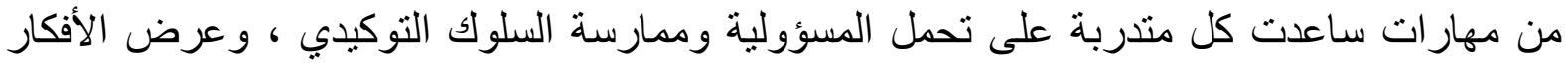

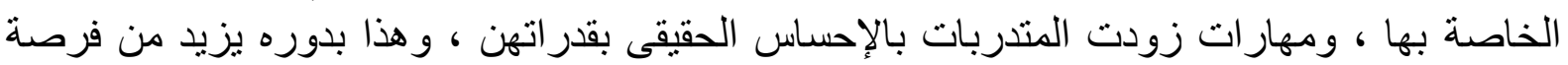

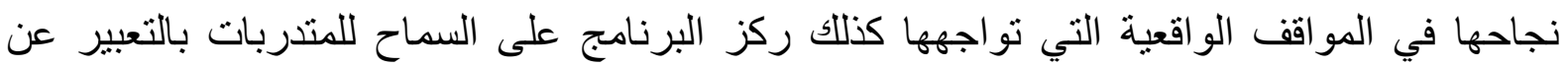

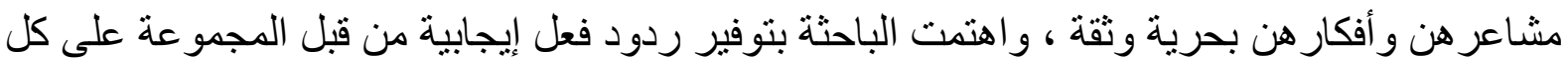

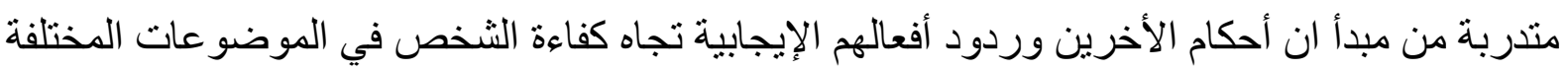

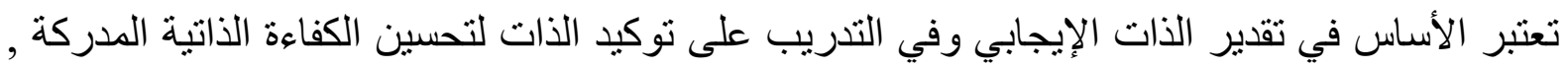

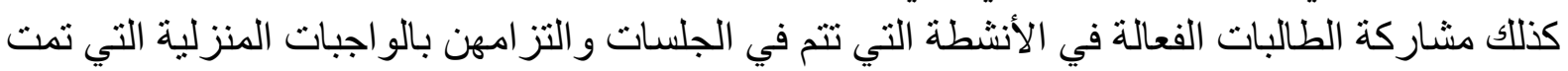

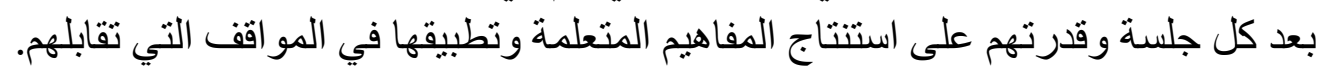

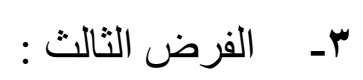

ينص الفرض الثالث على أنه "لا توجد فروق دالة إحصائياً بين القياسين البعدي والتتبعي

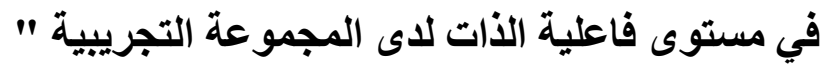

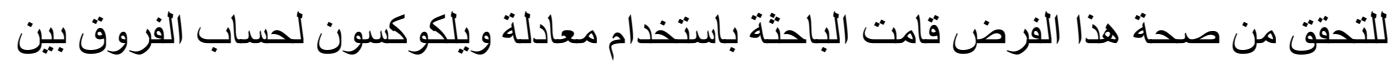

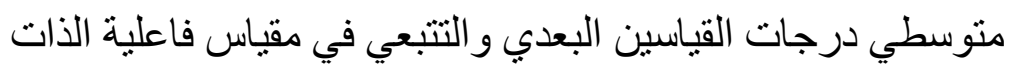


تنمية فاعلية الذات لتحسين طيب الحياة الذاتية لاي طالبات الجامعة

جدول (·r) الفروق بين منوسطي درجات المجموعة التجريبية في القياسين البعدي و التتبعي لإجمالي فاعلية الذات

\begin{tabular}{|c|c|c|c|c|c|c|c|}
\hline الإلالائة & "z" قيمة & $\%$ & العظمة الدرة & الانحر اف & المتوسط الحسا_ & القياس & المتغير \\
\hline \multirow[b]{2}{*}{$\cdot, \cdot 7$} & \multirow[b]{2}{*}{$r, \cdot r$} & $\% \wedge r, \vee q$ & \multirow[b]{2}{*}{$1 Y 7$} & $r, 90$ & $I \cdot r, \cdot V$ & البعدي & \multirow{2}{*}{ إجاعلية } \\
\hline & & $\% \wedge r, \tau$. & & rז, & $1 \cdot 1,7$. & التتبعي & \\
\hline
\end{tabular}

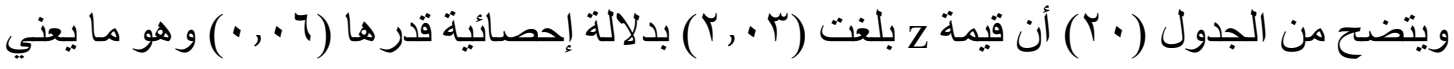

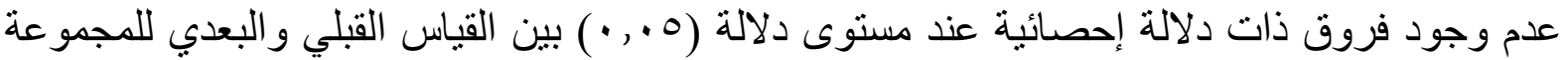

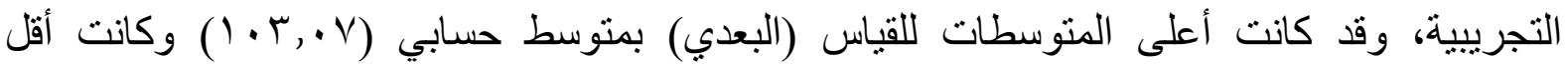

المتوسطات للقياس (التتبعي) بمتوسط حسابي ( • 7 , 1 ( ). جدول ( اYY) الفروق بين متوسطي درجات المجموعة التجريبية في القياسين القبلي والبعدي لإبعاد فاعلية الذات

\begin{tabular}{|c|c|c|c|c|c|c|c|}
\hline الدلالة & "z" قيمة "z & $\%$ & الدرجة & الانحر اف & المتوسط & القياس & البعد \\
\hline \multirow{2}{*}{$\cdot, 19$} & \multirow{2}{*}{$\cdot, 1 \leq$} & $\% \wedge r, \cdot r$ & \multirow{2}{*}{ rr } & $Y, O Y$ & $T V, \cdot V$ & البعدي & \multirow{2}{*}{ المعرفي الإدر اك } \\
\hline & & $\% \wedge 1, \wedge r$ & & $T, T V$ & $r V, \ldots$ & التتبعي & \\
\hline \multirow{2}{*}{$\cdot, Y V$} & \multirow{2}{*}{1,17} & $\% \wedge \wedge, \wedge q$ & \multirow{2}{*}{ r. } & $r, .9$ & YT,TV & البعدي & \multirow{2}{*}{ الثقة بالنفس } \\
\hline & & $\% \wedge \vee, \vee \wedge$ & & $1, V Y$ & YT,Tr & التتبعي & \\
\hline \multirow{2}{*}{$\cdot, \cdot 9$} & \multirow{2}{*}{$1, \wedge r$} & $\% \wedge \wedge, 90$ & \multirow{2}{*}{$r}$. & $T, T \varepsilon$ & $Y Y, T V$ & البعدي & \multirow{2}{*}{ المثنابرة } \\
\hline & & $\% \wedge \wedge, 99$ & & $r, Y q$ & $Y I, \wedge V$ & التتبعي & \\
\hline \multirow{2}{*}{ דז, • } & \multirow{2}{*}{$\cdot, 9 \leq$} & $\left.\% 0^{\wedge} \cdot, \wedge\right)$ & \multirow{2}{*}{ سr } & $T, \wedge 0$ & $Y T, T V$ & البعدي & \multirow{2}{*}{ التحكم في } \\
\hline & & $\% \wedge,, \ldots$ & & $Y, \varepsilon \leqslant$ & $\varepsilon$. & & \\
\hline
\end{tabular}

$$
\text { ويتضح من الجدول (Y) ما بلي: }
$$

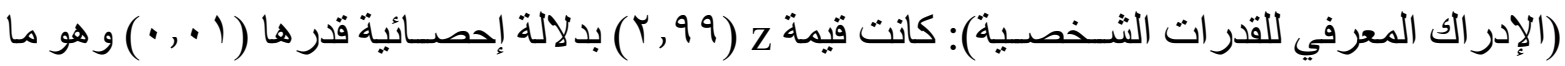

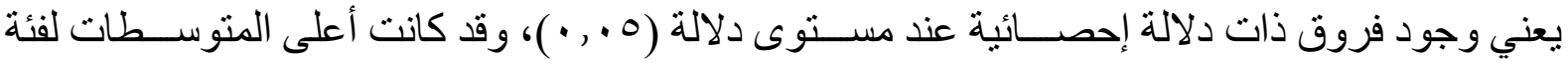

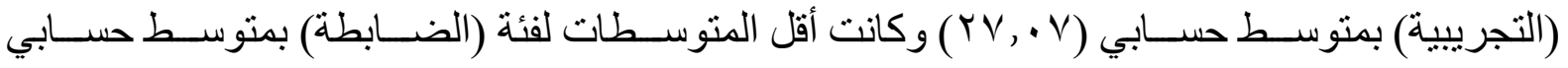

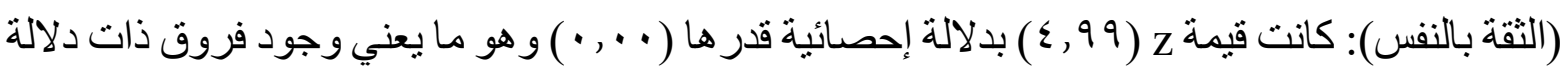
إحصائية عند مستوى دلالة (0. , •))، وقد كانت أعلى المتوسطات لفئة (التجريبية) بمتوسط حسابي

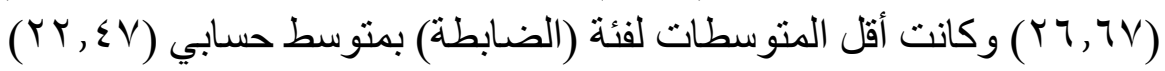


تنمية فاعلية الذات لتحسين طيب الحياة الذاتية لاي طالبات الجامعة

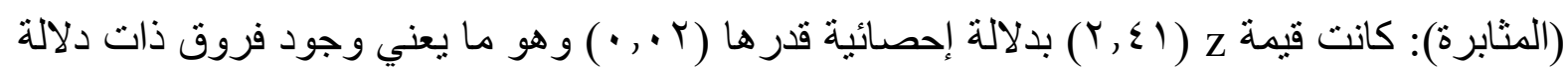

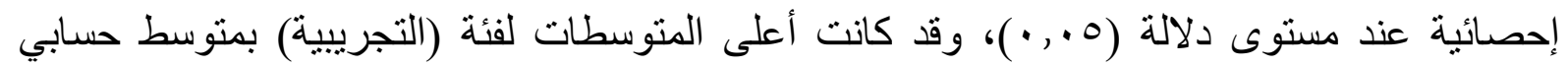

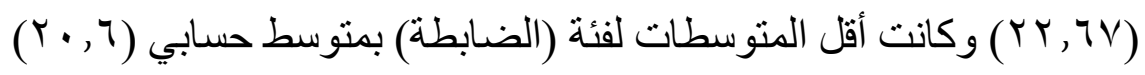

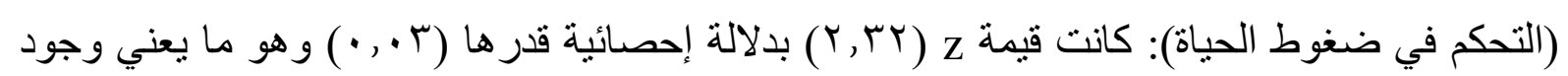

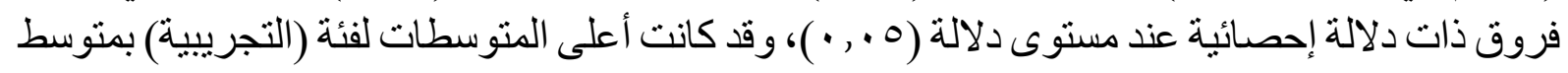

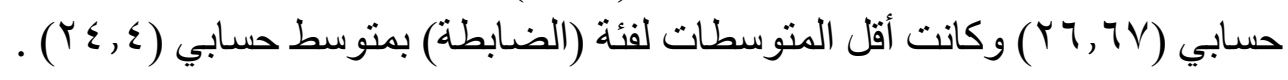
مناقشة نتائج الفرض الثالث:

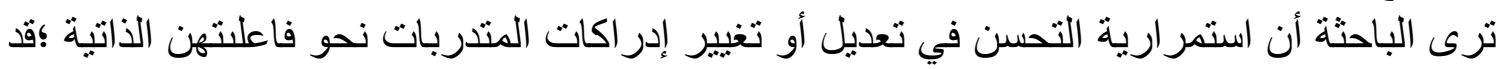

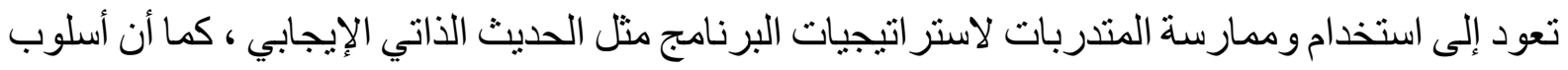

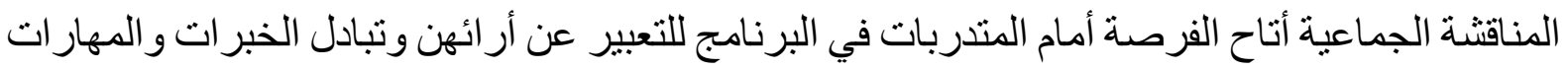

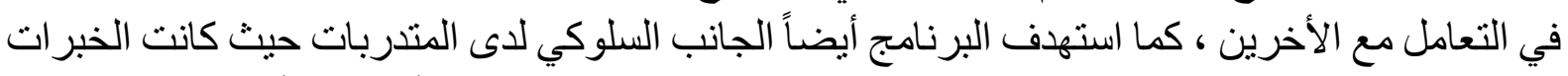

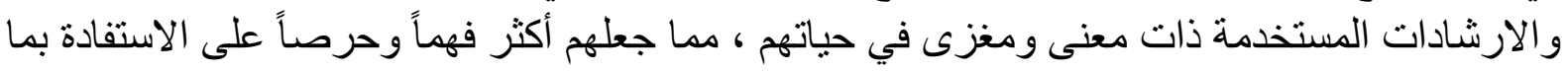

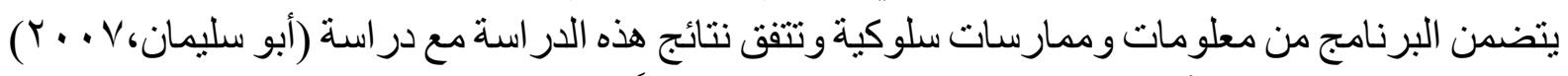

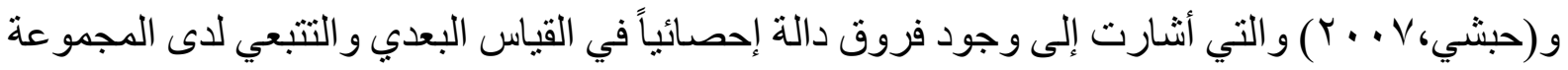
التجريبية.

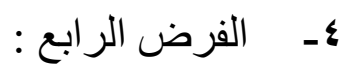

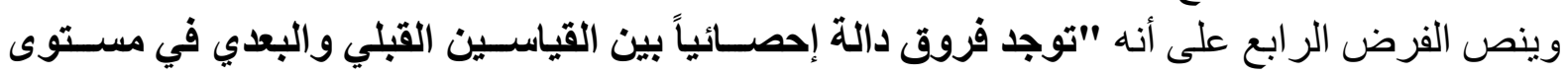

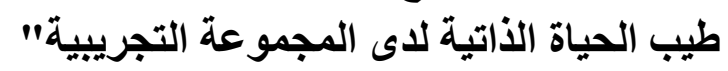
للتحقق من صـحة هذا الفرض قامت الباحثة بإسـتخدام معادلة و يلكوكسـون لحسـاب الفروق بين متوسطي درجات القياسين القبلي و البعدي في مقياسي طيب الحياة الذاتية أولاً: مقياس الوجدان الإيجابي والوجدان السلبي:

جدول (Yr) الفروق بين متوسطي درجات المجمو عة التجريبية في القياسين القبلي و البعدي لمستوى الوجدان الإيجابي و الوجدان السلبي

\begin{tabular}{|c|c|c|c|c|c|c|c|}
\hline الإحصائية & قيمة" & $\%$ & العظمي & الانحر افياري & الحتوسطي & القياس & المتغير \\
\hline \multirow[b]{2}{*}{$\cdot, \cdots$} & \multirow[b]{2}{*}{$V, Y_{1}$} & $\% 7 \cdot, 7 \mathrm{~V}$ & \multirow[b]{2}{*}{$1 \ldots$} & $7, V$ & $7 \cdot, 7 V$ & القبلي & \multirow{2}{*}{ 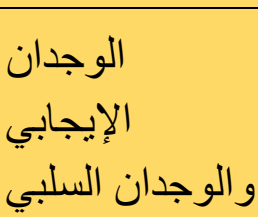 } \\
\hline & & $\%$ & & $q, 1 r$ & $V \tau, V T$ & البعدي & \\
\hline
\end{tabular}

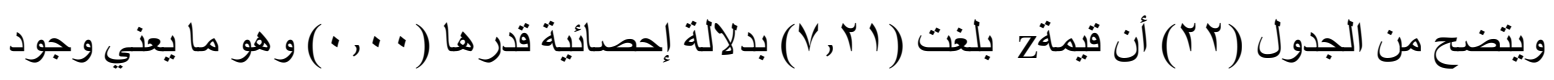

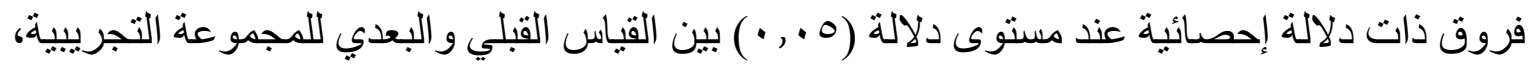

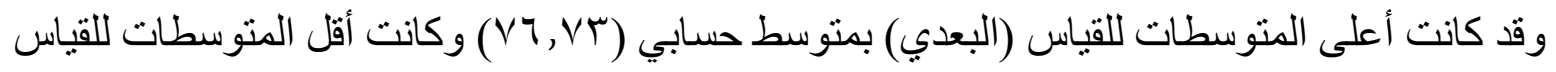

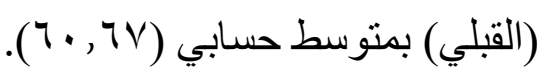
ثانياً : مقياس الرضا عن الحياة: 
تنمية فاعلية الذات لتحسين طيب الحياة الذاتية لاي طالبات الجامعة

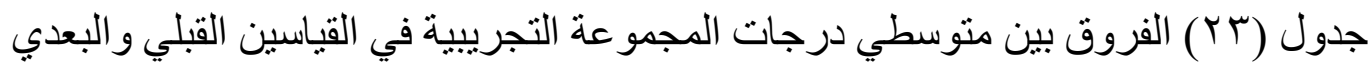

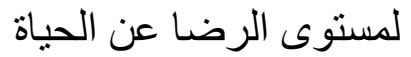

\begin{tabular}{|c|c|c|c|c|c|c|c|}
\hline الدلالة & "قيمة"z" & $\%$ & الدرجة & الانحراف & المتوسط & القياس & المتغير \\
\hline \multirow{2}{*}{$\cdot, \ldots$} & \multirow{2}{*}{$T, \wedge \vee$} & $\% \vee \cdot, \leqslant \Lambda$ & \multirow{2}{*}{ ro } & $\varepsilon,+7$ & $T \Sigma, T V$ & القبلي & الرضسا عن \\
\hline & & $\% \wedge \neg, 々 \wedge$ & & $r, q 1$ & $r \cdot, r V$ & البعدي & الحياة \\
\hline
\end{tabular}

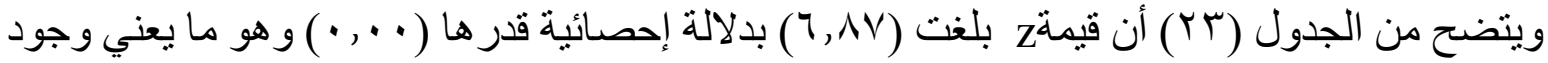

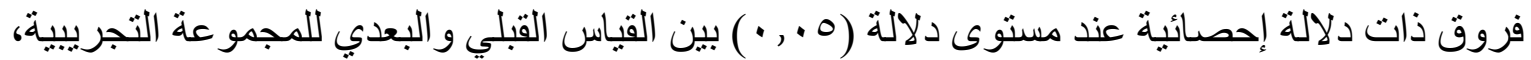

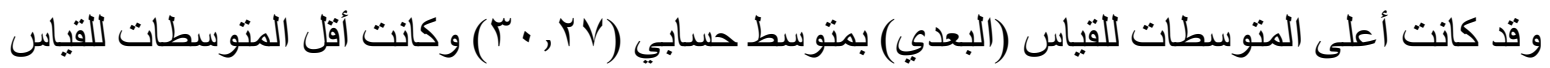

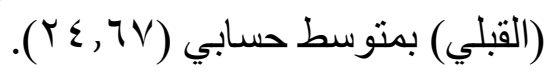

مناقشة نتائج الفرض الرابع:

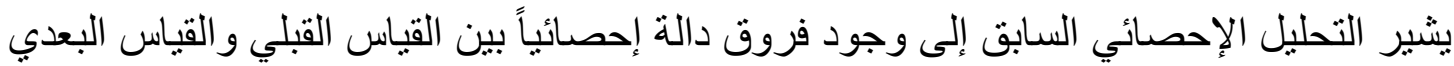

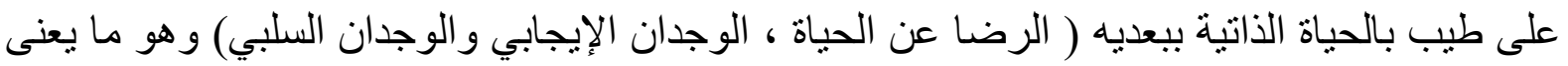

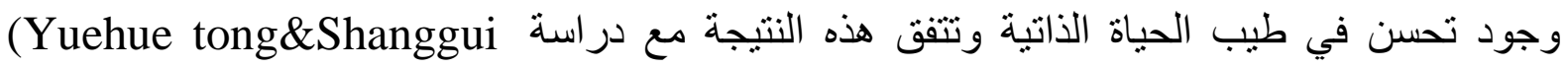

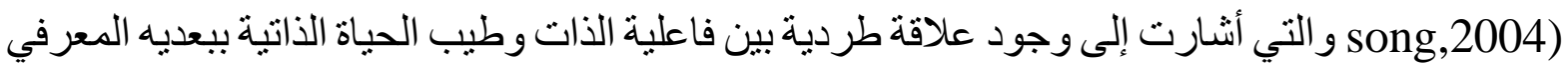

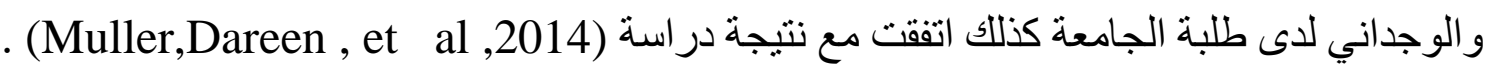

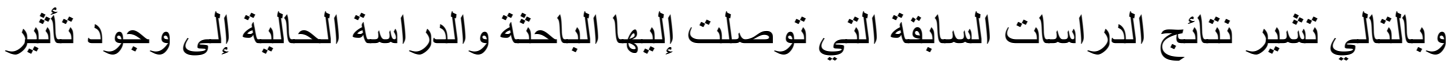

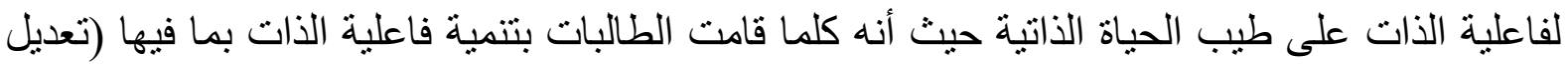

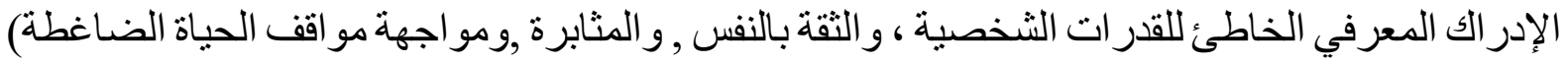

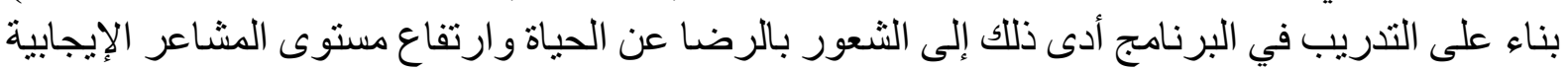

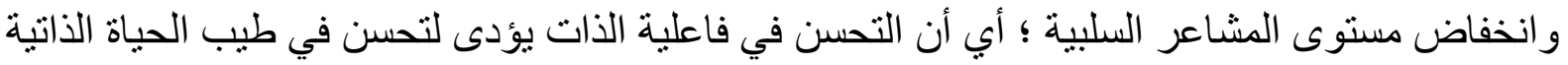

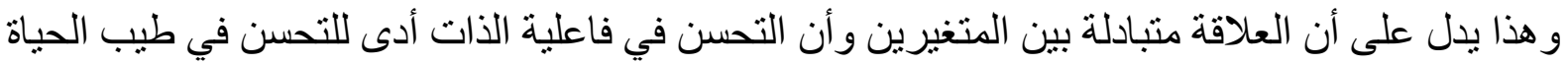
الذاتية على الرغم من عدم التطرق له في جلسات البرنامج الإرشادي.

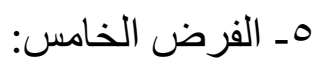

وينص الفرض الخامس على أنه "توجد فروق دالة إحصائياً بين المجموعة التجريبية والئية والمجموعة

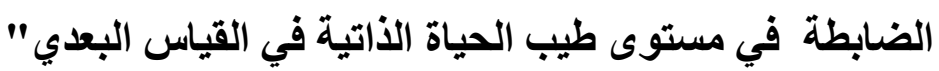

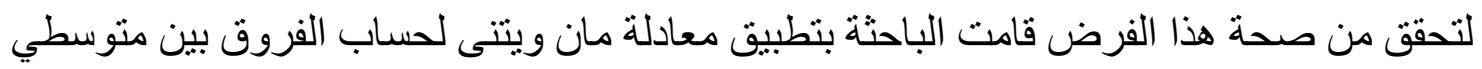
درجات العينتين التجريبية و الضابطة في مقياسي طيب الحياة الذاتية في القياس البعدي لئي

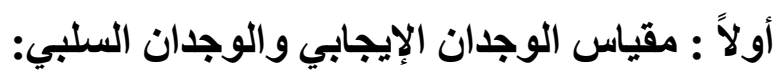

جدول (Tr) الفروق بين متوسطي درجات المجمو عتين الضابطة و التجريبية في الوجدان الإيجابي

\begin{tabular}{|c|c|c|c|c|c|c|c|c|}
\hline \multicolumn{9}{|c|}{ و الوجدان السلبي } \\
\hline الإحصائية & $\begin{array}{l}\text { "z" قيمة } \\
\text { "z" }\end{array}$ & $\%$ & العظمى & الالحعراف & |الحسابي & |العدد & المجمو عة & المتغير \\
\hline$\cdot, \cdot$ & $\varepsilon, \varepsilon$. & $\% \vee \neg, \vee r$ & $1 \ldots$ & $9,1 \pi$ & $V T, V T$ & 10 & التجريبية & \\
\hline
\end{tabular}


تنمية فاعلية الذات لتحسين طيب الحياة الذاتية لاي طالبات الجامعة

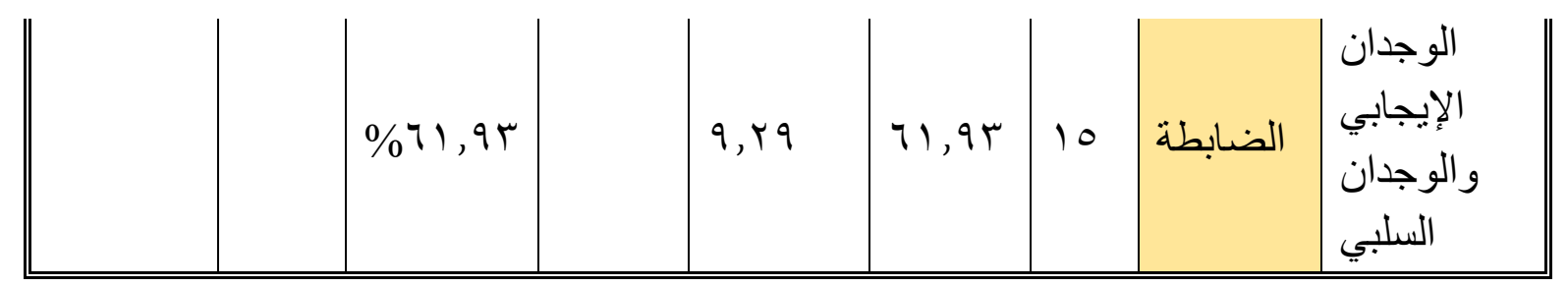

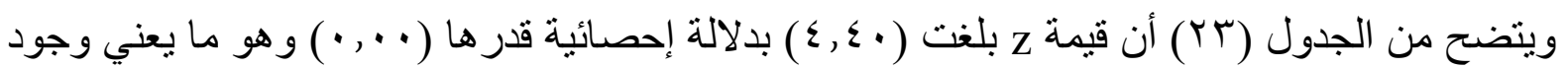

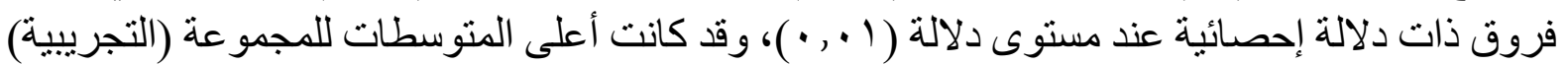

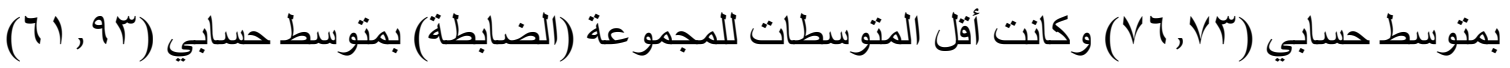
وقد تم حساب حجم الأثر للبرنامج على الوجدان الإيجابي والوجدان السلبي باستخدام مربع إيتا وقد كانت

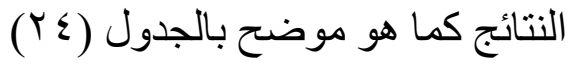
جدول (Y乏) حجم الأثر للبرنامج على مستوى المشاعر الإيجابية والسلبية

\begin{tabular}{|c|c|c|c|c|c|}
\hline مستوى حجم & الأثز & $\begin{array}{l}\text { قيمة دربع إيتا } \\
\text { (ך2) }\end{array}$ & درجات & قيمة التاء & المتغير \\
\hline كبير & 1,77 & $\cdot, \leqslant 1$ & rA & $\varepsilon, \varepsilon$. & الإبشاعرية \\
\hline
\end{tabular}

يلاحظ من الجدول (ع) وجود أثر كبير للبرنامج على مستوى المشاعر الإيجابية والسلبية لدى الطالبات

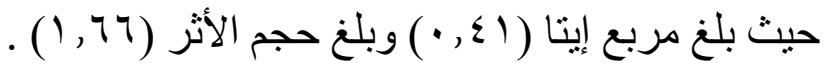
ثانياً : الرضا عن الحياة

جدول (0 إ) الفروق بين متوسطي درجات المجمو عتين الضابطة والتجريبية في الرضا عن الحياة

\begin{tabular}{|c|c|c|c|c|c|c|c|c|}
\hline الإحصائية & $\begin{array}{l}\text { قيمة" } \\
\text { "Z" }\end{array}$ & $\%$ & العظمى الدرجة & الانحريار افي & المستوسطي & العدد & المجمو عة & المتغير \\
\hline \multirow{2}{*}{$\cdot, \cdots$} & \multirow{2}{*}{$7, \wedge 9$} & $\% \wedge \neg, 々 \wedge$ & \multirow{2}{*}{ ro } & $r, 91$ & $r \cdot, r V$ & 10 & التجريبية & \multirow{2}{*}{ الرضنا } \\
\hline & & $\% 7 V, .0$ & & $Y, \leqslant V$ & $r T, \varepsilon V$ & 10 & الضـابطة & \\
\hline
\end{tabular}

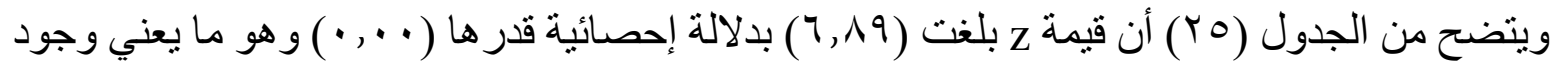

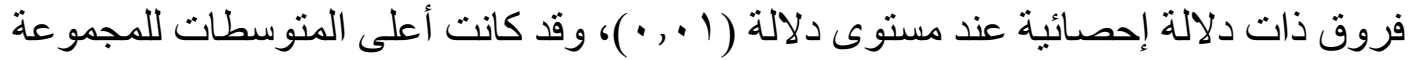

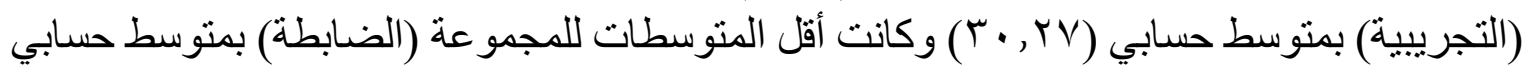
وقد تم حساب حجم الأثر للبرنامج على مستوى الرضا عن الحياة باستخدام مربع إيتا وقد كانت النتائج كما هو موضنح بالجدول (TT)

جدول (Tr) حجم الأثر للبرنامج على مستوى الرضا عن الحياة

\begin{tabular}{|c|c|c|c|c|c|}
\hline مستوى حجم & الأثر & 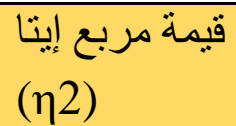 & الحربة & قيمة التاء & المتغير \\
\hline
\end{tabular}


تنمية فاعلية الذات لتحسين طيب الحياة الذاتية لاي طالبات الجامعة

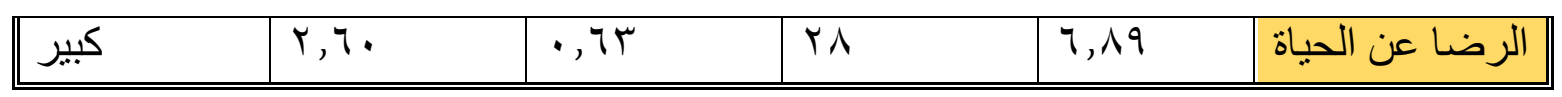

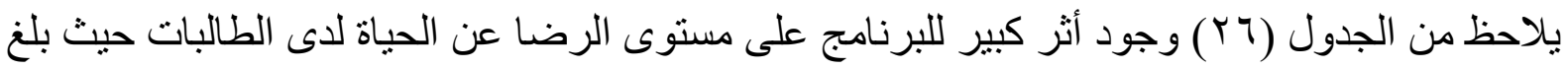

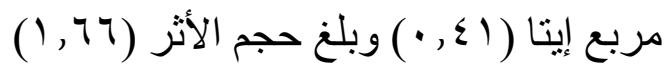

مناقشة نتائج الفرض الخامس:

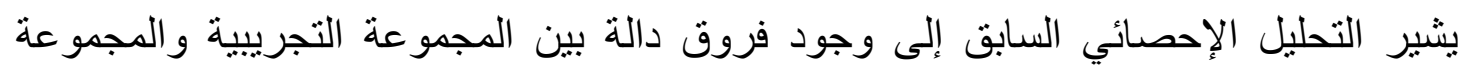

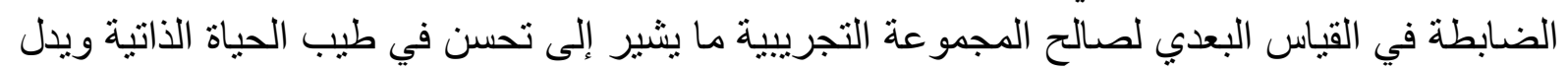

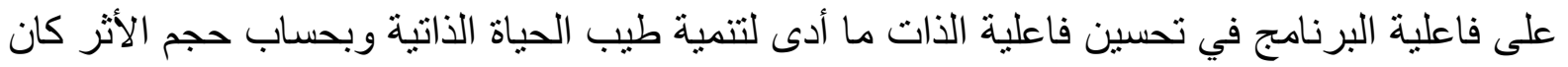

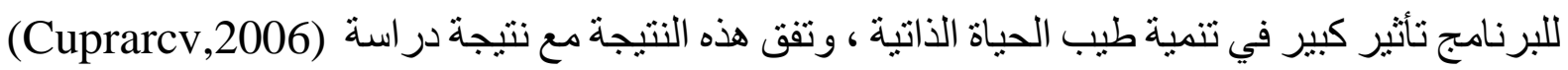

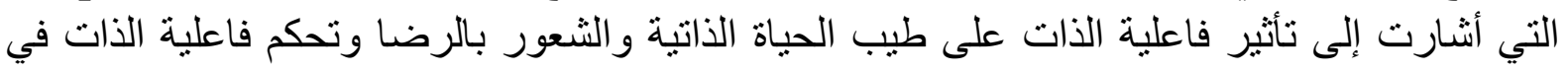

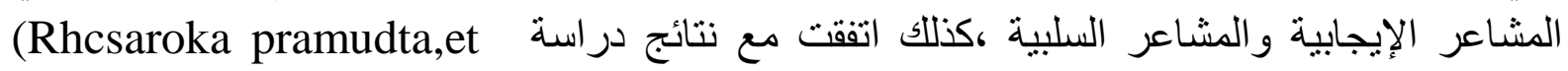

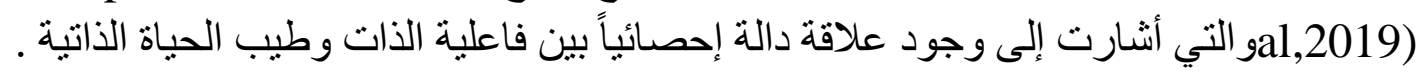

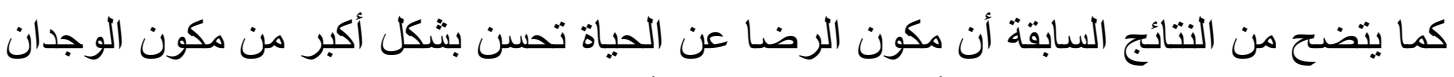

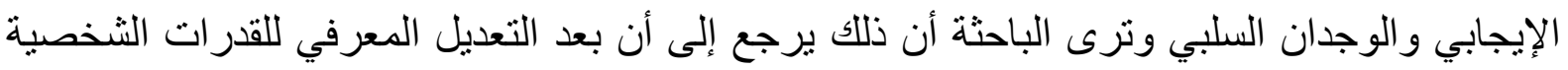

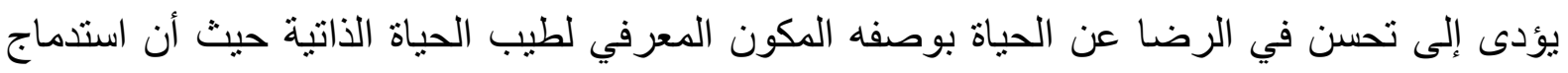

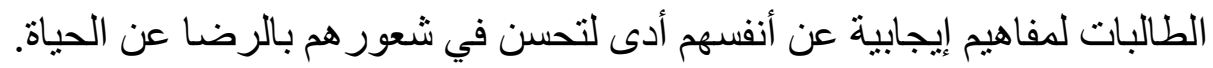

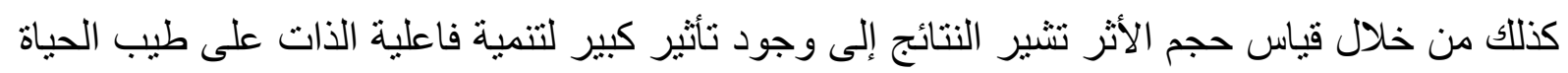
الأاتية ببعديها ( الرضا عن الحياة حنمان ، الوجدان الإيجابي و الوجدان السلبي).

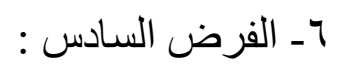

ينص الفرض السادس على أنه "لا توجد فروق دالة إحصائياً بين القياسين البعدي والتتبعي في مستوى

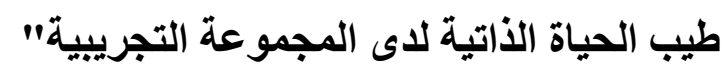

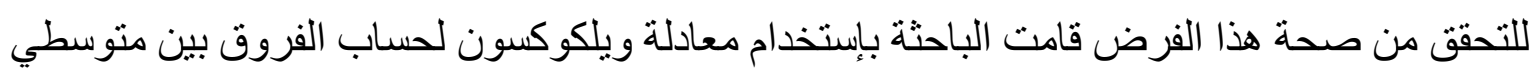

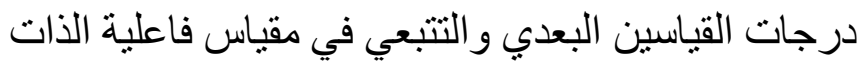
أولاً: مقياس الوجدان الإيجابي والوجدان السلبي :

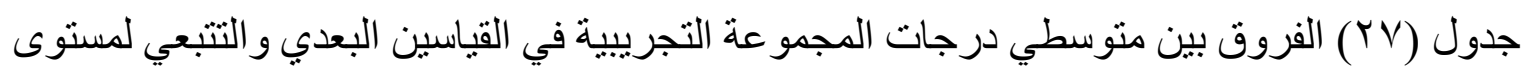
الوجدان الإيجابي و الوجدان السلبي

\begin{tabular}{|c|c|c|c|c|c|c|c|}
\hline الإحصائية & "z" قيمة & $\%$ & العظمي & الالحعراف & الحسابي & القياس & المتغير \\
\hline \multirow[b]{2}{*}{$\cdot, \cdot 7$} & \multirow[b]{2}{*}{$r, .1$} & $\% \vee \neg, \vee r$ & \multirow[b]{2}{*}{$1 \ldots$} & 9,11 & $V T, V Y$ & البعدي & الوجدان \\
\hline & & سr & & $1, \leqslant 7$ & VO, rT & التتبعي & والإليجابي \\
\hline
\end{tabular}


تنمية فاعلية الذات لتحسين طيب الحياة الذاتية لدي طالبات الجامعة

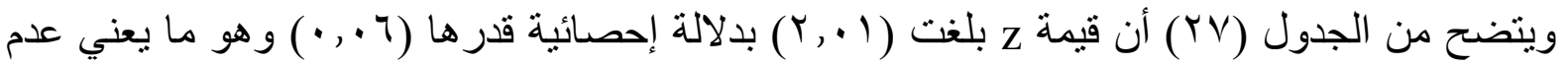

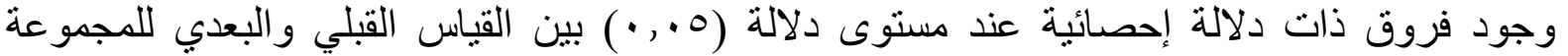

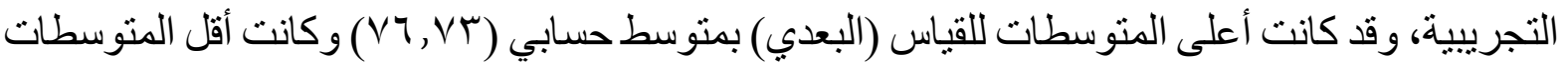

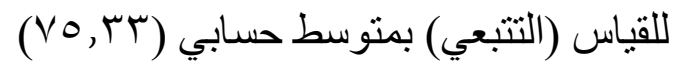

ثانياً : الرضا عن الحياة:

جدول (^^) الفروق بين منوسطي درجات المجمو عة التجريية في القياسين البعدي و التتبعي لمستوى الرضا عن الحياة

\begin{tabular}{|c|c|c|c|c|c|c|c|}
\hline الإحصائية & "z" قيمة & $\%$ & العظمي & الانحر اف المعياري & الحتوسطي & القياس & المتغير \\
\hline \multirow{2}{*}{$\cdot, r \varepsilon$} & \multirow{2}{*}{$1, r r$} & $\% \wedge \neg, \Sigma \wedge$ & \multirow{2}{*}{ o } & $r, 91$ & $r \cdot, r V$ & البعدي & \multirow{2}{*}{ عن الحياة الرضا } \\
\hline & & $\% \wedge r, \wedge)$ & & $r, o r$ & $r q, r r$ & التتبعي & \\
\hline
\end{tabular}

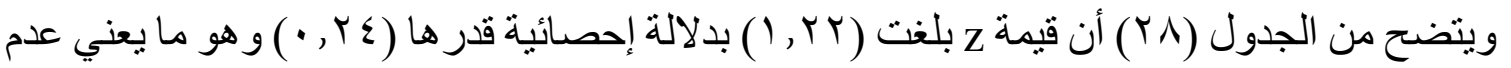

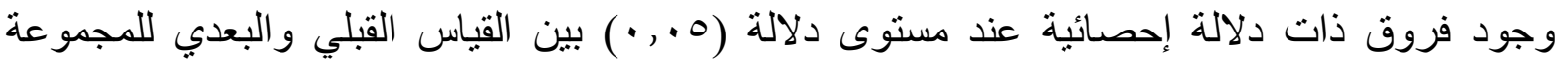

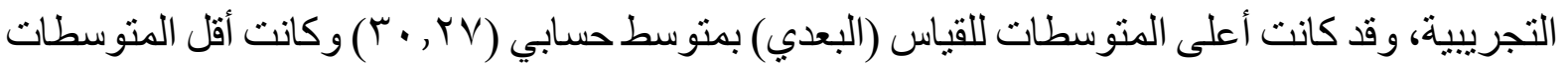

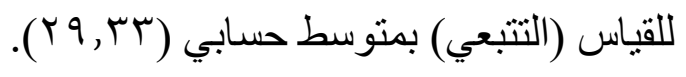
مناقشة نتائح الفرض السادس: يثير التحليل الإحصائي السابق إلى عدم وجود فروق دالة إحصائياً بين القياسين البعدي والتبنعي على التي

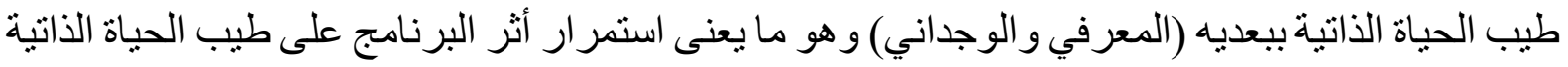

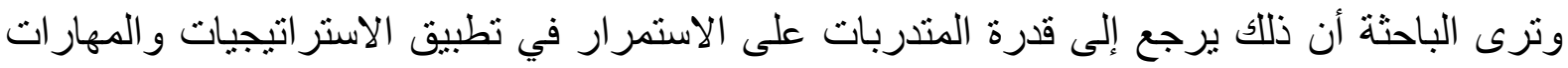

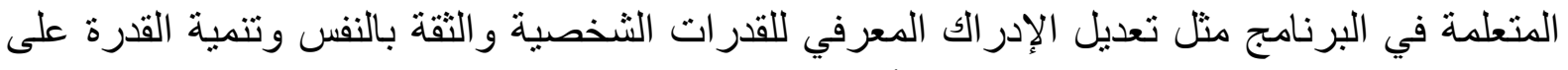

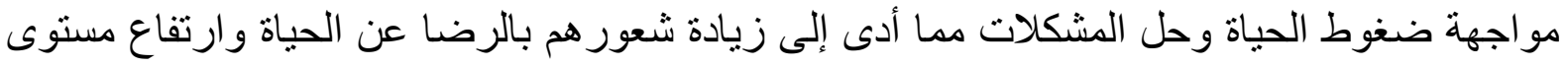

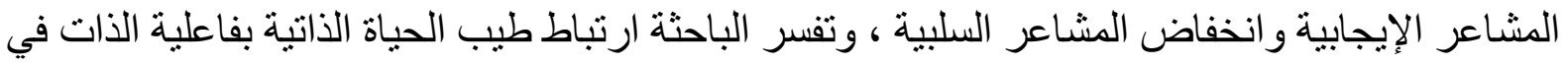

ضوء أن فاعلية الذات يمكن أن تخفف من الضغوطو وتعزز الرضا عن الحياة وتزيد المشاعر الإيجابية. توصيات البحث: من خلال النتائج التي توصل إليها البحث الحالي توصى الباحثة بالأتي: ا ـإعداد بر امج إرشادية لتنمية فاعلية الذات على المر احل العمرية المختلفة لما لفاعلية الذات من أهمية

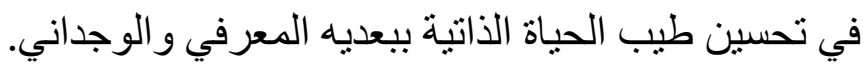

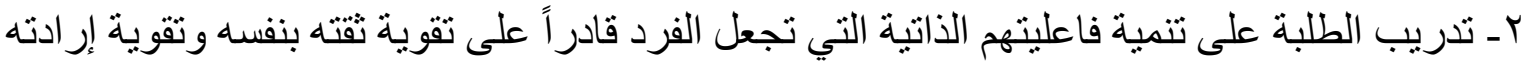
في مو اجهة التحديات، و التخطيط الجيد لمستقبله من خلال اخصائيين نفسيين مدربين في هذا المجال.

\section{بحوث مقترحة:}

ا ـتنمية فاعلية الذات لتحسين طيب الحياة النفسية لدى طلبة الجامعة . r ـالدور الوسيط لفاعلية الذات بين طيب الحياة واضطر ابات الشخصية لدى طالبات الجامعة. r _فاعلية برنامج إرشادي لتنمية طيب الحياة الذاتية لدى طالبات الجامعة. 


\section{قائمة المراجع

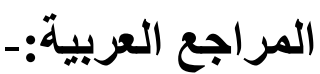

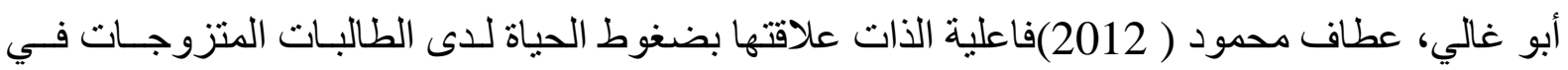

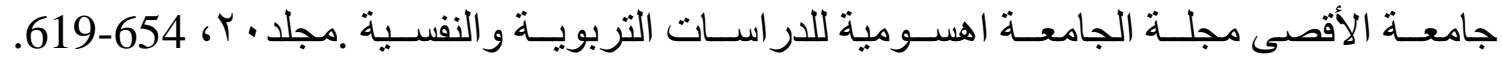

اليوسف، رامي محمود( 2013)المهار ات الاجتماعيـة وعلاقتها بالكفـاءة الذاتيـة المدركـة والتحصــيل

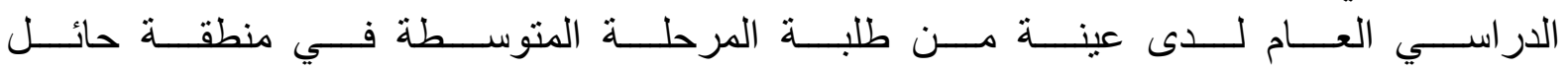

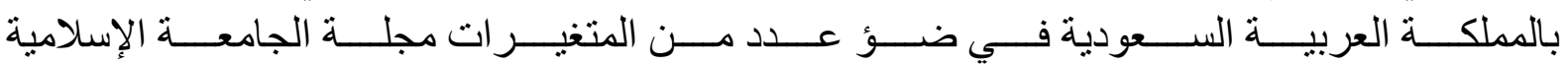

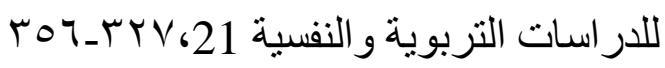

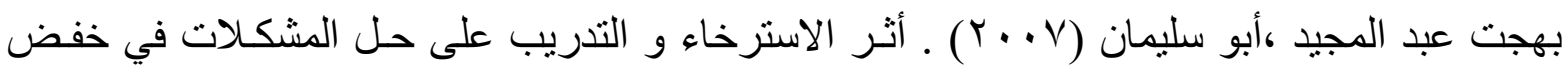

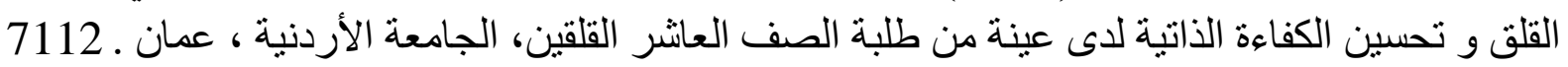

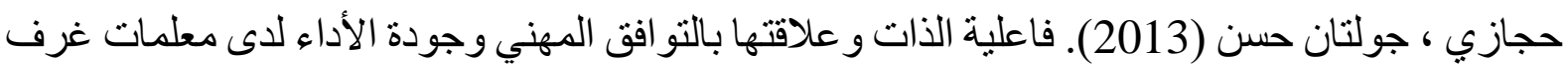

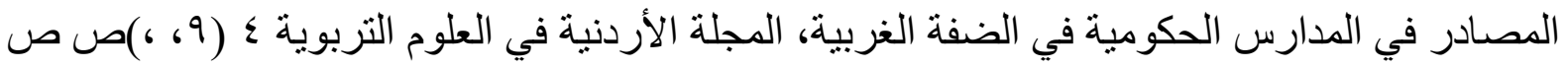

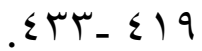

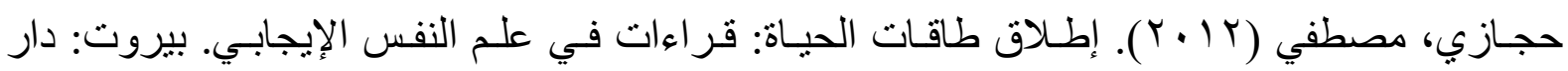
التتوير

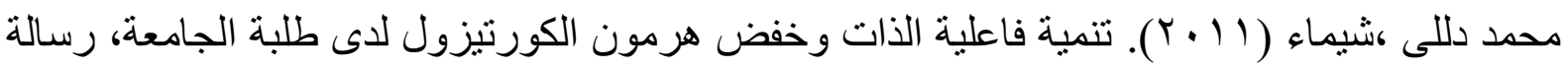

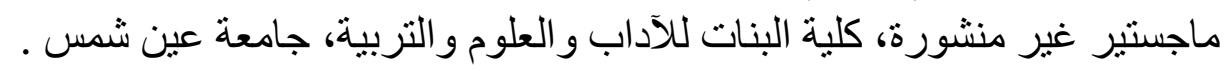

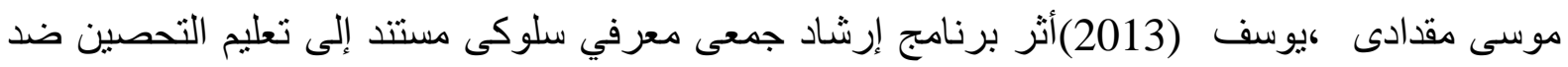

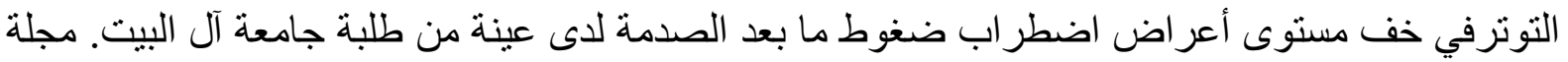
البحوث التربوية النفسية ، المجلد 123-122(2)

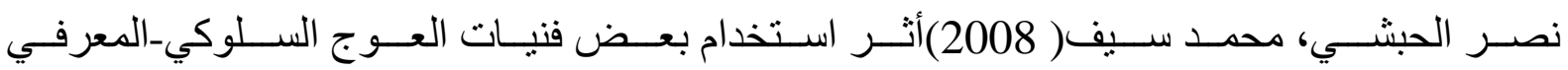

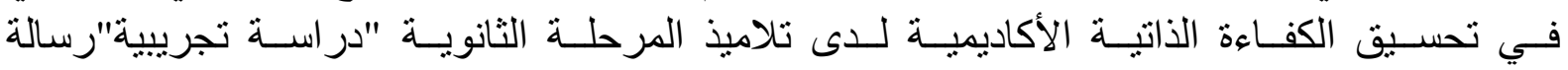

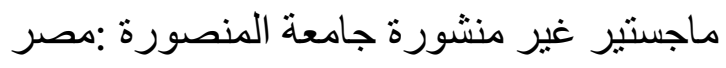

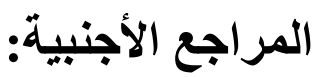

Agustiani, Hendriati \& Musa,Muwaga (2016). Self-efficacy and Self-Regulated Learning as Predictors of Students Academic Performance, The Open Psychology Journal, Volume 9, pp. 1-6. 
تنمية فاعلية الذات لتحسين طيب الحياة الذاتية لاي طالبات الجامعة

Bandura, A. (1982). Self-efficacy mechanism in human agency. American Psychologist, 37, 122-147.

Bandura, A. (1983). Self-efficacy determinants of anticipated fears and calamities. Journal of Personality and Social Psychology, 45, 464-469.

Bandura, A. (1994). Self-efficacy. In V.S. Ramachandran (Ed.), Encyclopedia of human behavior (vol. 4, pp. 71-81). New york: Academic press.

Bandura, A. (1995). Exercise of personal and collective efficacy in changing societies. In A. Bandura (Ed.), Self-efficacy in changing societies (pp. 145). New York: Cambridge University Press.

Bandura, A. (1997). Self-efficacy: The exercise of control. New York: Freeman.

Bandura, A. (2012). On the Functional Properties of Perceived Self-Efficacy Revisited Journal of Management, 38(1), 9-44.

Caprara, G. V., \& Steca, P. (2005). Affective and Social Self-Regulatory Efficacy Beliefs as Determinants of Positive Thinking and Happiness. European Psychologist, 10(4), 275-286. https://doi.org/10.1027/10169040.10.4.275

Carr, A. (2004). Positive psychology: The science of happiness and human strengths. New York: Brunner-Routledge

Carver, C. S., \& Scheier, M. F. (1999). Stress, coping, and self-regulatory processes. In L. A. Pervin \& O. P. John (Eds.), Handbook of personality: Theory and research (p. 553-575). Guilford Press.

Deci, E. L., Ryan, R. M., Gagne, M., Leone, D. R., Usunov, J., \& Kornazheva, B. P. (2001). Need satisfaction, motivation, and well-being in the work organizations of a former eastern bloc country: A cross-cultural study of self-determination. Personality and Social Psychology Bulletin, 27, 930942

Denovan, A. \& Macaskill, A. (2017). Stress and subjective well-being among first year UK undergraduate students. Journal of Happiness Studies, 18 (2), 505-525.

Desmette, D., Jaminon, C., \& Herman, G. (2001). Le sentiment d'efficacité personnelle de chômeurs en formation, un construct dynamique ? Revue Européenne de Psychologie Appliquée, 51(3), 217-228. 


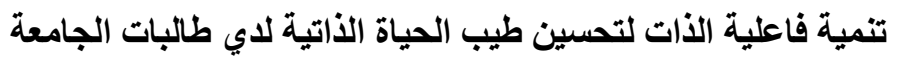

Dienedr, E., Heintzelman, S.J., Kushlev, K., Tay, L., Wirtz, D., Lutes, L.D. \& Oishi, S. (2016). Findings all psychologists Should Know from the New Science on Subjective Well-Being. (In press). Canadian Psychology, 1-42.

Diener, E., Lucas, R. E., \& Oishi, S. (2002). Subjective well-being: The science of happiness and life satisfaction. In C. R. Snyder \& S. J. Lopez (Eds.), Handbook of positive psychology (p. 463-73). Oxford University Press.

Diener, E., Lucas, R.E. \& Oishi, S. (2002): Subjective Well-Being. Handbook of positive psychology, New York: Oxford University Press.

Diener, E., Napa-Scollon, C.K., Oishi, S., Dzokoto, V. \& Suh, E.M. (2000). Positivity and the construction of life satisfaction judgments: Global happiness is not the sum of its parts. Journal of Happiness Studies, 1(2), 159-176.

Eid, M., \& Larsen, R. J. (Eds.). (2008). The science of subjective wellbeing. Guilford Press.

Glovsky, G. (2000). Self-efficacy and expectancy: Are these constructs and their Professional Psychology, San Digo.

Hornich, Agnieszka A., (2008). "Examination of Self-Efficacy and Locus of Control in Protecting Community Integration Following Moderate to Severe Traumatic Brain Injury" (2008). Theses, Dissertations and Capstones. 651.

Jackson, J. W. (2002). Enhancing Self-Efficacy and Learning Performance. The Journal of Experimental Education, 70(3), 243-254.

Jeromy, A. \& Sharon, G. (2015). Predicting Psychological and Subjective WellBeing from Personality: Incremental Prediction from 30 Facets Over the Big 5. Journal Happiness Study, 17, 59-80.

Kepes, S. (2008). self-efficacy: Scale development and nomological validation. Doctoral dissertation, University of Arkansas.

Keyes, C. L., Dhingra, S. S., \& Simoes, E. J. (2010). Change in level of positive mental health as a predictor of future risk of mental illness. American Journal of Public Health, 100(12), 2366-2371.

Klug, H.J. \& Maier, G.W. (2015). Linking goal progress and subjective wellbeing: A meta-analysis. Journal of Happiness Studies, 16(1), 37-65. 


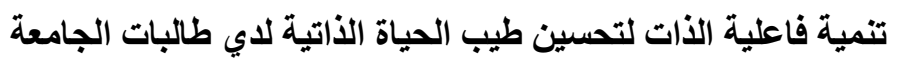

Kulaksizoglu, A. \& Toipuz, C. (2014). Subjective Well Being Levels of University Students. Journal of Educational and Instructional Studies in the World, 4(3), 25-34.

Lent, R. W. (2005). A Social Cognitive View of Career Development and Counseling. In S. D. Brown \& R. W. Lent (Eds.), Career development and counseling: Putting theory and research to work (p. 101-127). John Wiley \& Sons, Inc.

Lent, R.W. (2005). A social cognitive view of career development and counseling. In S. D. Brown \& R. W. Lent (Eds.), Career development and counseling: Putting theory and research to work (pp. 101-127). New York: Wiley.

Maddux, J.E. (2009). Self-efficacy. In S.J. Lopez (Ed), The encyclopedia of positive psychology (pp. 874-880). Oxford: Wiley-Blackwell.

Manddux, J.E. (2002). Self-efficacy: The power of believing you can. In C.R. Snyder \& S.J. Lopez (Eds.), Handbook of positive psychology (pp. 277287). Oxford: University Press.

Miller, J., \& Pilkomis, P. (2007). Neuroticism and affective Instability: The Same or Different? The American Journal of Psychiatry, 163 (5), 839-845.

Miller, J., \& Pilkomis, P. (2007). Neuroticism and affective Instability: The Same or Different? The American Journal of Psychiatry, 163 (5), 839-845.

Müller, Doreen, Zieglmann, Jochen p.1 Simonson, Julia Tesch- Kömerr. I 乏: subjective wellbeing in later adulthood; Is self-efficacy the key. German center of Gerontology, Berlin, Germany.

Pajares,F.(1996). self-efficacy beliefs in the writing of high school students Apathy analysis, psychology in the schools,33,163-175.

Rhesaroka Pramudita, Arie Qorthobi, Reny Rachmawatie (2019). Relationship between Self-Efficacy and the Subjective Well-Being at Belitung 1 Public High School Students, International Journal of Science and Research (IJSR), Volume 8 Issue 7, 1589 - 1592

Reddy, M. (2011). The development of an American Sign Language General Self-Efficacy Scale for Use with Deaf Individuals. Doctoral dissertation, Alliant International University. 
تنمية فاعلية الذات لتحسين طيب الحياة الذاتية لاي طالبات الجامعة

Sarkar, J., Sengupta, P., Manna, N., Bauran, A., Saren, B., Sita, S., d Mundle, M. (2013). Depressive symptoms among undergraduate medical students: study from a medical science, 4(3), 13-18.

Schnk, D.H. (1984). Enhancing self-efficacy and achievement through rewards and goals: Motivational and informational effects. Educational Research, 78, 29-34.

Scholz, H., Franz, M., Heberlein, U. (2005). The hangover gene defines a stress pathway required for ethanol tolerance development. Nature 436(7052): 845--847.

Skrabski, Á., Kopp, M., \& Kawachi, I. (2004). Social capital and collective efficacy in Hungary: Cross-Sectional associations with middle-aged female and male mortality rates. Journal of Epidemiology and Community Health, 58, 340-345.

Sood, S., Bakhshi, A., \& Gupta, R. (2012). Relationship between personality traits, spiritual intelligence and wellbeing in university students. Journal of Education and Practice, 3(10), 55-60.

Stratton, S.T., (2005). Development of Measure of perceived self-Efficacy for Mexican American Children. Doctoral dissertation, Northern Arizona, University.

Thomas. J. W. and Rohwer. D. (1986). Academic studding: the Role of learning strategies, Journal of Educational psychologist.Vol.21.(1) and (2).

Wood, N.L. (2012). Individual Differences in Decision Maaking Styles as Predictors of Good Decision Making. Master dissertation, State University.

Yoland Van 241 \& Manimia dhwrup (2018). Self-efficacy and its relationship with satisfaction with life and happiness among university student page. 389 - 393K Journal of psychology in Africa, Volume 28, 2018, Issue 
تنمية فاعلية الذات لتحسين طيب الحياة الذاتية لاي طالبات الجامعة

Developing self-efficacy to improve the subjective wellbeing of female university students

Fatma Omar Abdel Aziz

PHD Degree - Psychology Department

Faculty of Women for Arts, Science \& Education

Ain Shams University - Egypt

Fatma.omar@ rocketmail.com

Prof. Dr. Azza Saleh Al-Alfy

Professor of Psychology - Psychology

Department

Faculty of Women for Arts, Science \&

Education

Ain Shams University - Egypt
Dr. Maggie William Youssef Assistant Professor of Psychology Psychology Department Faculty of Women for Arts, Science \& Education Ain Shams University - Egypt Tadres@gmail.com

\section{Abstract:}

The aim of the current research is to test the effectiveness of a counseling program in developing self-efficacy and its impact on the development of subjective well-being with its cognitive (life satisfaction) and emotional dimensions (positive sentiment and negative sentiment). The study sample consisted of 30 students (15) experimental samples and (15) control group The study used the experimental approach and the study relied on the following tools: The self-efficacy scale (prepared by the researcher) and the two measures of subjective well-being, the Self-Satisfaction Index (by Edward Dinner, translated by Saffa El-Assar et al.) And the Positive and Negative Sentiments Scale (prepared by David Watson and Lee Anna Clark, and Oak Telegin, translated by Saffa El-Assar et al.) and the counseling program prepared by the researcher, who took 15 sessions. The study found improvement in both self-efficacy and subjective well-being of the experimental group in the post-measurement, and the self-efficacy and subjective well-being improved in the experimental group than in the control group in the post-measurement, and the improvement in the level of self-efficacy and subjective well-being continued in the experimental group in the follow up measurement.

Keywords: self-efficacy - subjective well-being - counseling program. 